Danielle Duque Estrada Pacheco

\title{
Evaluation of Shear Transfer Mechanisms and Strength of GFRP Reinforced Concrete Beams
}

Dissertation presented to the Programa de Pósgraduação em Engenharia Civil of PUC-Rio in partial fulfillment of the requirements for the degree of Mestre em Engenharia Civil.

Advisor:

Prof. Daniel Carlos Taissum Cardoso

Co-advisor:

Prof. Martin Noël 


\section{Danielle Duque Estrada Pacheco}

\section{Evaluation of Shear Transfer Mechanisms and Strength of GFRP Reinforced Concrete Beams}

Dissertation presented to the Programa de Pósgraduação em Engenharia Civil of PUC-Rio in partial fulfillment of the requirements for the degree of Mestre em Engenharia Civil. Approved by the Examination Committee below.

Prof. Daniel Carlos Taissum Cardoso

Advisor

Departamento de Engenharia Civil e Ambiental - PUC-Rio

Prof. Martin Noël

Co-Advisor

University of Ottawa

Prof. Raul Rosas e Silva

Departamento de Engenharia Civil e Ambiental - PUC-Rio

Profa. Claudia Maria de Oliveira Campos

Departamento de Engenharia Civil -UFF

Rio de Janeiro, April 26th, 2019. 
All rights reserved.

\section{Danielle Duque Estrada Pacheco}

Bachelor in civil engineering at Universidade Federal Fluminense, in 2013. Worked with design of reinforced concrete and steel structures. Her area of interest encompasses innovative materials for concrete structures and experimental researches.

Bibliographic data

Pacheco, Danielle Duque Estrada

Evaluation of shear transfer mechanisms and strength of GFRP reinforced concrete beams / Danielle Duque Estrada Pacheco ; advisor: Daniel Carlos Taissum Cardoso ; co-advisor: Martin Noël. - 2019.

102 f. : il. color. ; $30 \mathrm{~cm}$

Dissertação (mestrado)-Pontifícia Universidade Católica do Rio de Janeiro, Departamento de Engenharia Civil e Ambiental, 2019.

Inclui bibliografia

1. Engenharia Civil e Ambiental - Teses. 2. Barras de polímero reforçado com fibra de vidro (GFRP). 3. Mecanismos de transferência de esforço cortante. 4. Vigas de concreto armado. 5. DIC. I. Cardoso, Daniel Carlos Taissum. II. Noël, Martin. III. Pontifícia Universidade Católica do Rio de Janeiro. Departamento de Engenharia Civil e Ambiental. IV. Título.

CDD: 624 


\section{Acknowledgments}

To God, for all.

To CNPq and Pontifical Catholic University of Rio de Janeiro (PUC-Rio), for the financial support.

To Stratus, Ibrata and Pultrall for providing the materials used in this research.

To all my professors of the Master's Program at Pontifical Catholic University of Rio de Janeiro (PUC-Rio), for the all the knowledge acquired during this journey.

To my advisor, Prof. Daniel Cardoso, who was always kindly understanding and guided me with serenity and confidence to the end of this work. Also, thanks to my co-advisor, Martin Noël, for having me in Ottawa and making it possible for me to have an incredible experience as part of this research at uOttawa.

To all staff members of LEM-DEC and uOttawa labs, who helped me run the experiments and set up the tests. Special thanks to Euclides for his inescapable quest to help not only me, but all those who use the LEM-DEC laboratory.

To Claudia Campos and Raul Rosas, for accepting to be part of the examination committee, bringing their deep knowledge and experience in the subject and undoubtedly contributing to a better work.

To my dear friend Thomás Resende, for all the help in the whole process, all the knowledge shared, all the moments that you supported me when it was humanly impossible to accomplish the experimental tasks that were required, and for your friendship, that was one more valuable thing that this work made me experience.

To my parents, Jair and Regina, for all the support and unconditional love. 
To my love Thiago Sampaio, who was by my side during this entire process, helping me, encouraging me and never letting me give up. Thank you for always believing in me. There will never be enough words to thank you for everything you have done for me.

To my grandmother Guiomar Pacheco (in memoriam), to whom I owe everything I am. Thank you for being the most wonderful person in the world and inspiring me every day. 


\section{Abstract}

Pacheco, Danielle Duque Estrada; Cardoso, Daniel Carlos Taissum (Advisor); Noël, Martin (Co-Advisor). Evaluation of Shear Transfer Mechanisms and Strength of GFRP Reinforced Concrete Beams. Rio de Janeiro, 2019. 102 p. Dissertação de Mestrado - Departmento de Engenharia Civil e Ambiental. Pontifícia Universidade Católica do Rio de Janeiro.

This work aims to evaluate the shear strength of reinforced concrete beams with glass fiber reinforced polymer bars and to investigate qualitatively the contribution of the different shear transfer mechanisms to the final strength of the beam. An experimental program was conducted, including material characterization, dowel action tests, push-off tests, and finally, four-point bending tests on beams. Different parameters were investigated, such as the number of longitudinal bars for dowel action effect, maximum size of the coarse aggregate for aggregate interlock and the presence of stirrups for the beam tests. The monitoring of the development of the critical crack was performed with the aid of digital image correlation (DIC). The results showed that there was no difference in the behavior of the dowel action effect and the aggregate interlock through the tests performed. For beam tests, it was observed that all the specimens exhibited a concrete diagonal tension failure and for beams without stirrups, dowel action seemed to provide significant contribution to the shear strength after the crack, when the load reduces and the deflections increases, resulting from the loss of aggregate interlock as the crack opens. It was also observed that the presence of stirrups increased up to three times the shear strength of the beams tested and that there was rupture of the stirrup at the bent region.

\section{Keywords}

Glass fiber reinforced polymer (GFRP) rebars; shear transfer mechanisms; reinforced concrete beams; DIC. 


\section{Resumo}

Pacheco, Danielle Duque Estrada; Cardoso, Daniel Carlos Taissum (Orientador); Noël, Martin (Co-orientador). Avaliação de Mecanismos de Transferência da Força Cortante e Resistência de Vigas de Concreto Reforçado com Barras de Fibra de Vidro. Rio de Janeiro, 2019. 102 p. Dissertação de Mestrado - Departamento de Engenharia Civil e Ambiental. Pontifícia Universidade Católica do Rio de Janeiro.

Este trabalho tem como objetivo avaliar a resistência à força cortante de vigas de concreto reforçado com barras de fibras de vidro e investigar a contribuição dos diferentes mecanismos de transferência do esforço cortante para a resistência final da viga. Um programa experimental foi conduzido, incluindo ensaios para: caracterização do material, para avaliar o efeito de pino, para avaliar o engrenamento dos agregados e, por fim, ensaios de flexão de quatro pontos em vigas. Diferentes parâmetros foram investigados, como a quantidade de barras longitudinais para o efeito de pino, dimensão máxima do agregado graúdo para engrenamento dos agregados e a presença de estribos para os ensaios de vigas. $\mathrm{O}$ monitoramento do desenvolvimento da fissura crítica foi realizado com auxílio de correlação de imagem digital (digital image correlation, DIC, em inglês). Os resultados mostraram que não foi evidenciada diferença no comportamento de efeito de pino e de engrenamento dos agregados através dos ensaios realizados. Para os ensaios de vigas, observou-se que todos os espécimes apresentaram ruptura por tração da diagonal crítica e, para vigas sem estribos, a ação do efeito de pino pareceu contribuir significativamente para a resistência ao cisalhamento após a fissura, quando a carga diminui e as deflexões aumentam, resultado do menor engrenamento dos agregados à medida que a fissura se abre. Foi observado que a presença de estribos aumentou em até três vezes a resistência ao cortante das vigas ensaiadas e que houve ruptura do estribo na parte da dobra.

\section{Palavras-chave}

Barras de polímero reforçado com fibra de vidro (GFRP); mecanismos de transferência de esforço cortante; vigas de concreto armado; DIC. 


\section{Table of Contents}

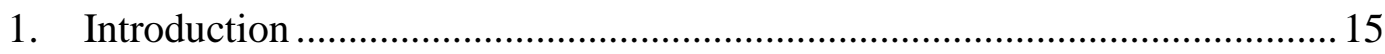

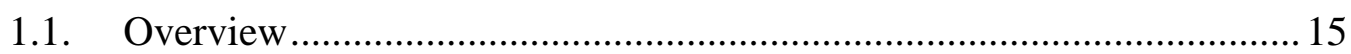

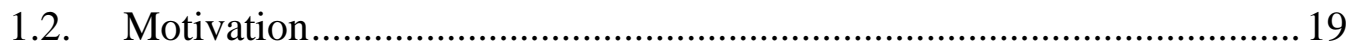

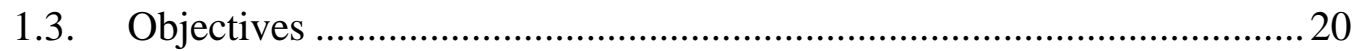

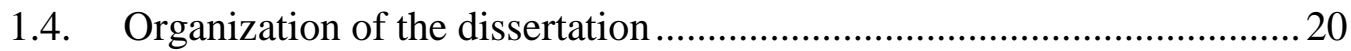

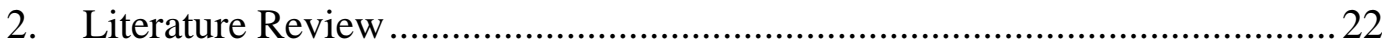

2.1. Behavior of conventional $\mathrm{RC}$ beams failing in shear .........................22

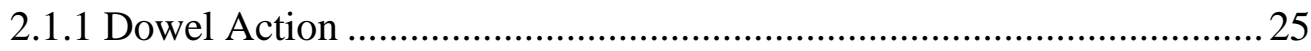

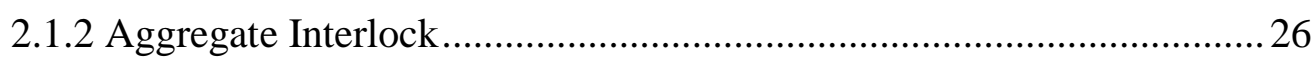

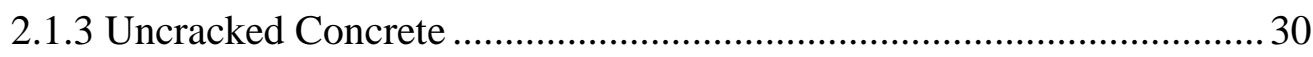

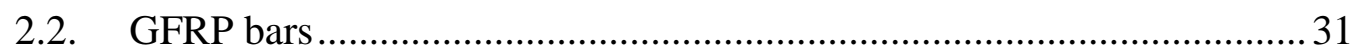

2.2.1. Characteristics and Mechanical Properties .................................... 31

2.2.2. Behavior of GFRP RC beams failing in shear............................... 33

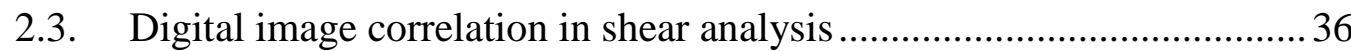

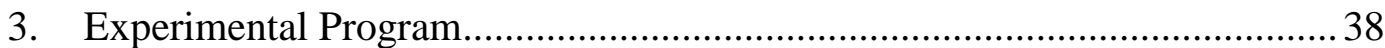

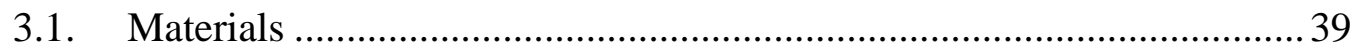

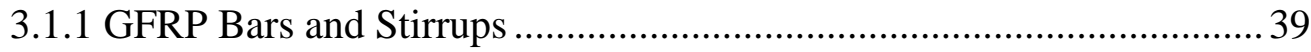

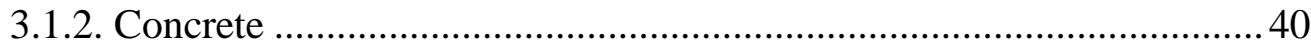

3.2. Mechanical Characterization Tests ................................................... 41

3.2.1. Tensile test of GFRP bars ..................................................... 41

3.2.2. Compression and Splitting Concrete Tests................................... 43

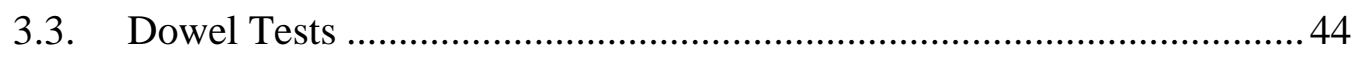

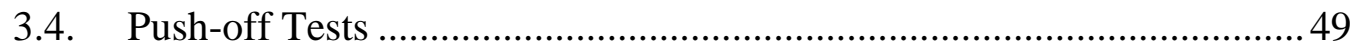




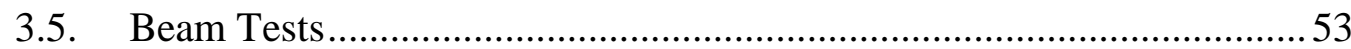

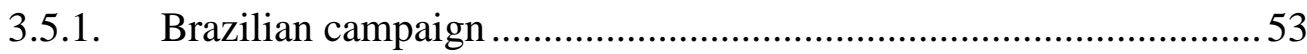

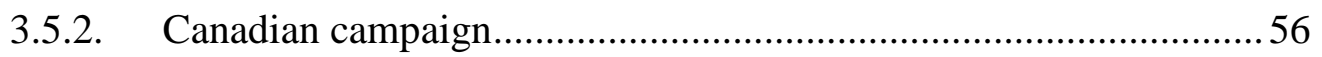

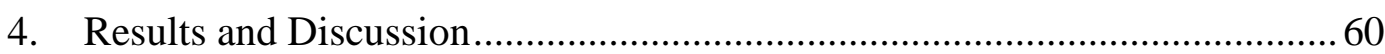

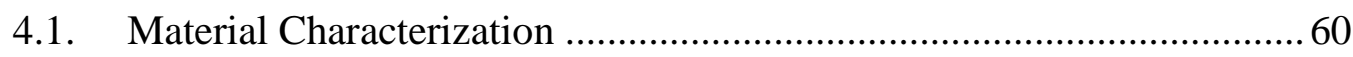

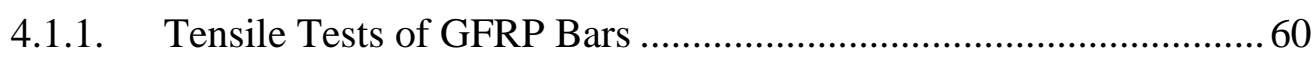

4.1.2. Compression and Splitting Concrete Tests..................................62 62

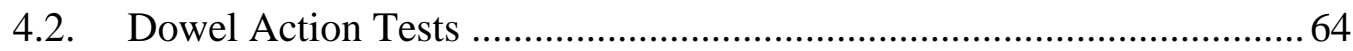

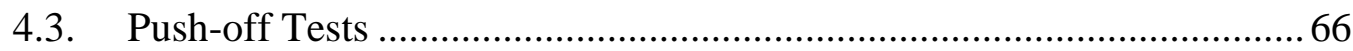

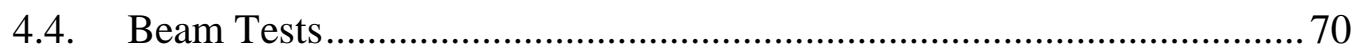

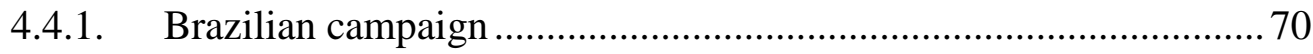

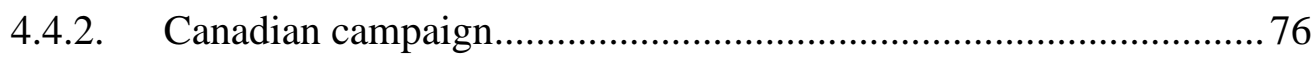

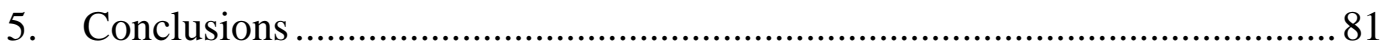

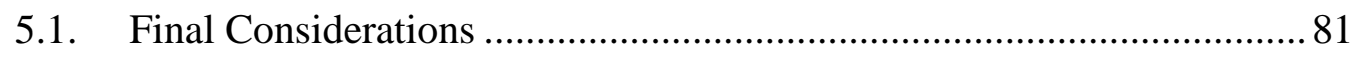

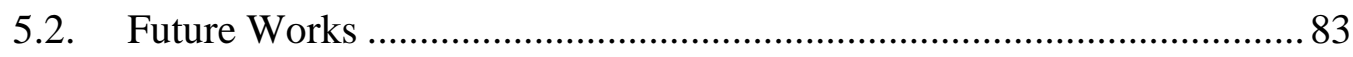

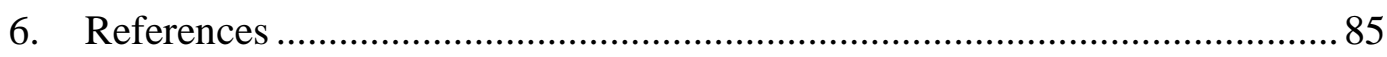

7. Appendix A - Dowel Action Tests Report ................................................. 93

7.1. Post-crack aspect of dowel specimens .............................................. 93

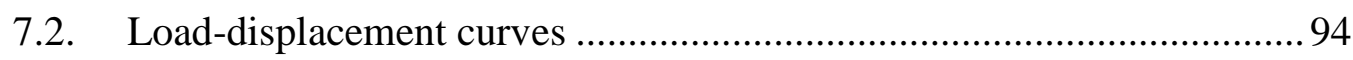

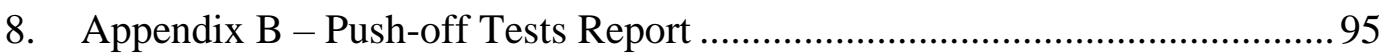

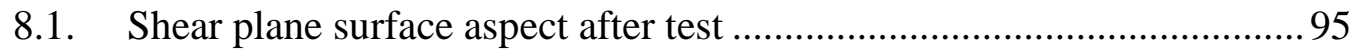

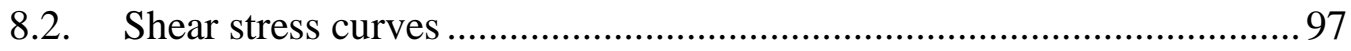

9. Appendix C - Beam Tests Report......................................................... 98

9.1. Failure mode of Brazilian campaign tested beams .............................. 98

9.2. Failure mode of Canadian campaign tested beams ............................. 101 


\section{List of Figures}

Figure 1.1 - Applications in structural systems (Source: https://www.tuf-

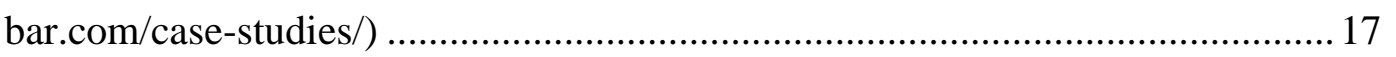

Figure 1.2 - Top mat GFRP bars during Sierrita de la Cruz Creek bridge

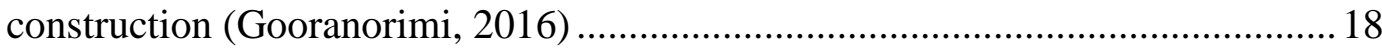

Figure 2.1 - Internal forces in a cracked beam without stirrups (WIGHT \&

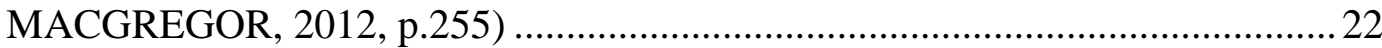

Figure 2.2 - Internal forces in a cracked beam with stirrups (Wight \& Macgregor, 2012, p.260) 24

Figure 2.3 - Distribution of the internal shears in a beam with stirrups (Wight \& Macgregor, 2012, p.260). .25

Figure 2.4 - Dowel action test setup of Krefeld and Thurston (Krefeld \& Thurston 1966). .26

Figure 2.5 - Contribution of aggregate interlock: (a) crack opening $w$ and sliding $s$, and (b) resulting normal stress $\sigma_{a g}$ and shear stress $\tau_{a g}$ due to aggregate interlock (Huber et al.; 2016) 27

Figure 2.6 - Push-off specimen geometry definition. Dimensions adopted in literature are plot in Table 2.1. .28

Figure 2.7 - Contribution of aggregate interlock (a) stresses transferred across a rough crack; (b) stresses transferred across a smooth crack (aggregate fracture) (Huber et al.; 2016) 29

Figure 2.8 - Pultrusion process (Source: http://fiberfence.com/wpcontent/uploads/2017/06/pultrusion-process.jpg) 31

Figure 2.9 - Surface deformation patterns for commercially available FRP bars: (a) ribbed; (b) sand-coated; and (c) wrapped and sand-coated. (ACI 440.1R-06)...... 32 Figure 2.10 - Bend zone of GFRP stirrups: (a) normal and bond stresses; (b) Kinking of the innermost fibers at the bend zone of FRP stirrups (bare fibers after removing the resin); (c) schematic drawing for fiber's orientation at the bend (Ahmed et al.; 2010). 
Figure 2.11 - Rupture of GFRP stirrups (Alkhrdaji et al.; 2001).........................33

Figure 2.12 - Stress-strain curve for FRP and steel (Hajimiragha, 2016)............. 34

Figure 2.13 - Principle of DIC technique (Correlated Solutions, 2018). .............. 36

Figure 2.14 - Typical output result from DIC: (a) reference image; (b) deformed image.

Figure 2.15 - Examples of patterns: (a) poor patterns (anisotropic, repetitive and low contrast); (b) good patterns. 37

Figure 3.1 - GFRP bars and stirrups used in Brazilian and Canadian campaigns. 40 Figure 3.2 - (a) GFRP samples after fixing the protective steel tubes; (b) setup for tensile test in GFRP bar (Sá, 2018).

Figure 3.3 - Concrete characterization test setup: (a) Compression test (BRA); (b) Splitting test (BRA); (c) Compression test (CAN); (d) Splitting test (CAN). ...... 44 Figure 3.4 - Scheme of dowel action specimen (dimensions in millimeters)....... 45 Figure 3.5 - 3D model and steel fixture for dowel action tests (dimensions in millimeters) 45

Figure 3.6 - Internal loading block reinforcement (dimensions in millimeters). .. 46 Figure 3.7 - Positioning of the GFRP and the internal block reinforcements....... 46 Figure 3.8 - Pieces of expanded polystyrene used in dowel action specimens. .... 47

Figure 3.9 - Dowel action specimens molding process sequence. ….................... 48

Figure 3.10 - Setup for dowel action tests. 49

Figure 3.11 - Scheme and reinforcement layout of push-off specimen (dimension in millimeters) 50

Figure 3.12 - Push-off specimens molding process............................................... 51

Figure 3.13 - Scheme of the test setup for push-off specimens........................... 51

Figure 3.14 - Localization of the displacement transducers................................52

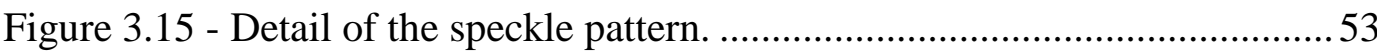

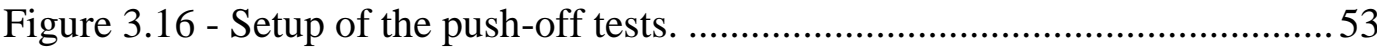

Figure 3.17 - Scheme for beam specimens (BRA): (a) beams without stirrups; (b) beams with stirrups. Dimensions in millimeters. ................................................5 54

Figure 3.18 - Molding process for beam specimens (BRA) ….............................55

Figure 3.19 - Setup of the beam tests (BRA). ......................................................56

Figure 3.20 - Scheme of beam specimens (CAN): (a) beams without stirrups; (b) beams with stirrups. Dimensions in millimeters. ...............................................57

Figure 3.21 - Molding process for beam specimens (CAN) …...........................5 57 
Figure 3.22 - Wire transducer: (a) position of the transducer; (b) closest view of the transducer; (c) detail of the spring-loaded spool (Source: https://intertechnology.com/Celesco/pdfs/SP2.pdf) ..........................................58

Figure 3.23 - Hydraulic hand pump used to apply load .......................................5

Figure 3.24 - Setup of the beam tests (CAN) .................................................59

Figure 4.1 - Tensile test results for GFRP bars (BRA): (a) Experimental stress-strain curves for each specimen; (b) failure modes of tested bars (Adapted from Sá, 2018).

Figure 4.2 - Segregation analysis of hardened concrete: (a) Brazilian campaign; (b) Canadian campaign 63

Figure 4.3 - Stress-strain curves 64

Figure 4.4 - Experimental load-displacement curves for each dowel action specimen. 65

Figure 4.5 - Failure modes of dowel action tested specimens 66

Figure 4.6 - Shear stress curves: (a) shear stress $v s$ crack sliding; (b) shear stress $v s$ crack width; (c) crack sliding vs crack width. 67

Figure 4.7 - Failure modes of push-off tested specimens. 68 Figure 4.8 - Crack opening and sliding immediately after the rupture obtained from DIC analysis. 69

Figure 4.9 - Load-displacement curves of beam tested. 70

Figure 4.10 - Crack formation process: (a) Beam 3L-NS A; (b) Beam 3L-S E. .. 71 Figure 4.11 - Crack pattern of the critical shear crack: (a) specimens without stirrups; (b) specimens with stirrups .72

Figure 4.12- Typical failure modes: (a) beams without stirrups; (b) beams with stirrups. .72

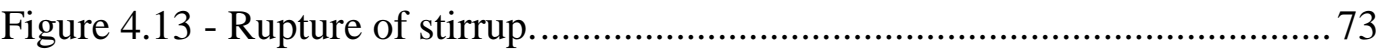

Figure 4.14 - Crack pattern for beam 3L-NS A obtained from DIC analysis....... 73 Figure 4.15 - Selection of crack segments and points for analysis using DIC for the Brazilian campaign 75

Figure 4.16 - Prediction of the contribution of shear transfer mechanisms for Beam 3L-NS A .75

Figure 4.17 - Experimental load-displacement curves of beam tested.................. 76

Figure 4.18 - Crack formation process: (a) Beam 2L-NS C; (b) Beam 2L-S F. ... 77 
Figure 4.19 - Crack pattern of the critical shear crack: (a) specimens without

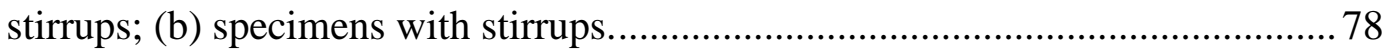
Figure 4.20 - Typical failure modes: (a) beams without stirrups; (b) beams with

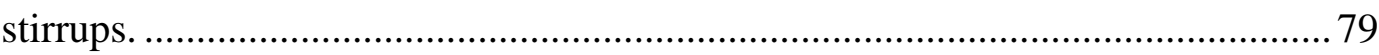

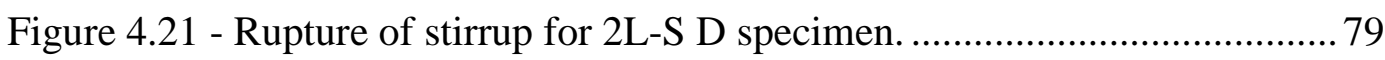

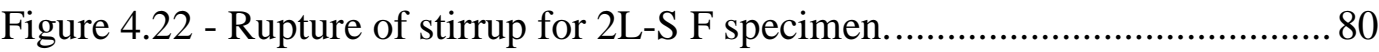

Figure 4.23 - Crack pattern for beam 2L-NS C obtained from DIC analysis........ 80 


\section{List of Tables}

Table 2.1 - Some push-off specimen dimensions adopted in literature.................28

Table 3.1 - Summary of experimental program tests (dimensions in millimeters)39

Table 3.2 - GFRP bars properties reported by manufacturers.............................. 40

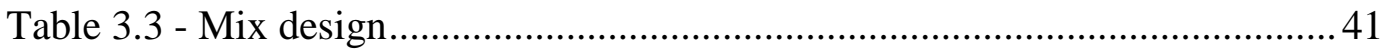

Table 4.1 - Tensile test results in GFRP bars (Adapted from Sá, 2018). .............. 61

Table 4.2 - Summary of the results for each type of test...................................... 63

Table 4.3 - Ultimate compressive strength fc, compressive modulus Ec and strain of concrete at compressive stress peak $\varepsilon \mathrm{c} 2$ of the specimens.................................64

Table 4.4 - Summary of dowel action test results. .............................................. 65

Table 4.5 - Summary of push-off tests results.................................................. 67

Table 4.6 - Summary of the beam tests results.................................................... 70

Table 4.7 - Summary of the beam tests results................................................... 76 


\section{Introduction}

\subsection{Overview}

The corrosion of steel reinforcement is one of the major causes of deterioration of concrete structures exposed to aggressive environments, which directly affects the durability of this type of structure. Reinforced concrete (RC) bridges and other structures near marine environments tend to deteriorate after some years of use because of corrosion of steel bars used in their construction and, in some countries, the corrosion may also result from deicing salt spread on the bridge road surface in winter months. The deterioration may also make the concrete surrounding the steel rebars to crack due to the expansive products formed during corrosion process and ultimately fall off, thus weakening the structure's loadcarrying capacity (Mallick, 2007).

Looking for new solutions to prolong and extend the service lives of existing structures while also enabling the design and construction of durable new structures, innovative and cost-effective materials, such as non-corrosive Fiber Reinforced Polymer (FRP) reinforcement, has emerged as an alternative material for a number of structural engineering applications.

FRP is a composite material consisting of high strength fibers embedded in a polymer matrix. The properties of a composite are completely different from those of their constituents. It is the interaction between the fibers and the matrix that gives FRPs their unique physical and mechanical characteristics. In general, fibers provide the strength and stiffness of the composite and carry most of the applied load, while the matrix bonds and protects the fibers and allows the transfer of stresses from fiber to fiber through shear stresses (Nanni et al.; 2014). In the present work, glass fiber reinforced polymer (GFRP) composite is the object of study, which consist in a polymeric matrix reinforced by glass fibers.

GFRP was initially developed by aerospace industry after World War II. The advantages over the traditional construction materials expanded the use of this composite for a number of applications in different industries. Some benefits such 
as high strength-to-weight ratio, ease of application and installation, transparency to magnetic fields and radar frequencies, electrically and thermally nonconductivity make GFRP bars an interesting alternative to traditional steel bar in RC. The use of GFRP reinforcing bars for concrete structures has been under development since 1960s in the United States and the 1970s in Europe and Japan. However, the commercialization of this material became remarkable only in the 1980s. Among the applications, one may cite its use in bridges at sea, retaining/sea walls, ports infrastructure, as well as in bridge decks and railings where deicing salts are used. Furthermore, GFRP reinforcement is the ideal material to reinforce concrete structures temporarily, such as "soft-eyes" that have to be demolished partially by tunnel boring machines (TBMs). The "soft-eye" consists of a reinforcing cage using GFRP bars, which can be easily cut by the TBM. (NANNI et al.; 2014). Figure 1.1 shows some applications in structural systems:

- Neils Brook Bridge (a) is a $44 \mathrm{~m}$ single span bridge of $13.5 \mathrm{~m}$ width constructed in September 2016 using GFRP bars and bends. A total of $20,000 \mathrm{~m}$ of GFRP bars were used in the bridge, deck, approach slabs, wing walls and abutments. (https://www.tuf-bar.com/case-studies/)

- Water Treatment Plant (b) is the world's first RC water facility reinforced with GFRP bars. The component of the project reinforced with the composite material were the foundation, vertical walls, and cover slabs. (https://www.tuf-bar.com/case-studies/)

In 2016, Gooranorimi et al. investigated the performance of GFRP bars exposed to concrete alkalinity and ambient conditions after 15 years of service. They analyzed the first bridge in the state of Texas, Sierrita de la Cruz Creek, that implemented GFRP as primary concrete deck reinforcement. It was built in 2000 to replace the original bridge that was structurally deficient, presenting extensive damage caused by the corrosion of steel reinforcement. The result of this study showed evidence to the validation of the long-term durability of GFRP bars as concrete reinforcement in field applications. It is reasonable that GFRP have a great potential for replacing reinforced concrete and steel in bridges and other civil infrastructures. Figure 1.2 presents a photo of the Sierrita de la Cruz Creek bridge during construction. 


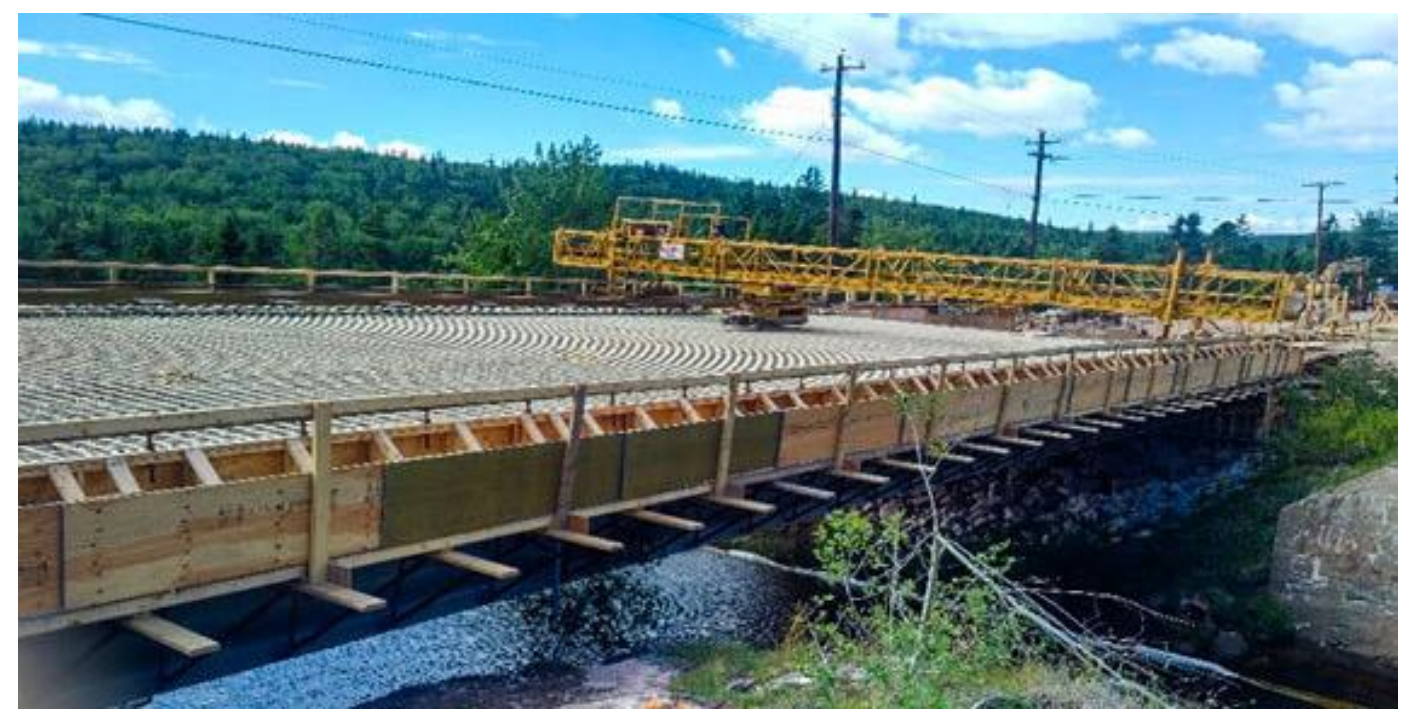

(a) Neils Brook Bridge, Cape Breton - Nova Scotia (Canada)

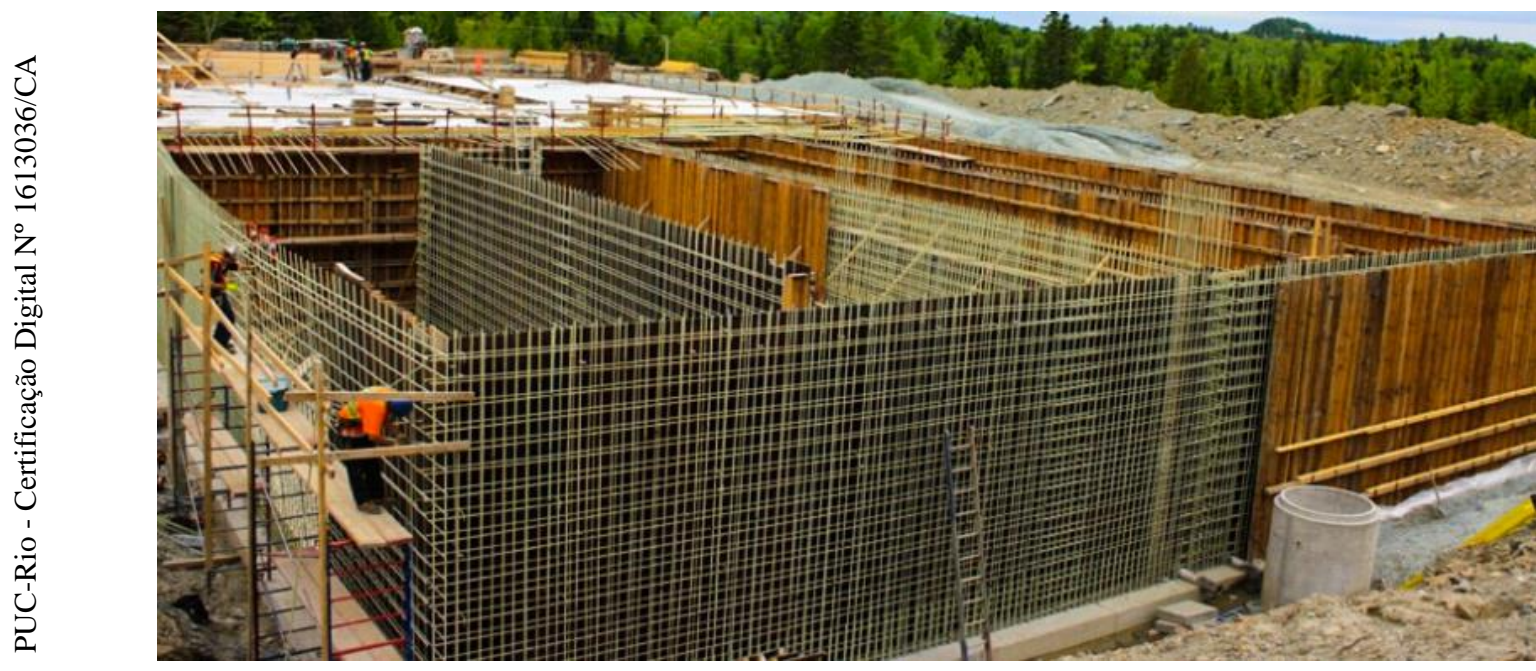

(b) Water Treatment Plant, Thetford Mines - Quebec (Canada)

Figure 1.1 - Applications in structural systems (Source: https://www.tuf-bar.com/case-studies/) 


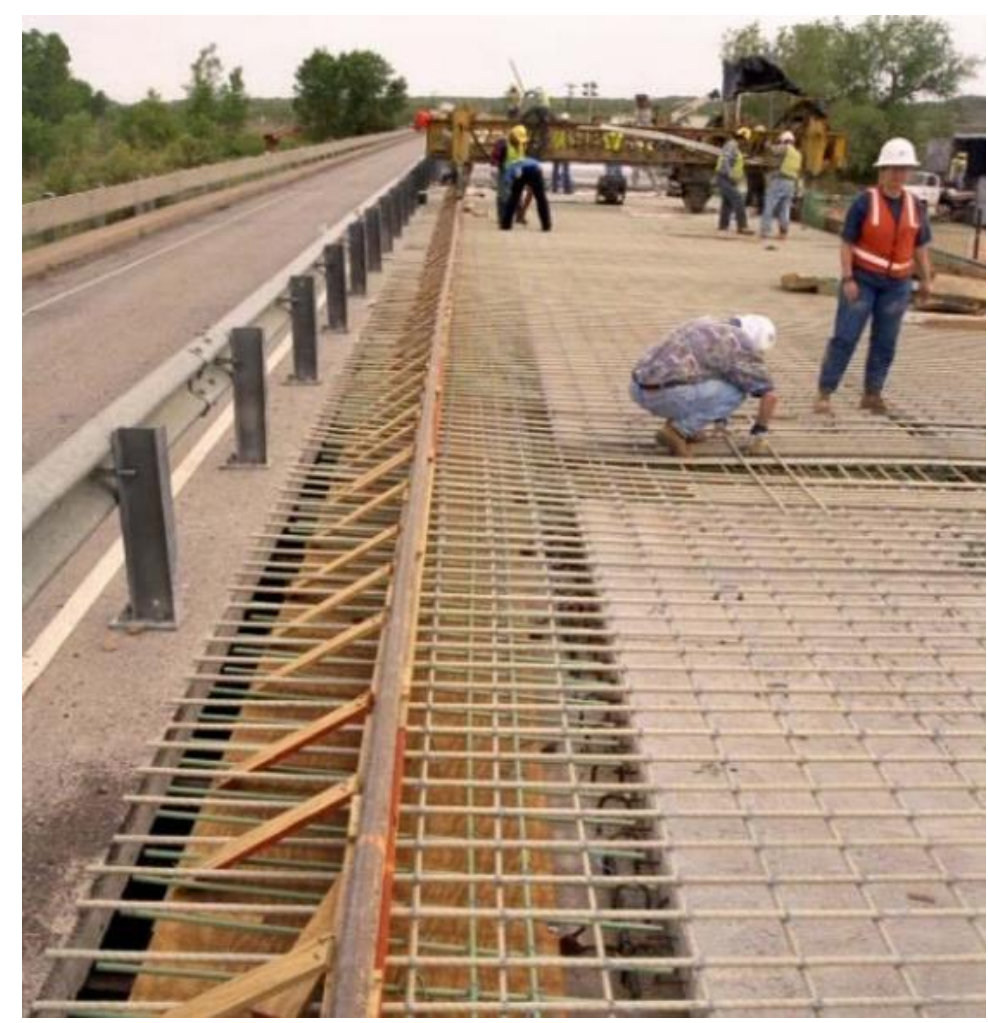

Figure 1.2 - Top mat GFRP bars during Sierrita de la Cruz Creek bridge construction (Gooranorimi, 2016)

Since the 1980s, significant efforts are underway worldwide to implement FRP rebars into design codes and. These include the:

- American Concrete Institute (ACI) - 440.3R-04: Guide Test Methods for FiberReinforced Polymers (FRPs) for Reinforcing or Strengthening Concrete Structures (United States of America) (ACI, 2004).

- American Concrete Institute (ACI) - 440.1R-06: Guide for the Design and Construction of Structural Concrete Reinforced with FRP Bars (United States of America) (ACI, 2006).

- American Association of State Highway and Transportation (AASHTO LRFD): Bridge Design Guide Specifications for GFRP Reinforce Concrete Bridge Decks and Traffic Railings (2009).

- CAN/CSA-S806-12: Design and Construction of Building Structures with FiberReinforced Polymers (2002 and 2012).

- CAN/CSA-S807-10: Specification for Fiber-Reinforced Polymers (2010)

- Intelligent Sensing for Innovative Structures (ISIS) - ISIS Design Manual No. 3:

Reinforcing Concrete Structures with Fiber Reinforced Polymers (Canada) (ISIS, 2001). 
- Japan Society of Civil Engineers (JSCE) - Recommendation for Design and Construction of Concrete Structures Using Continuous Fiber Reinforcing Materials (Japan) (JSCE, 1997).

\subsection{Motivation}

Shear problems in reinforced concrete $(\mathrm{RC})$ beams have been investigated for more than a century, but the complexity involved in the phenomenon still draws the attention of researchers interested in understanding how each load transfer mechanism contributes to the final strength. The recent works of Campana et al. (2013), Yang (2014), Cavagnis et al. (2015), Ruiz et al. (2015), and Huber et al. (2016), for example, studied the problem from a different perspective, considering participation of shear mechanisms in an attempt to develop a comprehensive mechanical approach to strength. This mechanical approach is usually based on the interpretation of a crack pattern after failure and on measured kinematics. The digital image correlation (DIC) technique has shown being promise for the monitoring of kinematics and crack pattern during the failure process and can lead to a better understanding of the shear failure process.

The use of GFRP RC members has increased in the last years, especially due to superior corrosion resistance, electromagnetic transparency and high strength to weight ratio of the reinforcement. However, its relatively low modulus of elasticity if compared to conventional reinforcing steel results in a greater flexibility and the formation of wider cracks. With respect to the shear behavior of GFRP RC beams, several studies have been carried out during the past 20 years and some of the remarks made by researchers who dedicated efforts to the problem are: i) in beams with stirrups, failure is governed by rupture of stirrups near the bent corner; ii) larger crack widths when compared to conventional steel RC; iii) small compression block; iv) reduced dowel action; and v) significant influence of reinforcement stiffness (e.g. Alkhrdaji et al.; 2001, Yost et al.; 2001, El-Sayed et $a l . ;$ 2006). However, most of the studies have been dedicated to the validation of design equations. According to ACI 440 1R-06, further research is needed to quantify the contribution of longitudinal FRP reinforcement in terms of dowel action to the shear strength of FRP-reinforced members. 


\subsection{Objectives}

The main objective of the dissertation is to improve and advance the knowledge about shear strength of GFRP RC beams by means of investigating qualitatively the contribution of different shear transfer mechanisms to the final strength of GFRP RC beams. An experimental program was proposed, including material characterization, dowel action, push-off and beam tests, aiming at:

- Characterization of the mechanical properties of the materials used in this study;

- Evaluation of the influence of increasing the number of longitudinal GFRP bars to the dowel action mechanism (reinforcing ratios of $0,75 \%$ and $1,12 \%)$;

- Evaluation of the influence of increasing the maximum size of coarse aggregate to the aggregate interlock mechanism;

- Evaluation of the shear behavior of GFRP RC beams with and without stirrups using GFRP bars with different type of surface treatment.

All tests were conducted at the Structures and Materials Laboratory of the Department of Civil and Environmental Engineering (LEM/DEC) at Pontifical Catholic University of Rio de Janeiro (PUC-Rio) during the years of 2017 and 2018, as well as at the Concrete Laboratory at University of Ottawa, during 2017.

\subsection{Organization of the dissertation}

This dissertation is divided into six chapters:

- Chapter 1 shows some arguments that motivated this study and briefly describes the experimental program carried out.

- Chapter 2 presents a detailed literature review, which is divided into two parts. The first one addresses on the shear behavior of conventional RC beams and the contribution of each shear transfer mechanisms to shear strength. The second part discusses the mechanical properties of GFRP bars and the behavior of GFRP RC beams failing in shear. 
- Chapter 3 describes the experimental program, including material description and molding process adopted. The test set-ups, instrumentation and equipment necessary to perform the material characterization, four-point bending tests, dowel action and push-off tests are detailed.

- Chapter 4 presents the results of the experimental program, including stress-strain for materials, load-displacement curves for specimens, strengths and failure modes.

- Chapter 5 brings forward the conclusion obtained throughout this project and provide recommendations for future research in the area.

- Chapter 6 consists of a list with all the references analyzed in this work. 


\section{Literature Review}

This chapter addresses a literature review about the shear behavior of conventional RC beams and the contribution of each shear transfer mechanisms to shear strength. Subsequently, the mechanical properties of GFRP bars and how they affect the shear transfer mechanisms in GFRP RC beams are presented.

\subsection{Behavior of conventional $\mathrm{RC}$ beams failing in shear}

In a simply-supported concrete beam without transverse reinforcement, the critical shear crack typically initiates from a flexural crack at the bottom of the beam and propagates toward the top surface. When the critical diagonal crack forms, the shear resistance results from the summation of force components associated to different mechanisms: $V_{c y}$, the shear at the portion of the concrete section at the compression zone that is not cracked by the diagonal crack; $V_{a y}$, the vertical component of the shear transferred across the crack by interlock of the aggregate particles on the two faces of the crack; and $V_{d}$, the dowel action of the longitudinal reinforcement (WIGHT \& MACGREGOR, 2012). Figure 2.1 illustrates the main contribution to the shear strength in a beam without stirrups.

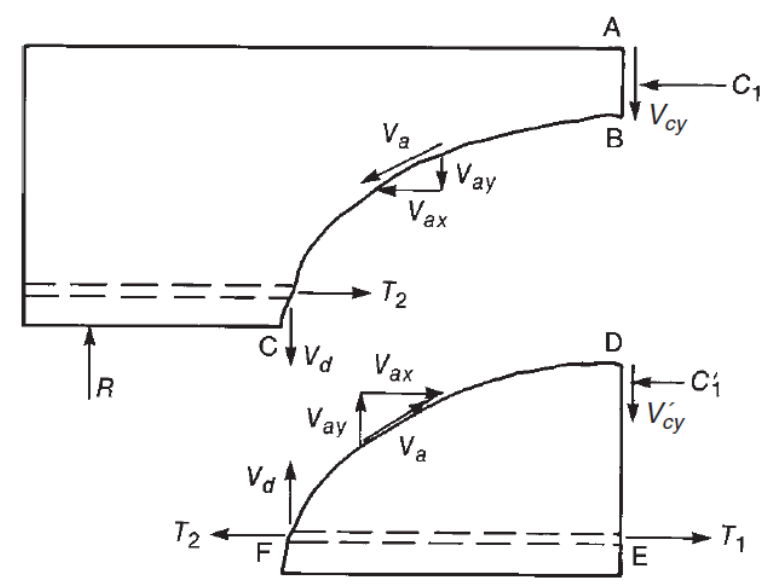

Figure 2.1 - Internal forces in a cracked beam without stirrups (WIGHT \& MACGREGOR, 2012, p.255) 
As the crack opening grows, the contribution of the aggregate interlock $\left(V_{a}\right)$ decreases, increasing the fraction resisted by $V_{c y}$ and $V_{d}$. When $V_{d}$ leads to a splitting crack in the concrete along the reinforcement, $V_{d}$ drops, approaching zero, and $V_{c y}$ increases until the loss of the load-carrying capacity of the uncracked compression zone. It is important to outline that the total shear strength is not necessarily the summation of each shear transfer mechanism individual strength, since the maximum of each mechanism may not match.

Some factors affect the shear strength of beams without stirrups such as the depth of the neutral axis, the tensile strength of concrete, the longitudinal reinforcement ratio, shear span-to-depth ratio, size of beam, distribution, size and strength of aggregates. In deep beams or in beams where loads are applied near the support, there is also the contribution of the arching action to the shear strength.

ACI 445R Report (1999) identifies the residual tensile stresses transferred across the tip of diagonal crack $\left(V_{c r}\right)$ in the fracture process zone (FPZ), as a shear transfer mechanism. Huber et al. (2016) investigated the contribution of various shear transfer mechanisms to the shear strength and they observed that for beams without stirrups, the contribution of the residual tensile stress in the FPZ is of particular relevance, but for beams with a minimum amount of shear reinforcement, this contribution is not significant. The function of the residual tensile stress is not agreed yet between researchers and it is widely accepted that this contribution can be neglected (Kim \& Park 1996; Sarkar \& Bose, 1999; Wight \& Macgregor, 2012; Yang, 2014).

For beams with stirrups, the free body diagram is similar to that for beams without stirrups, adding the contribution of the shear transferred by tension resisted by the stirrups, $V_{s}$. It is important to emphasize that the presence of stirrups does not prevent the shear cracks from forming; actually, they become effective in the shear transfer process only after the diagonal cracks have formed. Figure 2.2 shows the internal forces in a cracked beam with stirrups. 


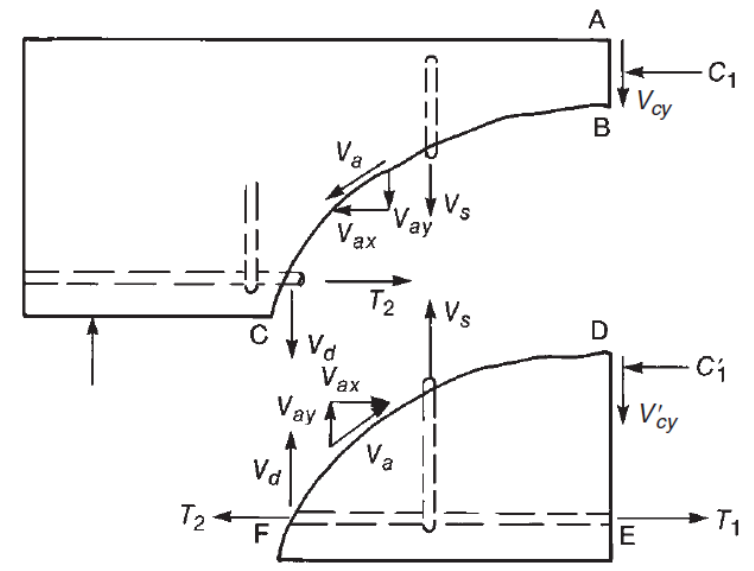

Figure 2.2 - Internal forces in a cracked beam with stirrups (Wight \& Macgregor, 2012, p.260).

Figure 2.3 shows the distribution of internal shear components in a beam with stirrups. Prior to flexural cracking, all the shear is carried by the uncracked concrete in the compression zone. Then, the flexure cracks form and the external shear is resisted by a combination of uncracked concrete, aggregate interlock, and dowel action components. The stirrups start to contribute after the formation of the inclined cracks, controlling crack opening and keeping the contribution of other mechanisms at a constant level. Once the stirrups yield, the inclined crack open growth rate increases and the contribution of the aggregate interlock decreases further, forcing $V_{d}$ and $V_{c y}$ to increase at an accelerated rate, until either a splitting (dowel) failure occurs, the compression zone crushes due to combined shear and compression, or the web crushes (Wight \& Macgregor, 2012).

The most common shear failure modes in RC beams are usually related to their shear span-to-effective depth ratio $(a / d)$ :

- Very short span (a/d from 0 to 1$)$ : an anchorage failure at the ends of the tension tie.

- Short span (a/d from 1 to 2.5): bond failure, a splitting failure, or a dowel failure along the tension reinforcement by crushing of the compression zone over the top of the crack (shear compression failure).

- Slender span (a/d from 2.5 to about 6): the inclined cracks disrupt equilibrium to such an extent that the beam fails at the inclined cracking load. 


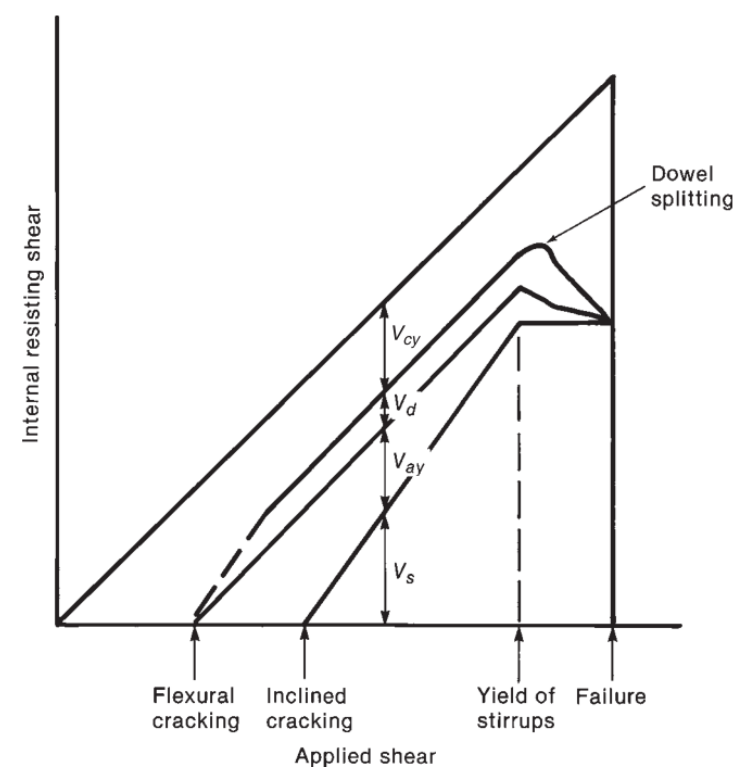

Figure 2.3 - Distribution of the internal shears in a beam with stirrups (Wight \& Macgregor, 2012, p.260).

\subsubsection{Dowel Action}

Dowel action is defined as the capacity of reinforcing bars to transfer forces perpendicular to their axis and thus contribute to the shear strength of RC members. A dowel force is generated as a result of the interaction between the reinforcing bars and the surrounding concrete when there is differential tangential displacement in the crack plane of the concrete (Walraven, 1980).

Several researchers have studied this mechanism in order to investigate the main parameters governing the dowel action. The most extensive experimental work in this field was done by Baumann \& Rüsch (1970), using a test configuration for beams proposed by Krefeld \& Thurston (1966), as shown in Figure 2.4. They investigated the dowel action by loading an internal block of a simply supported beam, which was separated from the rest of the beam by a fictitious preformed crack, so that load is transferred from the block to the beam exclusively by the longitudinal reinforcement.

Krefeld \& Thurston (1966) focused their investigation to study the effects of the bar diameter, bar spacings, depth of cover below the bars, and the distance of the crack to the end support on dowel specimens without stirrups. They concluded that $\mathrm{V}_{\mathrm{d}}$ increases with increasing the cover and it decreases with an increase of distance from the crack to support. 


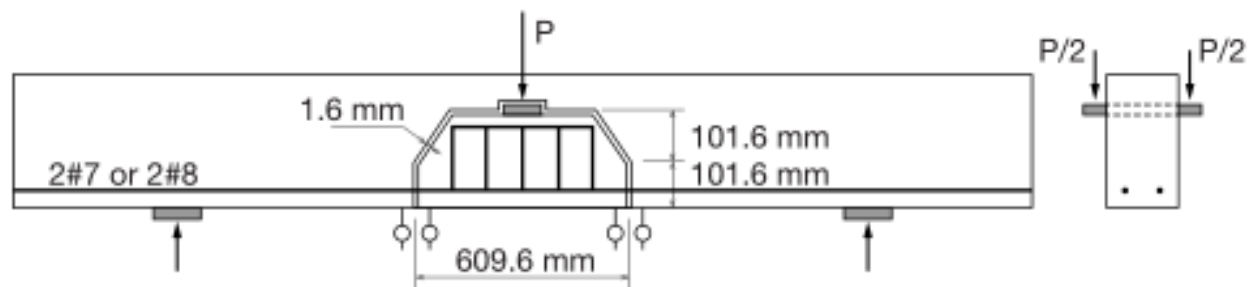

Figure 2.4 - Dowel action test setup of Krefeld and Thurston (Krefeld \& Thurston 1966).

Baumann \& Rüsch (1970) carried out an extensive experimental program investigating specimens with and without stirrups. They observed that even for beams without shear reinforcement, a large plastic deformation can be expected after the peak load. It was also found that the dowel strength increases with increasing tensile strength of concrete as well as beam net width and bar diameter.

Taylor (1974) also carried out dowel action tests with similar configurations in order to investigate the influence of concrete strength, number of longitudinal bars, depth of cover below the longitudinal bars, shear span, and the influence of the fictitious crack. It was observed that the dowel capacity increases with the tensile strength of concrete, beam net width and bar diameter.

Recent work by Vintzeleou \& Tassios (1986) and Chana (1987) has reaffirmed the well-known work by Baumann \& Rüsch (1970) on the resistance of dowels near a surface. However, there is still divergent opinion among researchers regarding the relevance of the dowel action on the shear strength as well as the relative importance of the parameters that affect the dowel resistance (Jelic et al.; 1999; Sarkar \& Bose, 1999; Singh \& Chintakindi, 2013; Panda \& Gangolu, 2017; among others).

\subsubsection{Aggregate Interlock}

The term aggregate interlock refers to the capacity to transfer shear force by contact between the aggregates protruding from one side of the crack surface with the matrix on the opposite side, so that the aggregates protruding from the crack surface provide resistance against slip (Cavagnis, 2017).

Bažant \& Gambarova (1980) and Gambarova (1981) proposed a model assuming that aggregate interlock is generated by slip of two rough surfaces, which 
relates the four components involved in the shear transfer process of a crack, which are: shear stress $\left(\tau_{a g}\right)$, normal stress $\left(\sigma_{a g}\right)$, crack width $(w)$, and crack sliding $(s)$. Figure 2.5 illustrates the contribution of the aggregate interlock.

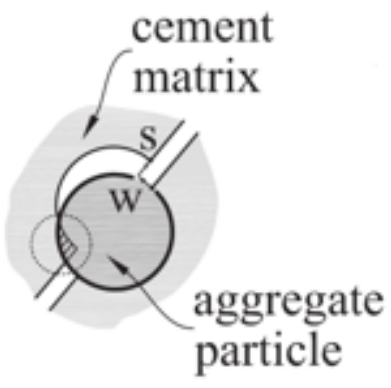

(a)

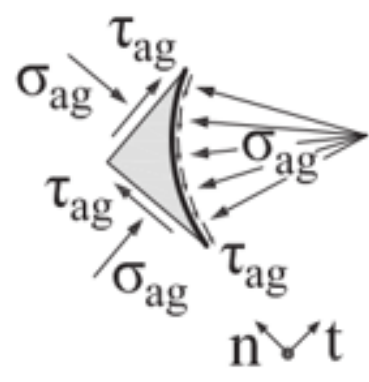

(b)

Figure 2.5 - Contribution of aggregate interlock: (a) crack opening $w$ and sliding $s$, and (b) resulting normal stress $\sigma_{a g}$ and shear stress $\tau_{a g}$ due to aggregate interlock (Huber et al.; 2016)

Different test specimens and setups have been adopted to investigate the influence of the main parameters governing this shear-carrying mechanism: concrete strength, aggregate size, type of aggregate, initial crack width, normal restraining stiffness. One of the most usual experiment in this context is the socalled push-off test. Figure 2.6 shows a scheme for this specimen, where the connecting plane of two ' $L$ ' blocks defines the shear plane. Table 2.1 presents the dimensions adopted in literature. The experiment consists in applying opposite forces aligned with the shear plane while controlling either normal stress or crack opening. In the former case, crack opening and sliding must be measured throughout test, so the correlation between stresses and motions can be established. Some authors pre-crack the shear plane to avoid undesired cracking patterns. 


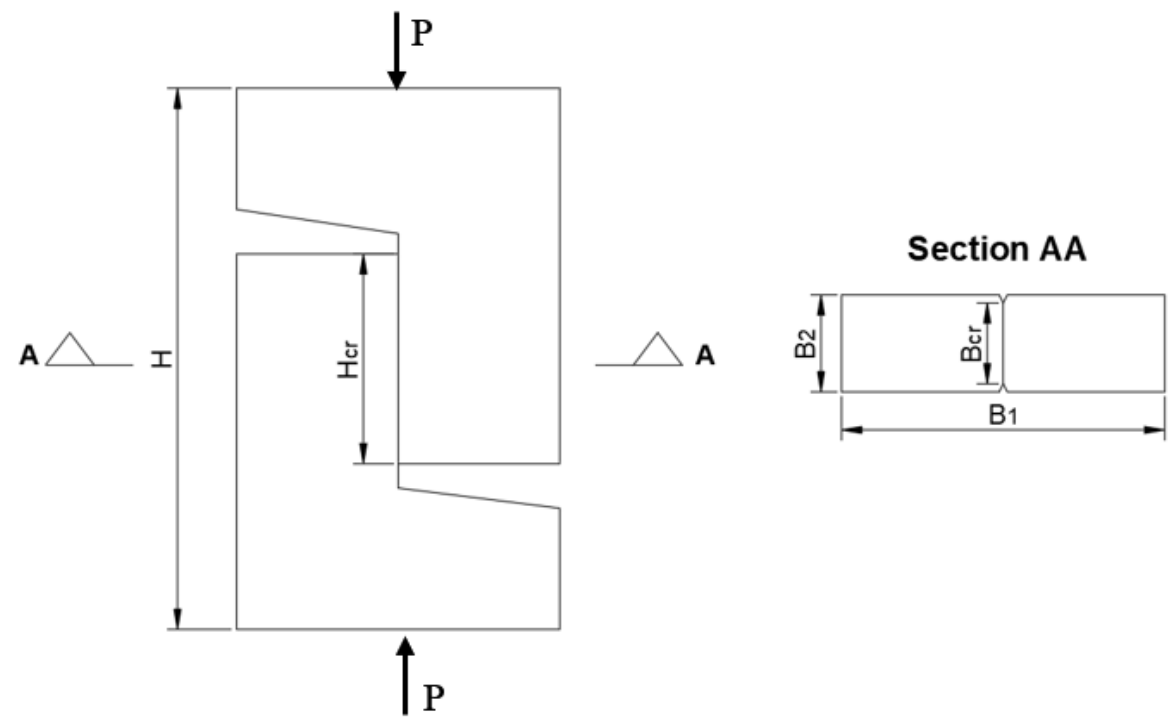

Figure 2.6 - Push-off specimen geometry definition. Dimensions adopted in literature are plot in Table 2.1.

Table 2.1 - Some push-off specimen dimensions adopted in literature.

\begin{tabular}{ccccc}
\hline $\begin{array}{c}\text { Dimensions* } \\
(\mathrm{mm})\end{array}$ & $\begin{array}{c}\text { Mattock et al. } \\
(1975)\end{array}$ & $\begin{array}{c}\text { Walraven } \\
(1980)\end{array}$ & $\begin{array}{c}\text { Sagaseta \& Vollum } \\
(2011)\end{array}$ & $\begin{array}{c}\text { Ovideo et al. } \\
(2013)\end{array}$ \\
\hline $\mathrm{H}$ & 660 & 600 & 700 & 670 \\
$\mathrm{H}_{\mathrm{cr}}$ & 305 & 300 & 350 & 260 \\
$\mathrm{~B}_{1}$ & 356 & 400 & 300 & 400 \\
$\mathrm{~B}_{2}$ & 178 & 120 & 165 & 120 \\
$\mathrm{~B}_{\mathrm{cr}}$ & 178 & 120 & 135 & 100 \\
\hline
\end{tabular}

* refer to Figure 2.6 for notation

Normal-strength concrete exhibits low bond strength between the aggregate particles and the cement matrix, so that the macro cracks form around the aggregates, making the aggregate particles remain embedded in one crack flank, as illustrated in Figure 2.7-a. In concrete with weak aggregate particles (for example light-weight concrete) or high-strength concrete, however, the aggregate particles primarily can split into two, resulting in a smoother crack surface, as illustrated in Figure 2.7-b. Thus, the crack roughness depends on the the bond strength between the aggregate particles and the cement paste as well as on the tensile strength of the aggregates (Huber et al.; 2016). 


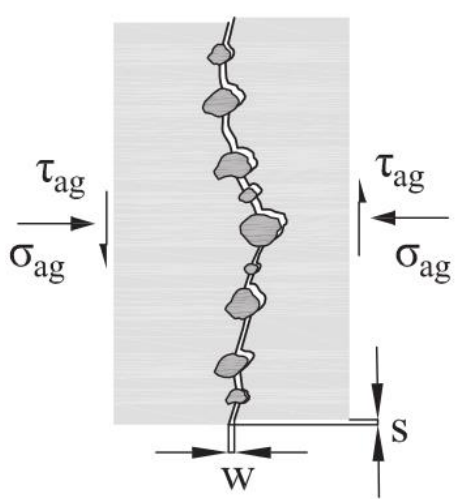

(a)

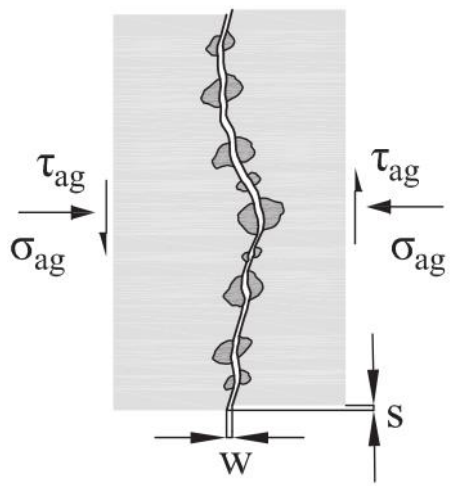

(b)

Figure 2.7 - Contribution of aggregate interlock (a) stresses transferred across a rough crack; (b) stresses transferred across a smooth crack (aggregate fracture) - (Huber et al.; 2016)

Mattock et al. (1976) executed push-off experiments in order to study the influence of the aggregate type. These tests were carried out using either lightweight or normal gravel concretes. From the experimental results, Mattock concluded that the strength of normal gravel concrete was consistently higher than that of lightweight concrete and that the difference in the shear stresses can be attributed to the differences in roughness of the crack surfaces. Mattock observed that in normal concrete the strength between the matrix and the aggregate particles was lower than the tensile strength of the aggregate particles and the cracks generally propagated around the aggregate spheres. On the contrary, in lightweight concrete, the bond between the matrix and the aggregate was higher than the tensile strength of the aggregate particles and the cracks crossed the aggregates.

Walraven (1981) performed tests on pre-cracked push-off specimens with external restraining bars that allowed varying the crack width and shear displacement during loading. For these specimens the crack opening was restrained passively, so that the crack opened according to the internal equilibrium in the crack plane. The advantage of these tests was that shear stresses, normal stresses, crack opening and shear displacement were directly measured. The performed tests showed that the shear forces across cracks induce tangential and normal displacements between the crack faces and that these displacements generate normal and shear stresses. Therefore, it was concluded that crack width, crack sliding, normal and shear stresses are all interrelated. The variables studied by the author where the concrete strength, the type of concrete, the concrete grade, the aggregate size and the initial crack width. 
Recent researches (Sherwood et al, 2006 and Yang et al, 2011) have shown that the nominal size of the coarse aggregate directly influences the aggregate interlock through the shear crack surfaces. Higher shear resistance was obtained with concrete mixtures with larger aggregates. The most likely explanation for this result is the increased surface roughness of the failure shear cracks caused by the larger aggregate.

\subsubsection{Uncracked Concrete}

This mechanism is defined as the ability to transmit shear by the uncracked compressed concrete region above the diagonal critical. In the uncracked part of a reinforced concrete cross section, the stress distribution still follows the theory of elasticity. The contribution of the uncracked zone is strongly influenced by the depth of the compression zone, which is also associated to the shape of the critical shear crack (Huber et al.; 2016).

Taylor (1974) presented a semi-empirical method to estimate contribution of the uncracked concrete, which demands the acquisition of specific deformation in the longitudinal direction in sections surrounding the loading section and in different levels of the compressed region. Another way to estimate this mechanism is based on the classical theory of beams and adopted by Mörch (1909), but distributions of shear stress different from that of this theory have also been adopted (Sherwood, 2008).

This effect is neglected in the present work, since all tested beams exhibited very narrow or imperceptible uncracked zones. 


\subsection{GFRP bars}

\subsubsection{Characteristics and Mechanical Properties}

FRP bars consist of continuous longitudinally aligned fibers embedded in a matrix and are characterized by a high tensile strength in the longitudinal direction only (i.e.; in the direction of fibers). They are commonly fabricated by a process called pultrusion, which consists in pull reinforcement materials, such as fiberglass roving, through a resin bath, impregnating all the fiber with a liquid thermosetting resin. As an example, the pultrusion process to manufacture a particular type of GFRP bar is illustrated in Figure 2.8. The glass fibers, initially packaged in rovings, are drawn through a resin bath where the material is thoroughly impregnated with a liquid thermoset resin. Before entering the resin bath, fibers are spread out to allow for even wetting. The resin-impregnated fibers are first guided through a metal die that defines the size of the final bar and, then, enter a curing oven. Before entering the oven, sand coating and helicoidal wraps are applied on the surface of the bar. Inside the oven, heat is transferred under precise temperature control to the bar. The heat activates the resin curing, changing it from a liquid to a solid. The solid bar emerges from the curing oven to the exact size of the die cavity. The bar is continuously pulled and, finally, cut to the desired length (Nanni et al.; 2014).

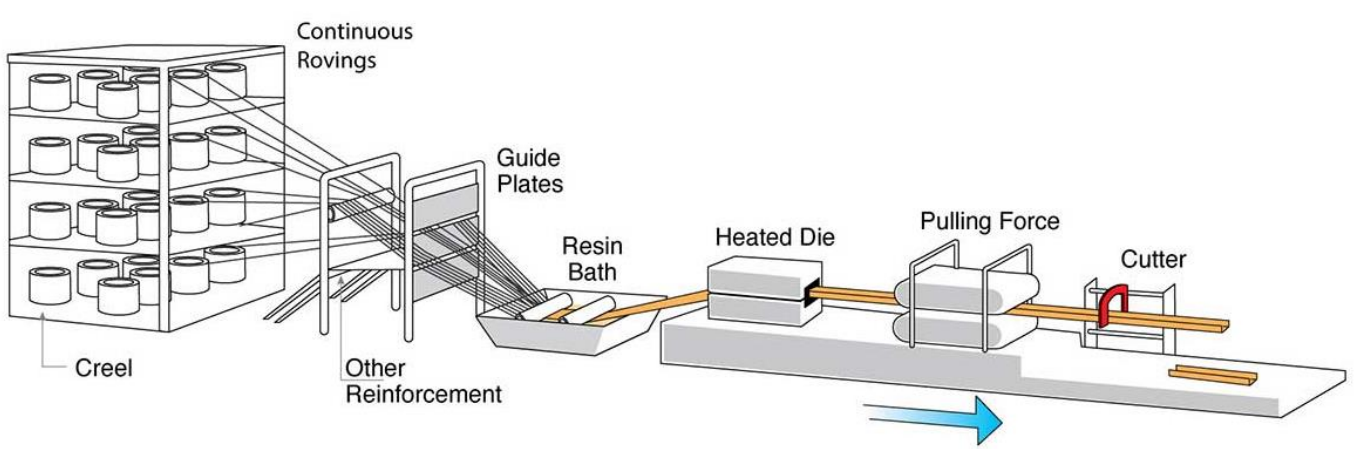

Figure 2.8 - Pultrusion process (Source: http://fiberfence.com/wpcontent/uploads/2017/06/pultrusion-process.jpg)

FRP bars are anisotropic, i.e. their mechanical properties are direction dependent. They are significantly stronger when loaded in tension parallel to the fibers, compared to any other direction. For bars used with concrete members, this behavior can affect the response when bars are requested transversely, for example: 
dowel action. FRP bars do not exhibit a yield plateau and they show no capacity for plastic deformation when loaded in tension. They are considered linear-elastic-tobrittle-rupture materials.

As previously mentioned in Chapter 1, GFRP bars have many advantages, such as high tensile strength, high chemical resistance, high strength-to-weight ratio, ease of application and installation, transparency to magnetic fields and radar frequencies, electrically and thermally non-conductivity, and excellent insulating properties. On the other hand, the disadvantages of glass fibers are: low tensile modulus, sensitivity to abrasion from handling, high hardness and relatively low fatigue resistance.

Commercially available GFRP bars have tensile strength ranging from 400 to $1000 \mathrm{MPa}$ and modulus of elasticity between 22 and $65 \mathrm{GPa}$. They usually receive a surface treatment in order to improve the bonding with concrete. Figure 2.9 shows some types of surface configuration for FRP bars that are commercially available.

(a)

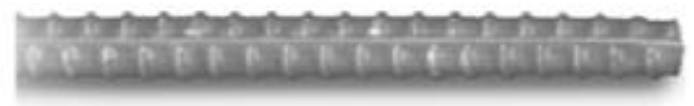

(b)

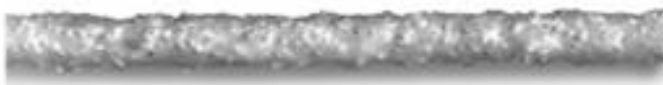

(c)

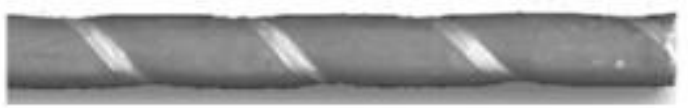

Figure 2.9 - Surface deformation patterns for commercially available FRP bars: (a) ribbed; (b) sand-coated; and (c) wrapped and sand-coated. (ACI 440.1R-06)

Several researchers investigated the behavior of bent FRP bars and they observed that the specimens failed by rupture of the bend (Maruyama et al. (1993), Nagasaka et al. (1993), Currier et al. (1994), Ueda et al. (1995), Ehsani et al. (1995), Nakamura et al. (1995), Imjai et al. (2007), Shehata et al. (2000), Ahmed et al. (2010), Bentz et al. (2010). Ahmed et al. (2010) observed that bent FRP is weak at the bent region and attributed the weakness to: stress concentrations in the curve of the bend, perpendicular loading of bent fibers, and the kinking of fibers in the bend as part of the manufacturing processes, as illustrated in Figure 2.10. In Figure 2.11 is presented the failure of beam tested by Alkhrdaji et al. (2001), which was caused by rupture of the bent part of the GFRP stirrup. 


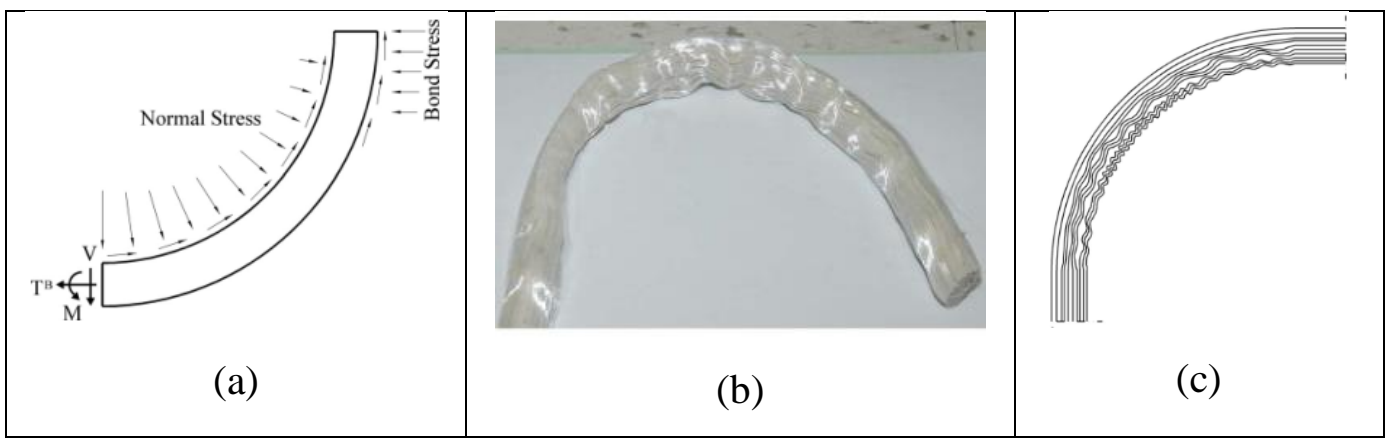

Figure 2.10 - Bend zone of GFRP stirrups: (a) normal and bond stresses; (b) Kinking of the innermost fibers at the bend zone of FRP stirrups (bare fibers after removing the resin); (c) schematic drawing for fiber's orientation at the bend (Ahmed et al.; 2010).

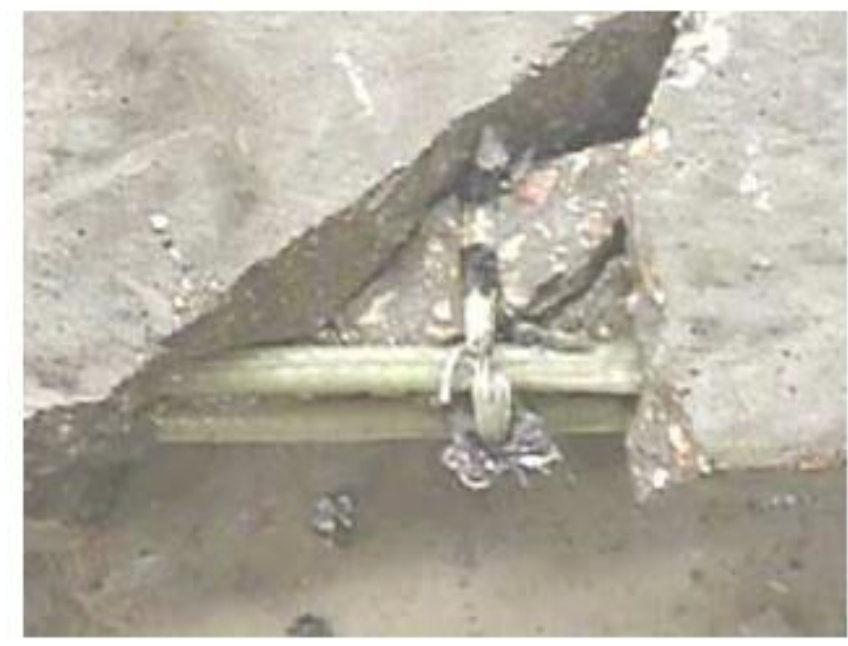

Figure 2.11 - Rupture of GFRP stirrups (Alkhrdaji et al.; 2001).

\subsubsection{Behavior of GFRP RC beams failing in shear}

The shear transfer mechanisms acting in a GFRP RC beam failing in shear are the same previously detailed in Section 2.1, for beams with steel-reinforced bars. However, because of that FRP reinforcing bars differ from steel reinforcing bars in many aspects including mechanical properties, some considerations (Bank, 2006) can be observed:

(i) The depth of the neutral axis in the FRP-reinforced section is typically much less than in a steel-reinforced beam because the lower axial stiffness, so the 
contribution from the concrete in the compression region to shear resistance is lower in the FRP-reinforced beam;

(ii) The width of the critical diagonal crack in an FRP-reinforced concrete beam is likely to be wider than in a steel reinforced beam since the flexural stiffness of the FRP reinforced beam will be lower than its steel counterpart (for the same load-carrying capacity);

(iii) The contribution of longitudinal FRP reinforcement in terms of dowel action will be less than that resisted by steel bars because of the lower strength and stiffness of FRP bars in the transverse direction. For a similar rebar diameter, FRP bars will have lower shear rigidity than that of steel bars;

(iv) FRP stirrups do not yield, so the influence of FRP stirrups to the capacity cannot be calculated simply considering the analogy with a plastic truss adopted for steel. In fact, the force that will develop in the FRP bar will depend on the sliding of the bar, which in turn will depend on how much the shear crack opens at the location where the FRP bar crosses the diagonal crack; this is not a trivial calculation.

It is also important to outline that the modulus of elasticity of GFRP is lower than that of steel, requiring a greater area of transverse reinforcement for a better control of the opening of the crack and to maintain a good contribution of the other shear mechanisms. Figure 2.12 presents a stress-strain curve comparing FRP and steel. The slope of the linear part of the curve is equivalent to the modulus of elasticity.

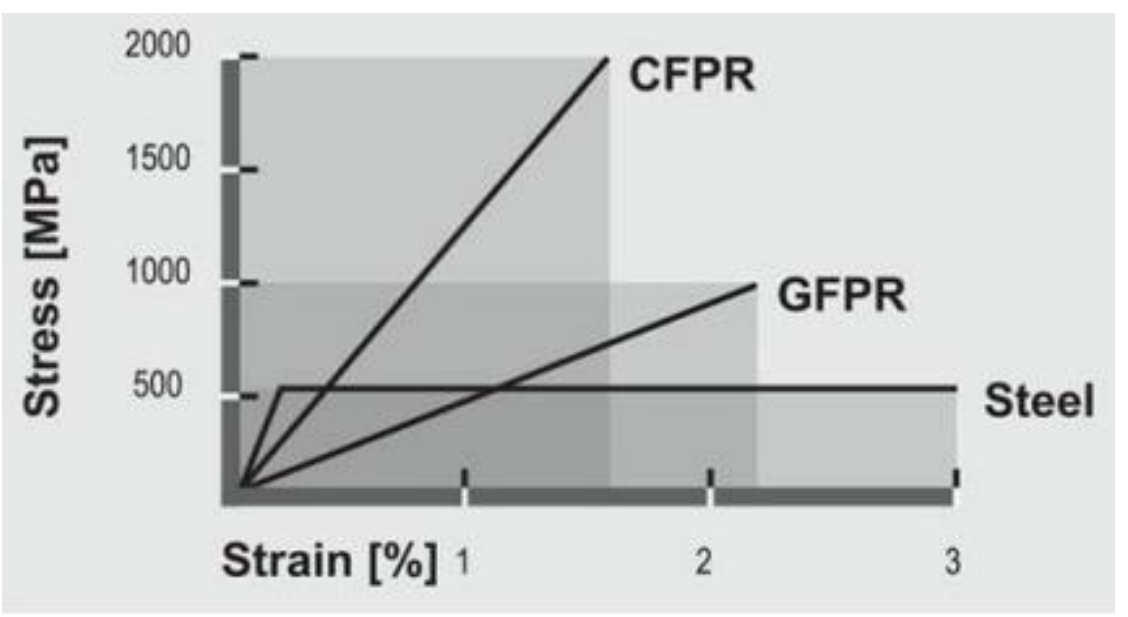

Figure 2.12 - Stress-strain curve for FRP and steel (Hajimiragha, 2016).

Several researchers (Michaluk et al.; 1998; Yost et al.; 2001; Tureyen and Frosch, 2002; El-Sayed et al.; 2005) have investigated the behavior of FRP- 
reinforced beams and slabs that failed in shear. They observed the lower longitudinal modulus of GFRP bars as being the primary factor leading to the lower shear strength of concrete reinforced with FRP bars. For this reason, in addition to those mentioned above, the shear strength of an FRP-reinforced section designed for the same nominal moment carrying capacity as a steel-reinforced section will have a lower concrete shear capacity than that of an equivalent steel-reinforced beam.

Shear failure modes of members with FRP as shear reinforcement are classified as either shear-tension failure mode or shear-compression failure mode. The shear tension failure mode is characterized by FRP shear reinforcement rupture, and the failure modes are described as brittle. The shear-compression failure mode is observed to be controlled by the crushing of the concrete web and the failure is relatively less brittle accompanied by larger deflections (GangaRao et al.; 2007).

Recent research (Ahmed et al.; 2010) showed that the presence of GFRP stirrups (similar to steel stirrups) enhances the concrete contribution after the formation of the first shear crack. The shear resistance is influenced by the spacing between the stirrups. A small spacing contributes to enhance the confinement of the concrete, to control the shear cracks, and to improve the aggregate interlocking.

The use of FRP as shear reinforcement has to be further explored to provide the foundation of a fully rational model to predict shear strength (Ahmed et al.; 2010). At present, most of the shear design provisions incorporated in existing codes and guides are based on the design formulas of members reinforced with conventional steel, considering some modifications to account for the differences between FRP and steel reinforcement (El-Sayed et al.; 2003). 


\subsection{Digital image correlation in shear analysis}

Digital Image Correlation (DIC) is non-contact method that can be used to find motions of chosen targets in a series of digital images relative to an initial undeformed state (Dutton, 2012). The method tracks the full-field movement of a random high-contrast speckle pattern applied to the sample's surface with sub-pixel accuracy and compares a reference image to a series of deformed images. Figure 2.13 shows the principle of DIC technique.

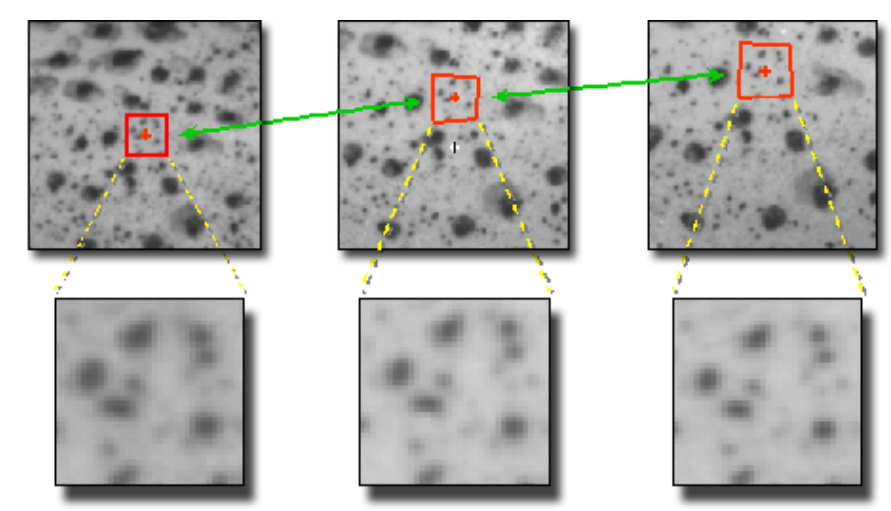

Figure 2.13 - Principle of DIC technique (Correlated Solutions, 2018).

DIC has been repeatedly proven to be accurate when compared to tradition devices such as strain gauges and extensometers and is also advantageous in determining crack movement because a priori knowledge of the crack location is not required. Figure 2.14 presents typical output result from a beam failing in shear obtained with DIC analysis.

Prior to tests, the surface of the specimen needs to be prepared and it must have a random speckle pattern, which can be the natural texture of the specimen or made by applying black and/or white paint to increase the contrast. The ideal pattern must be non-periodic and without a preferred orientation. The quality of the speckle pattern is highly related to the accuracy of the DIC results, it must reflect image contrast and the size depends on the test requirements and the resolution of the camera. Figure 2.15 shows same examples of poor and good patterns. 


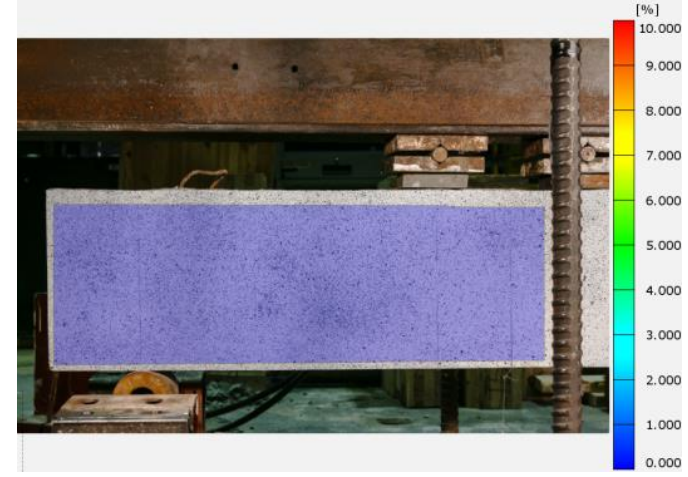

(a)

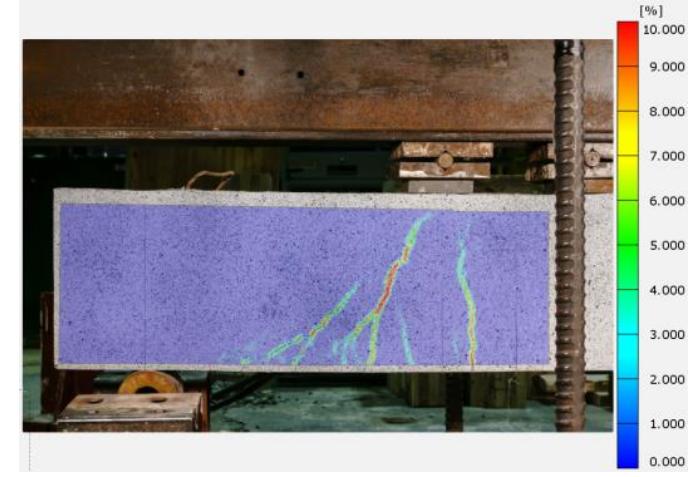

(b)

Figure 2.14 - Typical output result from DIC: (a) reference image; (b) deformed image.

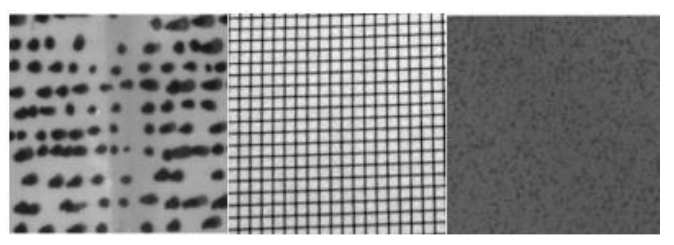

(a)

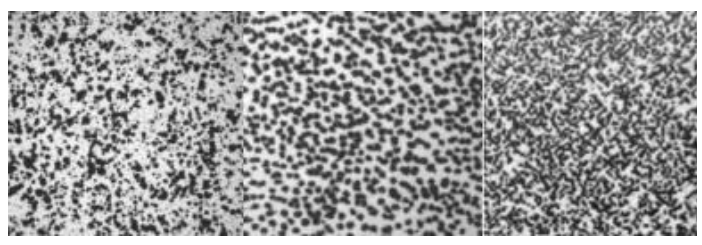

(b)

Figure 2.15 - Examples of patterns: (a) poor patterns (anisotropic, repetitive and low contrast); (b) good patterns.

In the last years, DIC has been implemented by several researchers (Huber et al.; 2016, Cavagnis et al.;2017, 2018 and Huang et al.; 2019) in order to investigate the shear transfer mechanisms of reinforced concrete members, based on the measured kinematics.

Huber et al. (2016) investigated the contribution of these mechanisms to the shear strength of RC beams and they noted that the governing shear transfer action depends on the crack shape and kinematics. They also concluded that DIC is an adequate tool for performing full field measurement of the crack kinematics, since this technique is capable of continuously tracking the critical shear crack. 


\section{Experimental Program}

In this chapter, a detailed description of the experimental program carried out to investigate the contribution of shear transfer mechanisms and strength of GFRP reinforced concrete beams is provided. Testing was conducted in the Structures and Materials Laboratory of Civil and Environmental Engineering Department at PUC-Rio (LEM/DEC) and in the Concrete Laboratory at University of Ottawa, Canada, hereafter referred as Brazilian (BRA) and Canadian (CAN) campaigns, respectively.

The experimental program was divided into 4 parts: i) material characterization; ii) dowel action tests, iii) push-off tests; and iv) beam tests. Parts i) and iv) were conducted in both laboratories whereas parts ii) and iii) were performed only at LEM/DEC. Besides the cylinder specimens for the characterization of the concrete, a total of 18 specimens were tested and a summary of the tests performed in the experimental program in Table 3.1. The specimens were labeled with an identifying code. The number before " $L$ " indicates the number of GFRP longitudinal bars in a layer. "NS" indicates that no stirrups were used. "S" indicates the presence of stirrups. For push-off tests, the label corresponds to the maximum size of the coarse aggregate adopted.

Materials used in the experimental program are described in the following sections, as well as the tests set-ups, instrumentation, and procedures adopted. 
Table 3.1 - Summary of experimental program tests (dimensions in millimeters)

\begin{tabular}{llllll}
\hline Test & Specimens & $\begin{array}{c}\text { Longitudinal } \\
\text { GFRP Bar } \\
\text { (Bottom) }\end{array}$ & $\begin{array}{c}\text { Longitudinal } \\
\text { GFRP Bar } \\
\text { (Top) }\end{array}$ & $\begin{array}{c}\text { GFRP } \\
\text { Stirrups }\end{array}$ & $\begin{array}{c}\text { Aggregate } \\
\text { maximum } \\
\text { size }\end{array}$ \\
\hline Dowel 2L & 1 (BRA) & $2 \phi 12.5$ & - & - & 12.5 \\
Dowel 3L & 1 (BRA) & $3 \phi 12.5$ & - & - & 12.5 \\
\hline Push-off 12.5 & 2 (BRA) & - & - & - & 12.5 \\
Push-off 25 & 2 (BRA) & - & - & - & 25 \\
\hline Beam 3L-NS & 3 (BRA) & $3 \phi 12.5$ & - & - & 12.5 \\
Beam 3L-S & 3 (BRA) & $3 \phi 12.5$ & $2 \phi 12.5$ & $\phi 8 @ 150$ & 12.5 \\
\hline Beam 2L-NS & 3 (CAN) & $2 \phi 12.5$ & - & - & 19 \\
Beam 2L-S & 3 (CAN) & $2 \phi 12.5$ & $2 \phi 12.5$ & $\phi 10 @ 150$ & 19 \\
\hline
\end{tabular}

\subsection{Materials}

\subsubsection{GFRP Bars and Stirrups}

The GFRP bars and stirrups used in the Brazilian campaign were supplied by Stratus Compostos Estruturais. The composite material was helically wrapped and made with Boron-free corrosion resistant E-CR glass reinforcement and vinyl ester polymeric matrix. On the other hand, the GFRP bars and stirrups used in the Canadian campaign were supplied by Pultrall and the material were sand-coated rather than helically wrapped. Figure 3.1 presents samples of GFRP bars and stirrups from both campaigns. For the longitudinal reinforcement, $12.5 \mathrm{~mm}$ diameter bars were adopted in both campaigns. For the stirrups, it was used $8 \mathrm{~mm}$ and $10 \mathrm{~mm}$ diameter for the Brazilian and Canadian campaigns, respectively. Table 3.2 shows the bars properties provided by the manufacturers. 


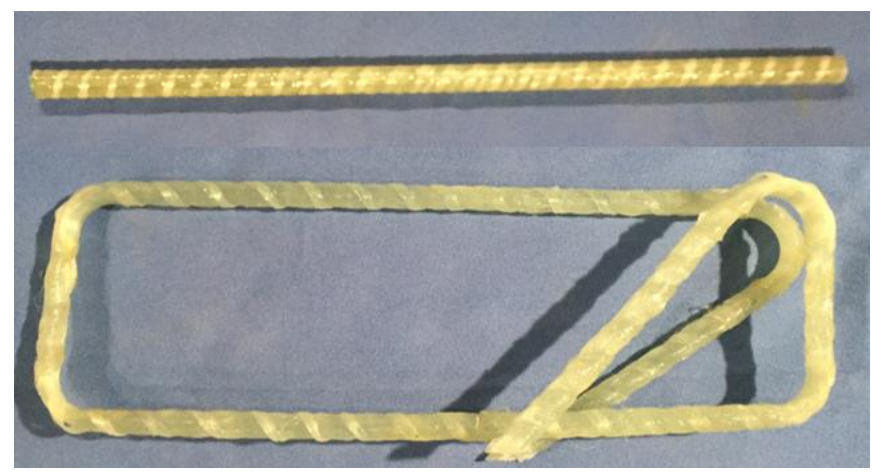

(a) GFRP bars and stirrups - Brazilian campaign

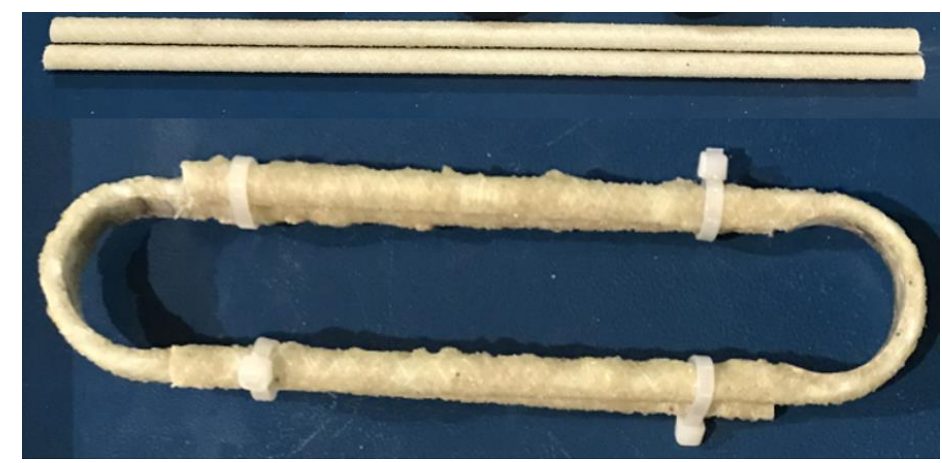

(b) GFRP bars and stirrups - Canadian campaign

Figure 3.1 - GFRP bars and stirrups used in Brazilian and Canadian campaigns.

Table 3.2 - GFRP bars properties reported by manufacturers.

\begin{tabular}{lll}
\hline \multicolumn{3}{c}{ Properties of GFRP bars } \\
\hline & BRA & CAN \\
\hline Tensile Stress (MPa) & 989 & 1091 \\
Tensile Modulus (GPa) & 48 & 41.9 \\
Tensile Strain (\%) & 2.05 & 2.35 \\
Compression Strength (MPa) & 494 & - \\
Shear Strength (MPa) & 210 & 184 \\
Poisson's ratio & 0.26 & 0.25 \\
\hline
\end{tabular}

\subsubsection{Concrete}

For the experimental program, different concrete design mixes were adopted for Brazilian and Canadian campaigns, as described in Table 3.3, for a compressive strength of $30 \mathrm{MPa}$ at 28 days. 
Table 3.3 - Mix design

\begin{tabular}{|c|c|c|}
\hline \multirow{2}{*}{ Material } & \multicolumn{2}{|c|}{$\mathrm{kg} / \mathrm{m}^{3}$} \\
\hline & BRA & $\mathbf{C A N}$ \\
\hline Cement CPII-F & 361 & 361 \\
\hline Fine aggregate & 853 & 853 \\
\hline Coarse aggregate & 916 & 916 \\
\hline Water & 191 & 191 \\
\hline Superplasticizer & $5.4(1.5 \%)$ & $0.9(0.25 \%)$ \\
\hline
\end{tabular}

Portland cement with 6-10\% limestone filler in weight was used in both campaigns. In the Brazilian campaign, the aggregates were supplied by IBRATA. The fine aggregate was dry industrial sand with fineness moduli of 2.02 and the maximum size of the coarse aggregate was $12.5 \mathrm{~mm}$. Only for the push-off tests, for two specimens were used $25 \mathrm{~mm}$ coarse aggregate maximum size instead of $12.5 \mathrm{~mm}$. The superplasticizer used was the MasterGlenium 51 manufactured by BASF and the weight adopted corresponds to $1.5 \%$ of that for the cement.

In Canadian campaign, it was used dry natural sand with fineness moduli of 2.46 and the maximum size of the coarse aggregate was $19 \mathrm{~mm}$. The superplasticizer used was the MasterGlenium 7500 manufactured by BASF and the weight adopted corresponds to $0.25 \%$ of that for cement.

The molding process used in both campaigns was the same. First of all, the coarse aggregate and the dry sand were added to the mixer, with $70 \%$ of the total amount of water. Then, the mix was stirred for one minute for homogenization. After that, the cement was added, and the mixer ran for another one minute. Afterwards, the rest of the water (30\%) and the superplasticizer were added, and the concrete was mixed for 15 to 20 minutes in order to achieve the desired consistency. After casting, specimens were moist cured for 2 days followed by 26 days of air curing, for a total of 28 days.

\subsection{Mechanical Characterization Tests}

\subsubsection{Tensile test of GFRP bars}

The mechanical properties of the GFRP longitudinal bars used in the Brazilian campaign were obtained from uniaxial tensile tests on six $400 \mathrm{~mm}$ long 
GFRP samples. All tests were performed by Sá (2018) and followed the recommendations of ASTM D7205M - 06 (2016).

Prior to test, all bars had a protective $19 \mathrm{~mm}$ diameter, $2 \mathrm{~mm}$ thickness and $100 \mathrm{~mm}$ long steel tube (anchor) placed on each end of a bar, between the bar and the grips of the tensile testing machine, to prevent grip-induced damage. Sikadur®32 (epoxy resin bonding agent) was used to set the steel tube to the bar (Figure 3.2a). Therefore, the samples of $400 \mathrm{~mm}$ long had a $200 \mathrm{~mm}$ free length between the anchors. The specimens were tested in a universal testing machine MTS 311, with capacity of $1200 \mathrm{kN}$, under displacement control at rate of $5 \mathrm{~mm} / \mathrm{min}$. The bars were instrumented with a clip gage at mid-length in order to monitor the strains during loading. Figure 3.2 presents the samples prepared to be tested and the setup for the tensile test in GFRP bars.

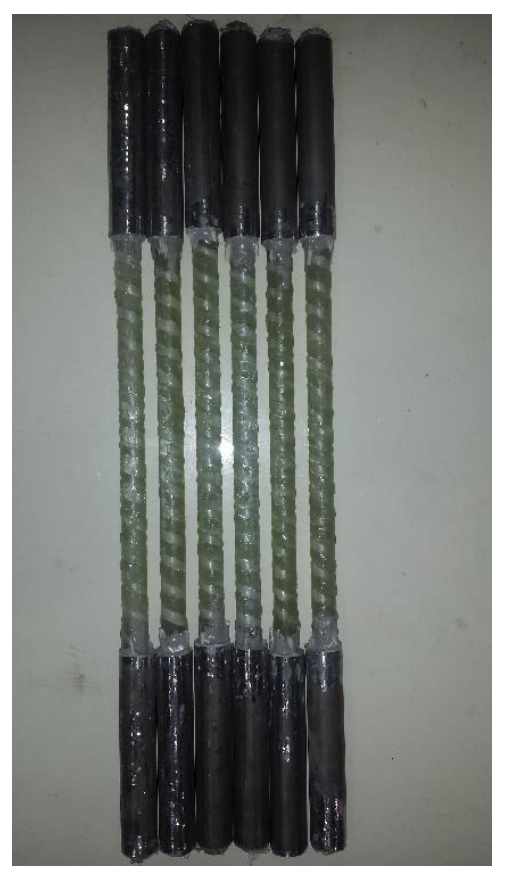

(a)

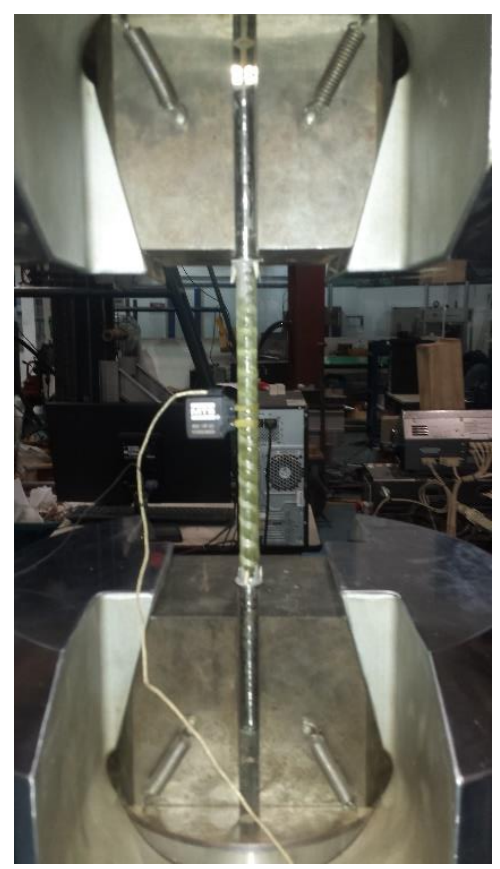

(b)

Figure 3.2 - (a) GFRP samples after fixing the protective steel tubes; (b) setup for tensile test in GFRP bar (Sá, 2018).

In the Canadian campaign, all tensile and shear tests were done on a SatecBaldwin UTM, with a $1780 \mathrm{kN}$ capacity load cell calibrated and with an Epsilon $200 \mathrm{~mm}$ extensometer. The samples were $1603 \mathrm{~mm}$ long and had a $510 \mathrm{~mm}$ anchor length. All tests were performed by Pultrall. 


\subsubsection{Compression and Splitting Concrete Tests}

In order to determine the ultimate compressive strength, stress-strain curve, and splitting tensile strength of concrete, characterization tests were conducted. Cylindric specimens of $200 \mathrm{~mm}$ high by $100 \mathrm{~mm}$ in diameter were tested on a testing machine Controls 50-C46Z00, with load capacity of $2000 \mathrm{kN}$ (Brazilian campaign) and Controls 50-C46C02 PILOT Automatic Compact-Line, with load capacity of $2000 \mathrm{kN}$ (Canadian campaign). The compressive axial load was applied at a rate of $0.25 \mathrm{MPa} / \mathrm{s}$ until failure of the specimen. To obtain the strains, two vertical displacement transducers, coupled to acrylic rings, were positioned around the specimen (only for Brazilian campaign). Figure 3.3 presents the characterization test setup for concrete cylinders.

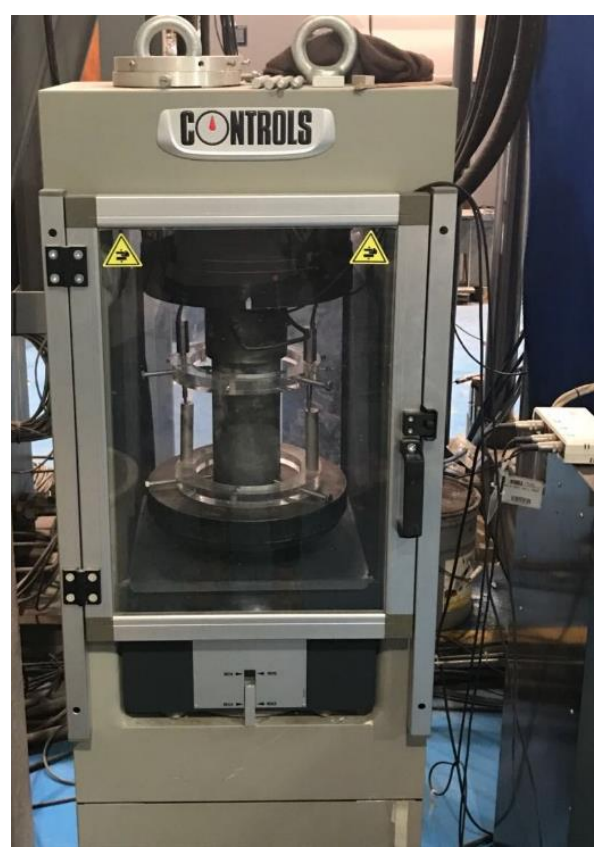

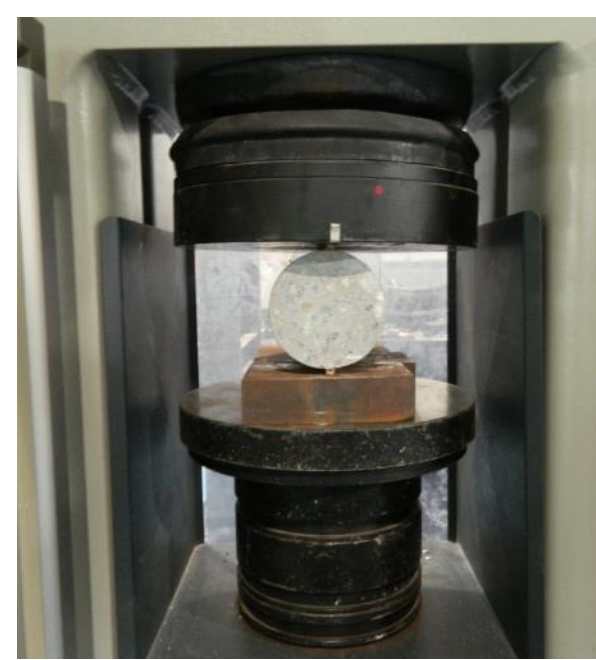

(b)

(a) 


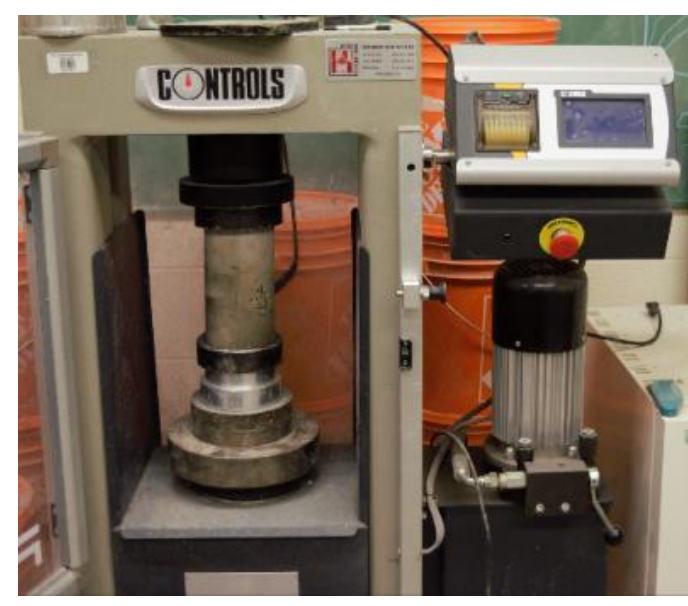

(c)

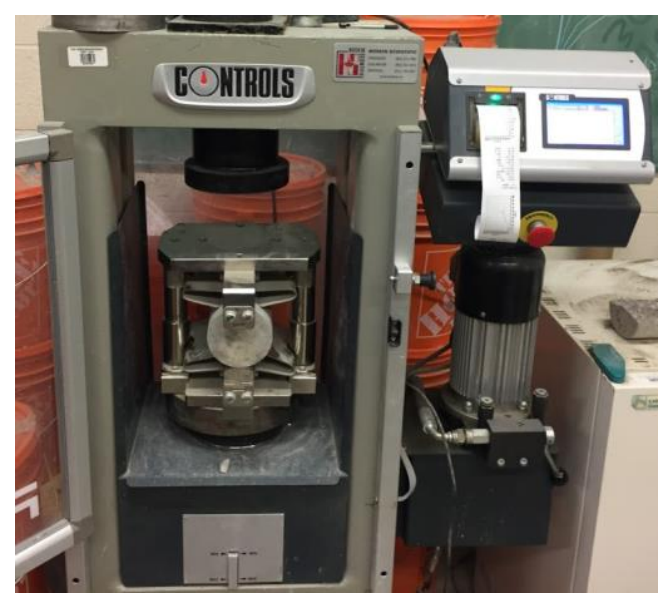

(d)

Figure 3.3 - Concrete characterization test setup: (a) Compression test (BRA); (b) Splitting test (BRA); (c) Compression test (CAN); (d) Splitting test (CAN).

\subsection{Dowel Tests}

In order to experimentally investigate the influence of the dowel action effect on the shear strength of reinforced concrete beams, two specimens with dimensions $150 \mathrm{~mm}$ wide, $250 \mathrm{~mm}$ deep and $1200 \mathrm{~mm}$ long. The specimens were internally reinforced with a single layer of two and three longitudinal GFRP bars of $12.5 \mathrm{~mm}$ at the bottom side and they were tested in bending using a setup configuration based on the model presented by Krefeld \& Thurston (1966), Baumann \& Rush (1970) and Taylor (1974). A scheme of the specimen adopted with dimensions and reinforcement used is presented in Figure 3.4. 


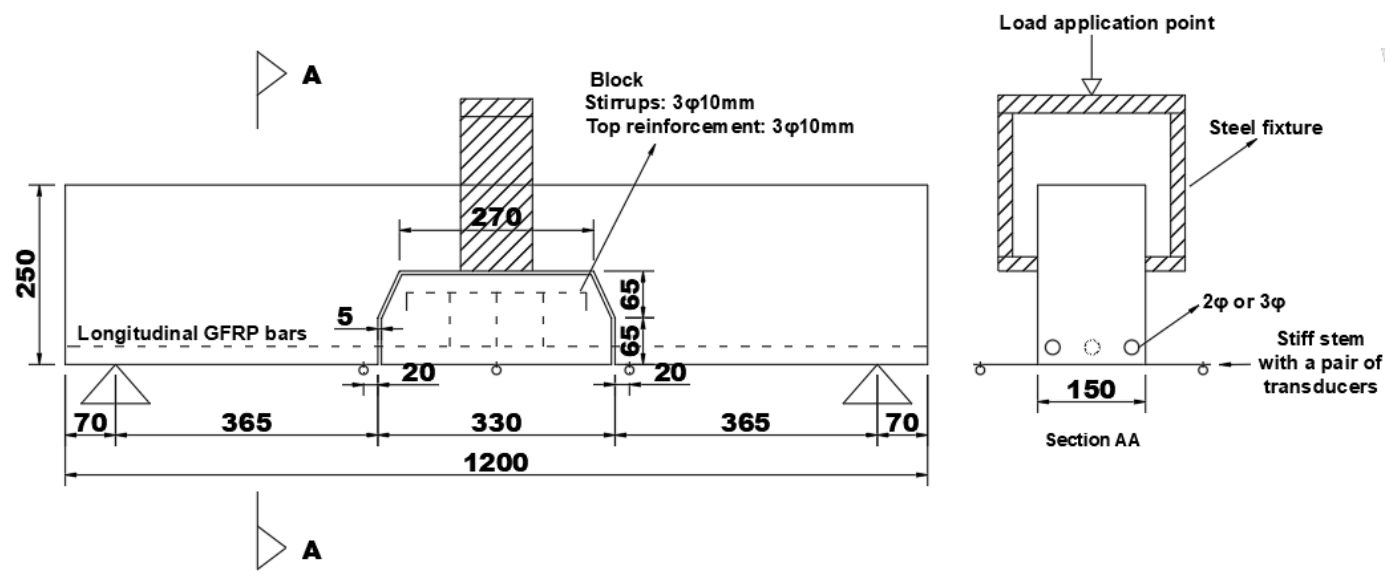

Figure 3.4 - Scheme of dowel action specimen (dimensions in millimeters).

The setup was specially prepared to ensure no contact between the surface of the internal loading block and the surface of the beam. The internal loading block was isolated from the other parts of the beam, and the longitudinal bars are the only means of connection between these elements. This was done to ensure load transfer exclusively by dowel action. For this purpose, a steel fixture was used to transfer the load to the internal block. Figure 3.5 presents a scheme with the steel fixture and a 3D model of the loading application setup. No stirrups were adopted in order to determine the minimum dowel action resistance of the longitudinal GFRP bars. Conventional steel reinforcement was adopted to avoid failure of the internal loading block. Figure 3.6 show the design and details of the internal loading block. The profile of the end surface of the block was intended to simulate a diagonal crack produced in a normal beam.
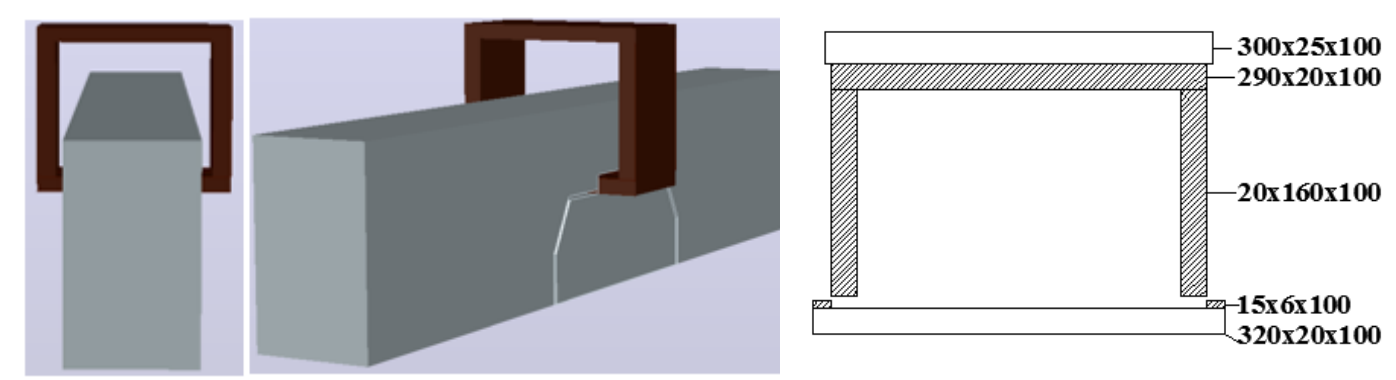

Figure 3.5 - 3D model and steel fixture for dowel action tests (dimensions in millimeters). 

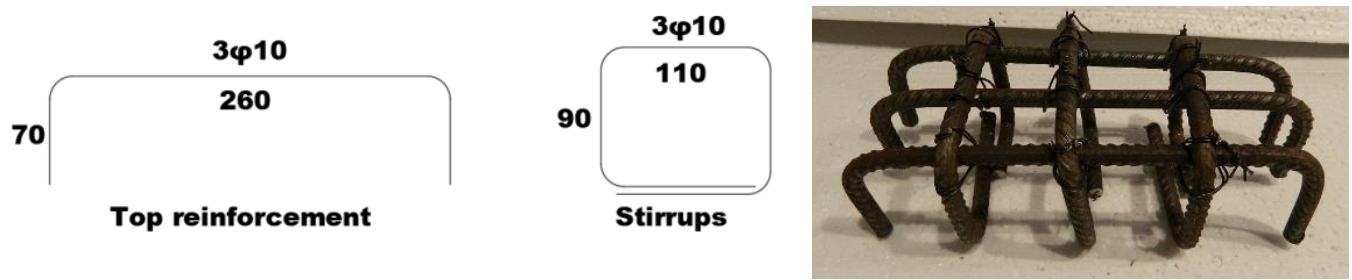

Figure 3.6 - Internal loading block reinforcement (dimensions in millimeters).

The specimens used in dowel tests were fabricated in two steps: i) casting of the internal loading block; and ii) casting of the beam itself. Plywood formworks were used and their internal surface was covered with biodegradable oil to avoid damaging formwork during specimen removal and, therefore, to allow their reuse.

Before casting the internal block, the longitudinal GFRP reinforcement and the internal loading block reinforcement made of conventional reinforcing steel were positioned inside the plywood formwork, as shown in Figure 3.7. In all specimens, the lateral and bottom covering were $3.0 \mathrm{~cm}$ and $2.5 \mathrm{~cm}$, respectively. The concrete for the internal loading block was mixed in a planetary mixer Amadio, model 20LA. The concrete was poured in the formwork manually and a rubber mallet was used to gently hammer the side of formwork to spread the concrete inside of it. To allow the correct curing of the concrete, after one hour a plastic film was used to seal the system by covering the concrete of the loading block for the next 24 hours.

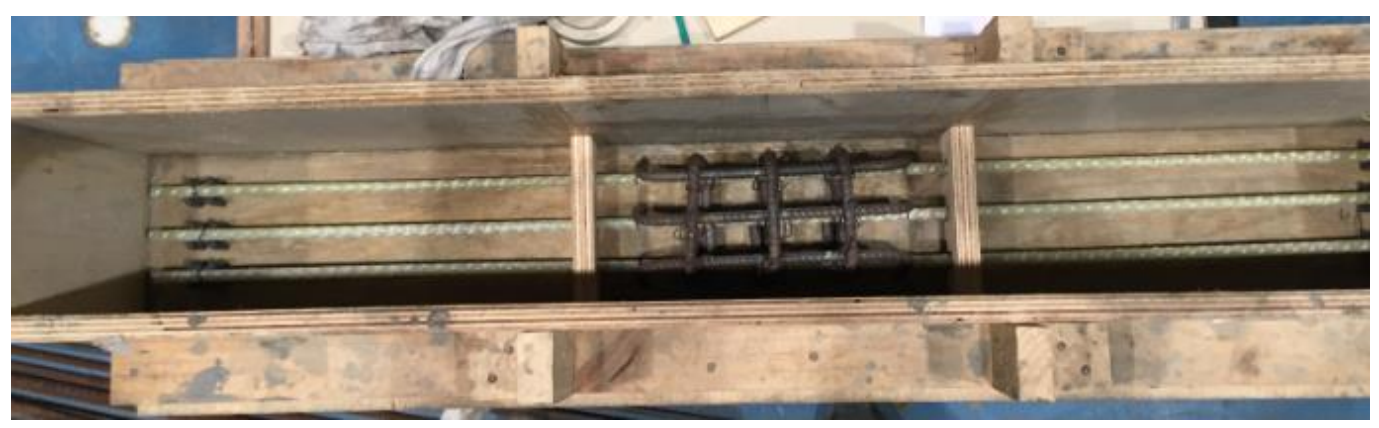

Figure 3.7 - Positioning of the GFRP and the internal block reinforcements.

Subsequently, the four pieces of plywood used to separate the internal loading block were replaced by four pieces of expanded polystyrene $5 \mathrm{~mm}$ thick each and covered with plastic film. At the top of the block, a 130x150x40mm piece of expanded polystyrene was positioned, as shown in Figure 3.8 

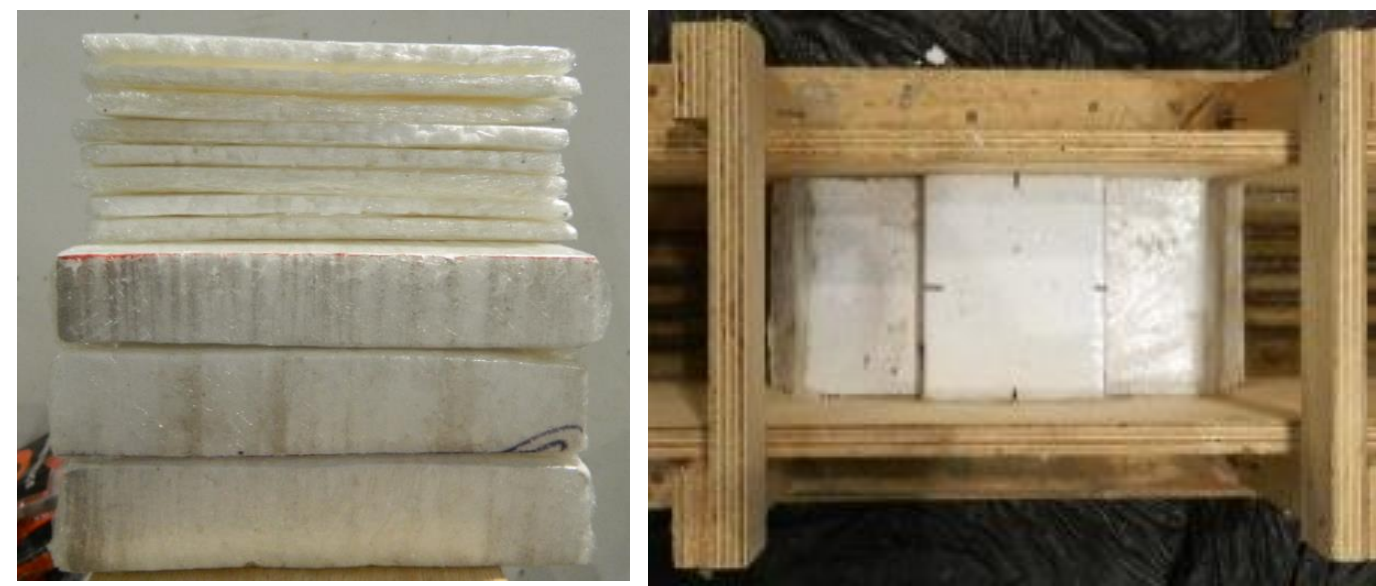

Figure 3.8 - Pieces of expanded polystyrene used in dowel action specimens.

Then, the rest of the beam was casted by pouring the concrete and again a rubber mallet was used spread the concrete inside the formwork. The concrete for the rest of the beam was produced in a mixer with capacity of $400 \mathrm{~L}$. Two hooks were attached to the top edges of the beam for handling.

The moist curing process was the next step and keeping the specimen covered with the plastic film for the next 72 hours. After this period, the beam was removed from the formwork and stored in the laboratory under normal environmental conditions, until it completed 28 days. Figure 3.9 shows the molding process of the dowel action specimens.
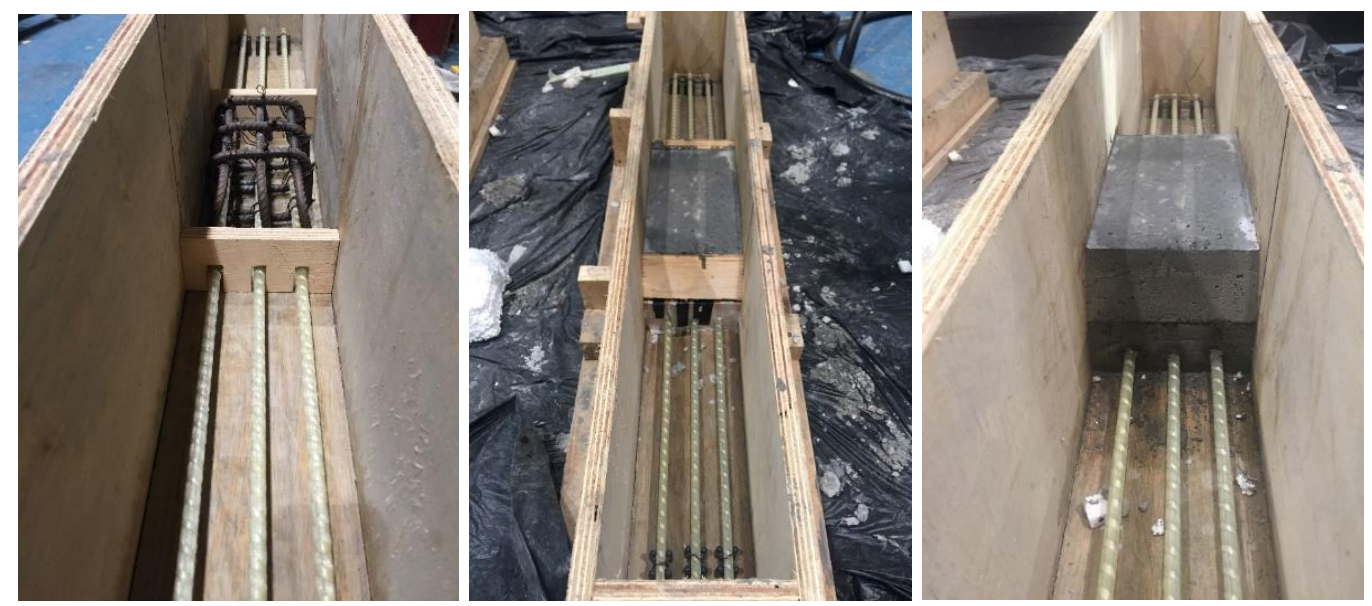

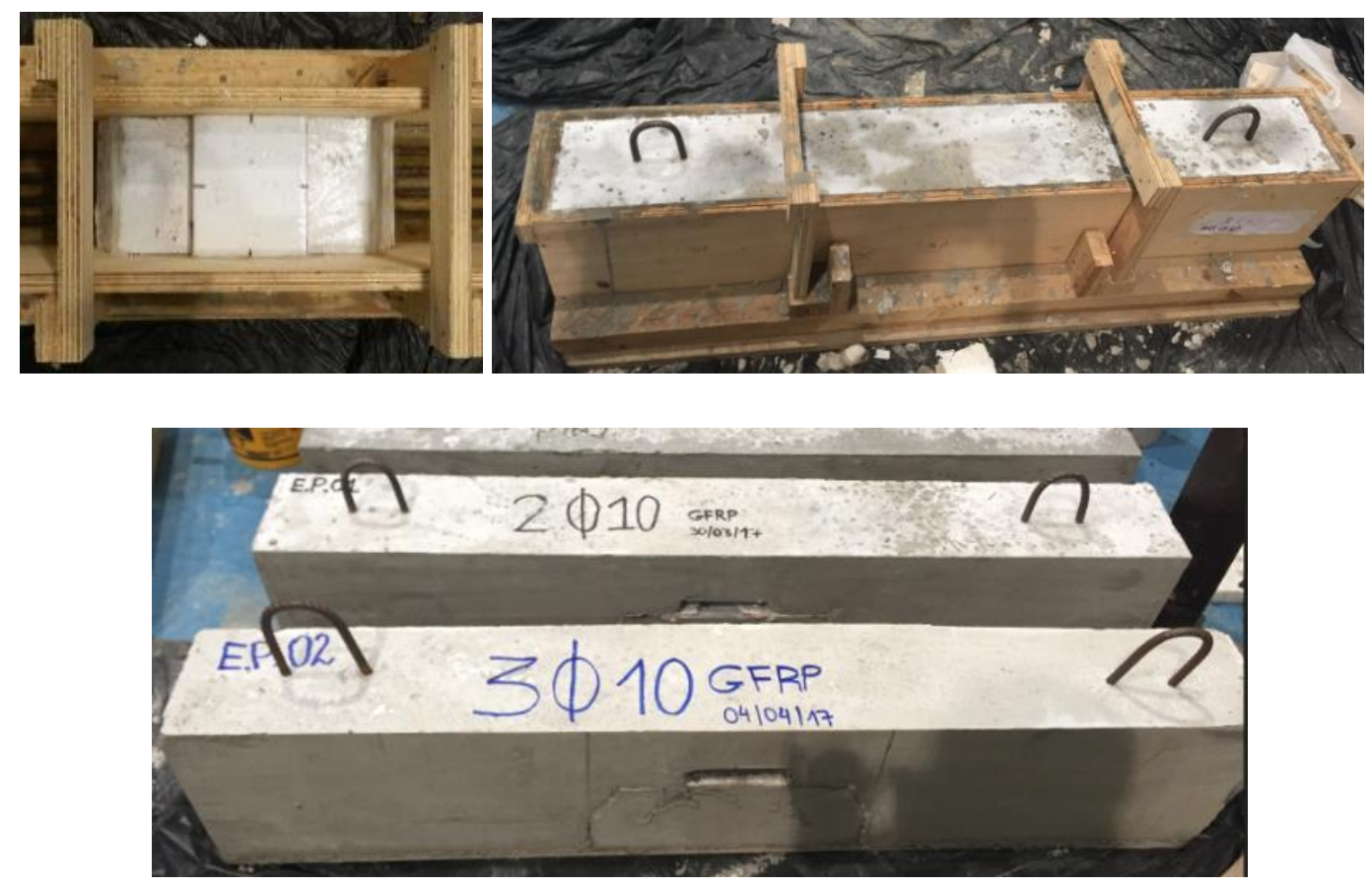

Figure 3.9 - Dowel action specimens molding process sequence.

Dowel tests were carried out in a 3-point bending configuration over a 1060 $\mathrm{mm}$ span. The specimen was supported on two roller assemblies mounted in a way to avoid longitudinal motions and the load was applied to the top of the central block using a steel fixture. To ensure the correct distribution of the load to the specimen, a spherical hinge was used between the actuator and the steel loading device. Specimens were instrumented with six transducers positioned in order to capture relative displacement between loading block and beam. Pairs of transducers were positioned under the specimen, at the center of the internal loading block and at the edges of the gap, $20 \mathrm{~mm}$ distant from the left and right extremities of the block, i.e. near the points of application of dowel force. The transducers were protected by stiff stems attached to them and pressed down using elastic bands to fix them to the bottom side of the specimen, as shown in Figure 3.10. 


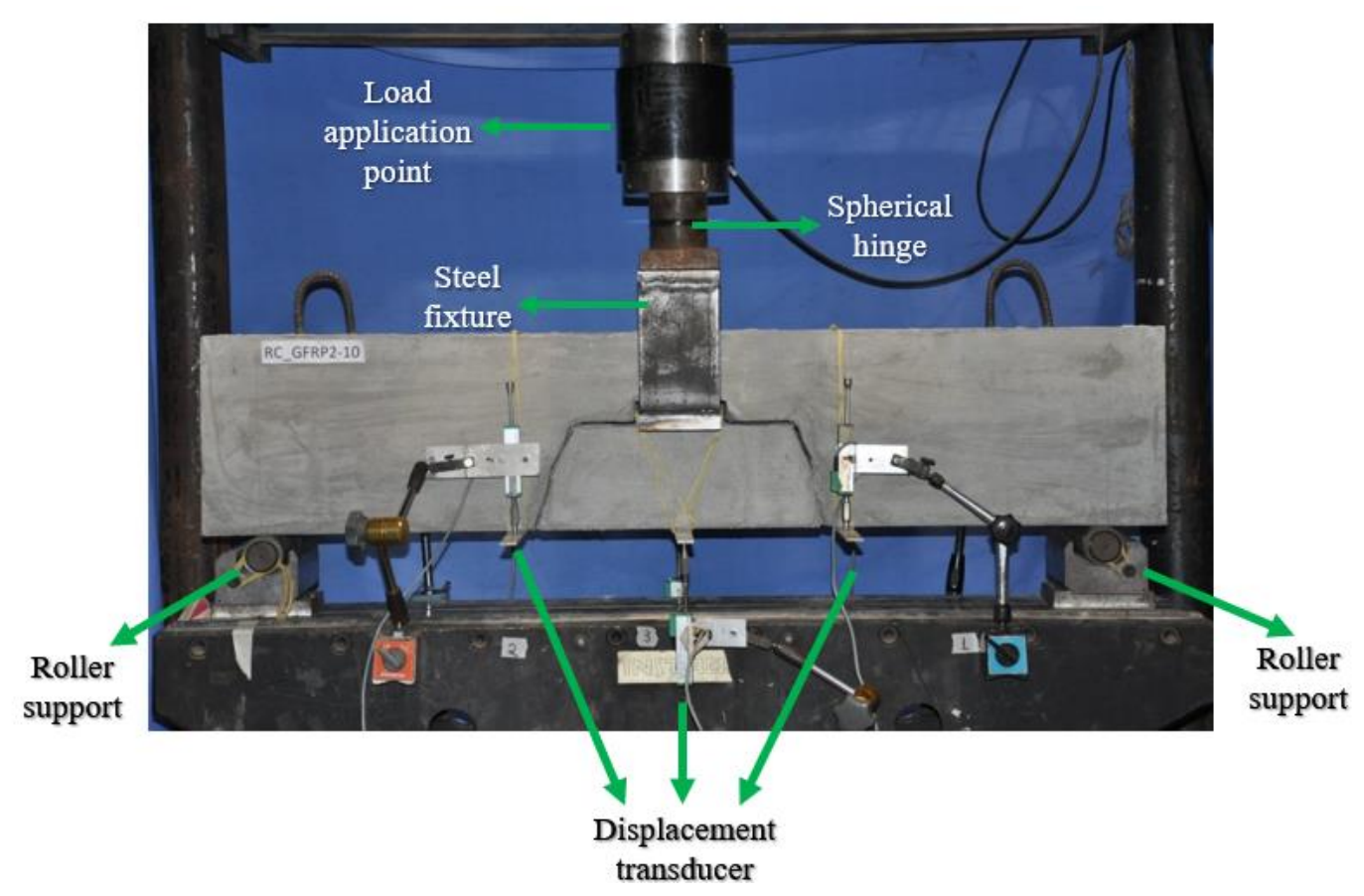

Figure 3.10 - Setup for dowel action tests.

Tests were conducted in LEM/DEC (BRA), in displacement control with a rate of $0.3 \mathrm{~mm} / \mathrm{min}$, using an MTS 244.41 actuator with $500 \mathrm{kN}$ capacity. Displacements and load data were gathered automatically at a frequency of $5 \mathrm{~Hz}$ with an HBM QuantumX MX440B acquisition system.

\subsection{Push-off Tests}

In order to experimentally investigate the influence of aggregate interlock on shear transfer through cracks, a total of four push-off specimens with two different type of aggregate were tested, where two duplicate specimens used coarse aggregate with maximum size $12.5 \mathrm{~mm}$ and the other two coarse aggregate with maximum size $25 \mathrm{~mm}$.

The idea of the push-off test is to produce shear without moment (pure shear) in desired cracked plane, when an axial force $(\mathrm{P})$ is applied parallel to this shear plane. To make this possible, the push-off specimens were produced with a geometry based on the model presented by Oviedo et al. (2013), with a rectangular shear section of $100 \mathrm{~mm} \times 260 \mathrm{~mm}$, formed by two "L" blocks, where the connecting plane of these two blocks defines the shear plane. Both "L" blocks were reinforced 
with conventional steel bars and stirrups. Figure 3.11 presents the dimensions and the reinforcement layout of the specimens.
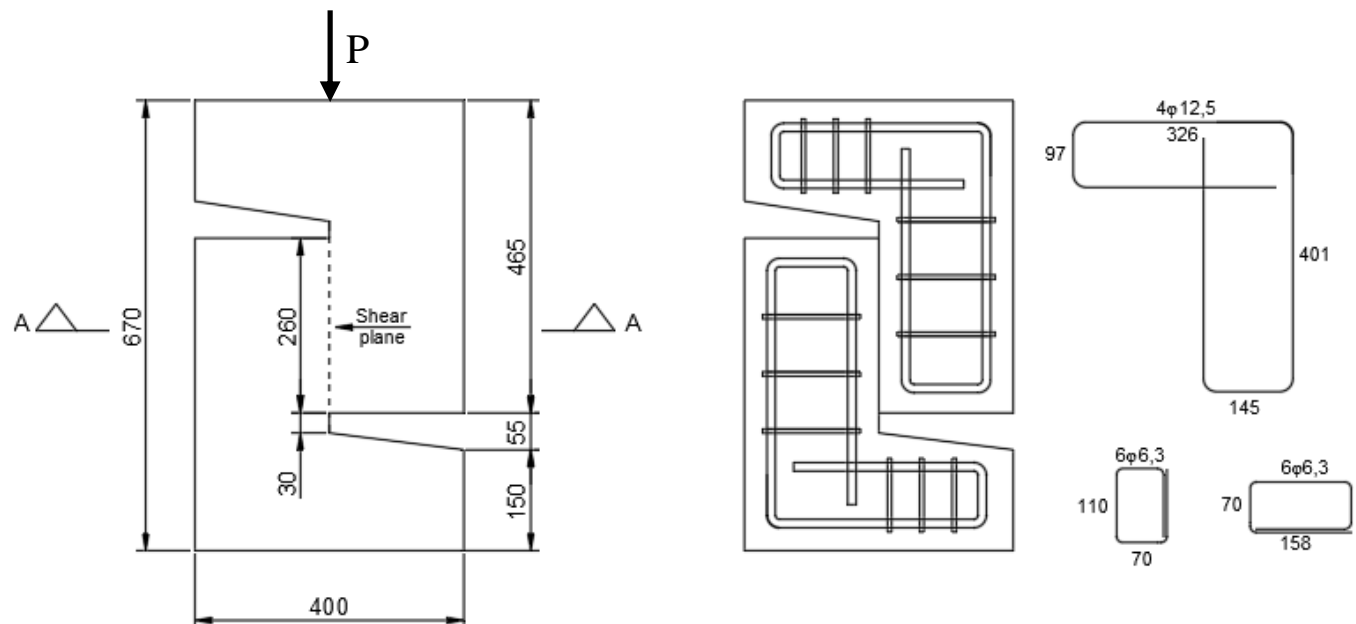

Figure 3.11 - Scheme and reinforcement layout of push-off specimen (dimension in millimeters).

The push-off specimens were fabricated using plywood formworks and their internal surface was covered with biodegradable demoulding oil in the same way used in the molding process for dowel action specimens. Before casting, a $10 \times 10 \mathrm{~mm}$ (width $\mathrm{x}$ depth) aluminum ' $\mathrm{V}$ '-shaped was positioned on the bottom surface of the formwork and aligned with the shear plane to introduce the desired notch. Then, the reinforcing cages for each "L" block were positioned inside the formwork and the concrete was poured. A rubber mallet was applied to consolidate the concrete. Once the casting was completed, another aluminum ' $\mathrm{V}$ ' was positioned on the top surface of the specimen. In all specimens, the lateral and bottom covering were $2.5 \mathrm{~cm}$. Figure 3.12 shows the molding process for push-off specimens. 

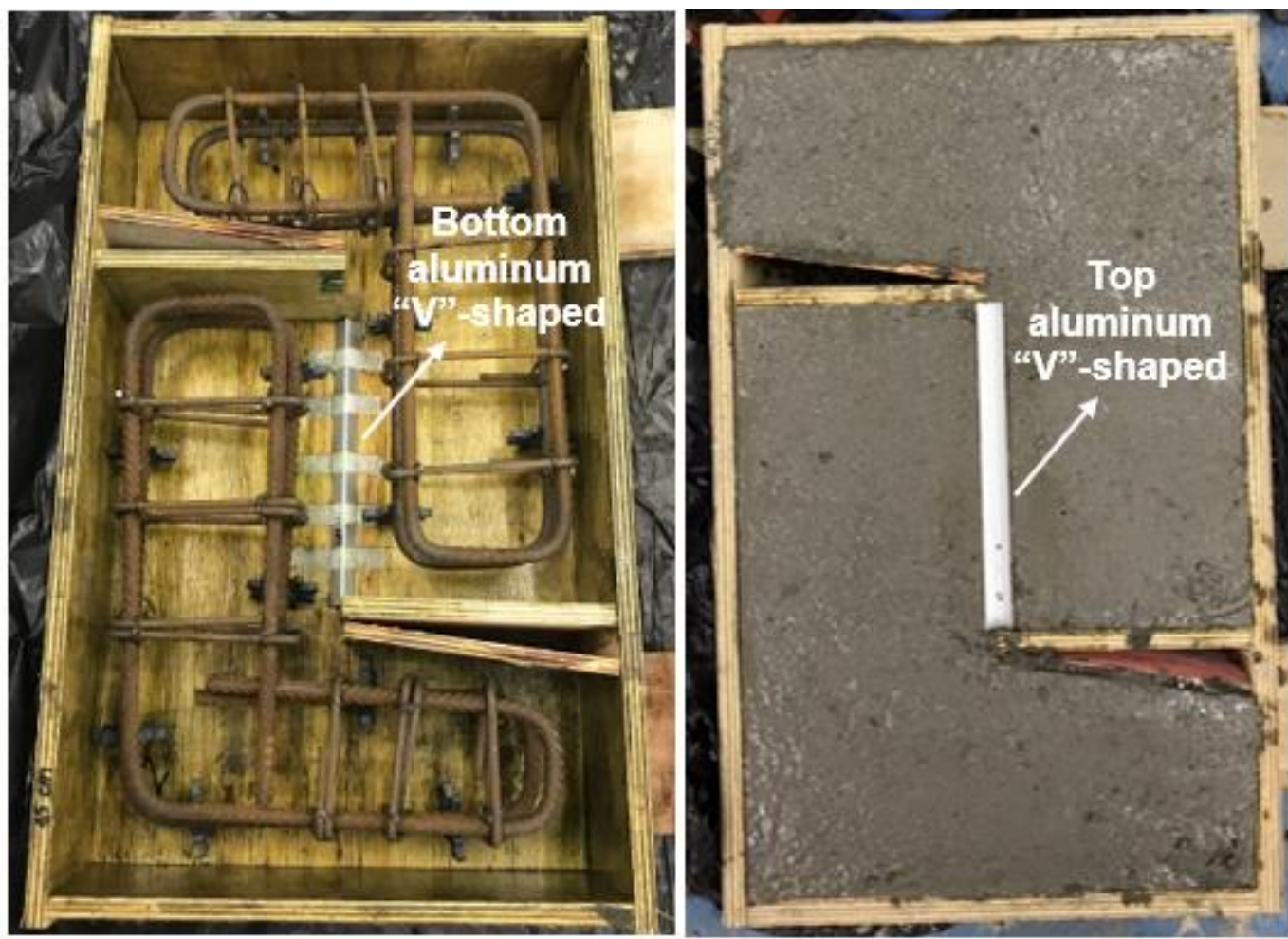

Figure 3.12 - Push-off specimens molding process.

The test setup was designed to allow a simultaneous and independent loading in both in the vertical and horizontal directions (aligned and perpendicular to the shear plane, respectively). The horizontal load was intended to produce a constant uniform normal stress acting throughout the shear plane. To ensure a proper load distribution in the specimen and to avoid undesired restraints against the motions of the ' $L$ ' blocks, spherical hinge and rollers were used as shown in Figure 3.13 .

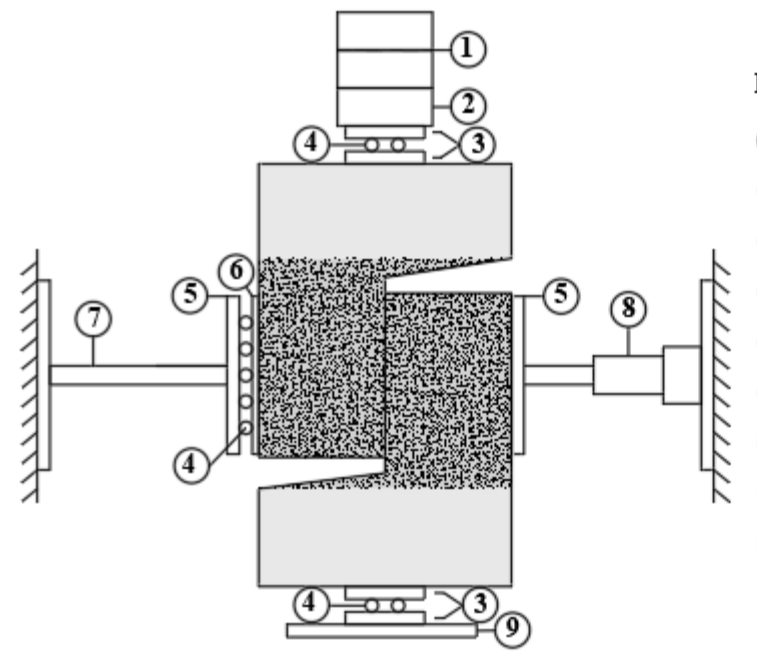

Legenda:

(1) Spheric al hinge ( $\varphi=150, \mathrm{~L}=120)$

(2) Steel billet ( $\varphi=150, \mathrm{~L}=65$ )

(3) Steel billet $(125 \times 20 \times 125)$

(4) Roller ( $\varphi=20, \mathrm{~L}=125)$

(5) Steel billet $(20 \times 250 \times 125)$

(6) Steel billet $(10 \times 250 \times 125)$

(7) Reaction structure

(8) Hydraulic jack

(9) Steel billet $(300 \times 20 \times 210)$

Figure 3.13 - Scheme of the test setup for push-off specimens. 
In order to measure the opening of the crack, two displacements transducers were positioned in the horizontal direction, in one of the faces of the specimen, equally spaced by one third of the shear section height, as shown in Figure 3.14. To measure the sliding, a displacement transducer was used in the vertical direction, 3 $\mathrm{cm}$ apart of the notch axis. In the other face of the specimen, it was adopted the digital image correlation technique to gather information about the crack kinematics. Thus, white paint was applied over the specimen surface, followed by a black speckle pattern consisting of randomly spaced dots (shown in Figure 3.15), so that a digital image correlation analysis could be performed. A light source providing diffuse light was used to mitigate glare/reflections. The images were captured with a Nikon D90 camera, with resolution greater than 3.0 megapixels, and sequential shots were taken under the command of the software DigicamControl. An overview of the testing setup is presented in Figure 3.16.

The test was conducted in LEM/DEC (BRA) and it began with the application of an increasing load in the horizontal direction $\left(F_{h}\right)$ until $8 \mathrm{kN}$ was reached (normal tensile equals to $\sigma=0,31 \mathrm{MPa}$ ), using a hydraulic jack, with 100 $\mathrm{kN}$ capacity. When this load was stabilized, the load in the vertical $\left(F_{v}\right)$ direction began to be applied by an MTS 244.41 actuator with $500 \mathrm{kN}$ capacity, with displacement control at a rate of $0.20 \mathrm{~mm} / \mathrm{min}$. Displacements and load data were gathered automatically at a frequency of $2 \mathrm{~Hz}$ with an HBM QuantumX MX440B acquisition system.

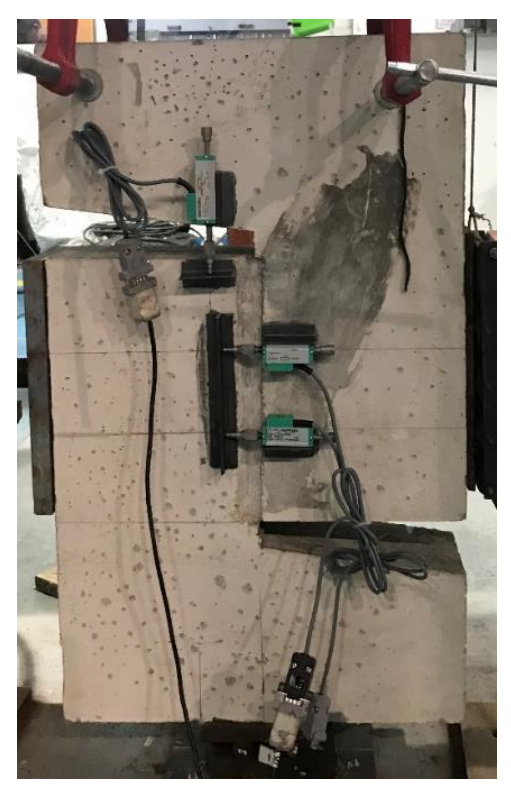

Figure 3.14 - Localization of the displacement transducers. 


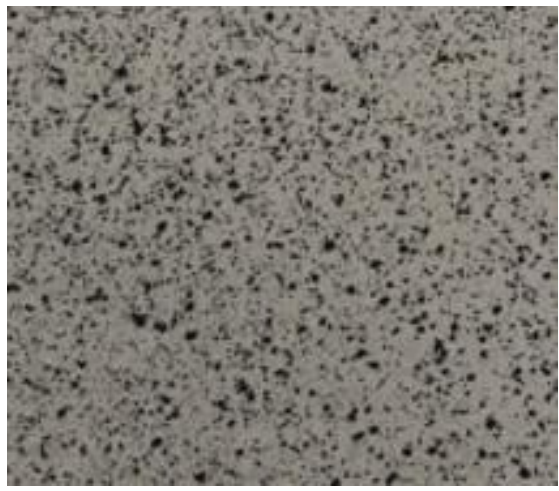

Figure 3.15 - Detail of the speckle pattern.

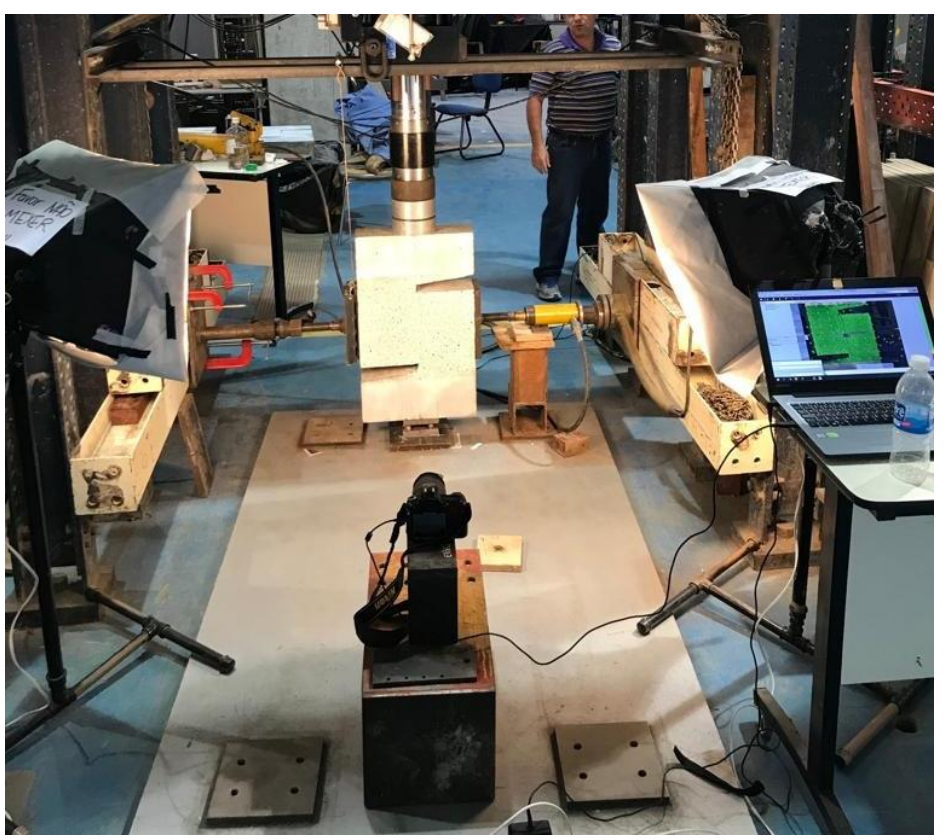

Figure 3.16 - Setup of the push-off tests.

\subsection{Beam Tests}

\subsubsection{Brazilian campaign}

In order to experimentally investigate the influence of the presence of GFRP stirrups, a total of six concrete simply supported beams with cross-section dimensions of $120 \times 300 \times 1200 \mathrm{~mm}$ were tested in a four-point bending configuration, with total and shear spans respectively of 1250 and $500 \mathrm{~mm}$. All beams were longitudinally reinforced with three bars of $12.5 \mathrm{~mm}$ at the bottom side. For three beams, transverse reinforcement using $8 \mathrm{~mm}$ diameter stirrups every 150 
$\mathrm{mm}$ was adopted along with two longitudinal bars of $12.5 \mathrm{~mm}$ at the top, for cage assembly purposes. A scheme of the configuration is shown in Figure 3.17.
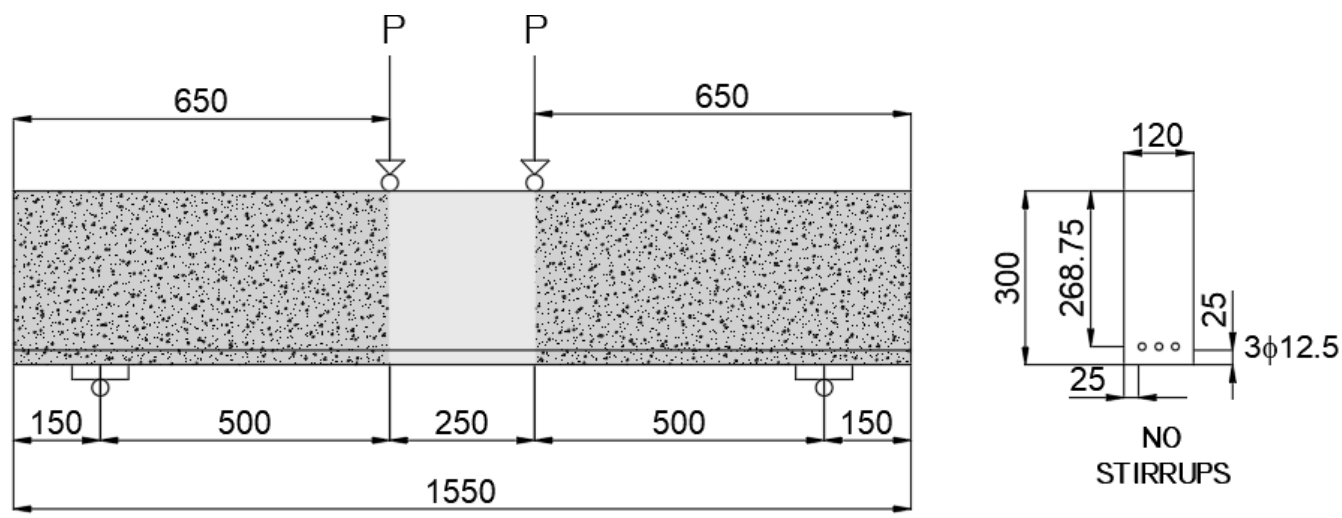

(a)
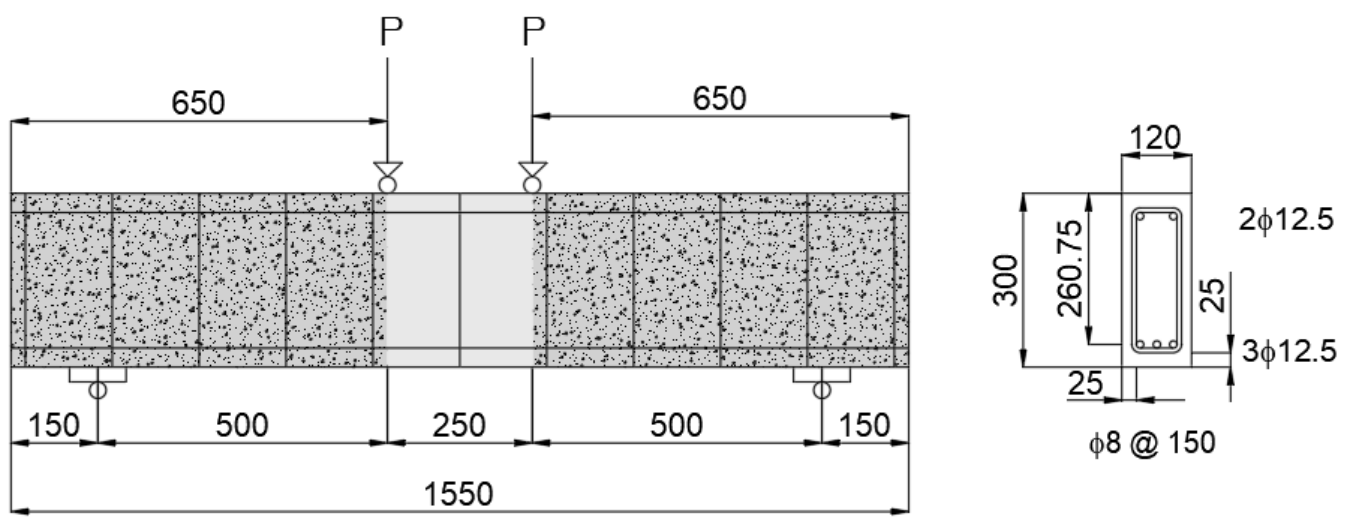

(b)

Figure 3.17 - Scheme for beam specimens (BRA): (a) beams without stirrups; (b) beams with stirrups. Dimensions in millimeters.

The beams were fabricated using plywood formworks and their internal surface was covered with biodegradable demoulding oil in the same way used in the molding process for dowel action specimens. The concrete of the beam was produced in a mixer with capacity of $400 \mathrm{~L}$. The reinforcing cages were positioned inside the formwork and the concrete was poured. A rubber mallet was applied to consolidate the concrete and two hooks were attached to the top edges of the beam for handling. In all specimens, the lateral and bottom covering were $2.5 \mathrm{~cm}$. Figure 3.18 shows the molding process for beam specimens.

As well as in the push-off tests, the DIC technique was adopted to obtain the crack kinematics. Thus, prior to testing, the beam surface was prepared with white paint before application of a random speckle pattern with a black spray and a diffuse 
light was used to mitigate glare/reflections. Images were recorded every minute during the test using two cameras with resolution greater than 3.0 megapixels. The specimens were loaded in displacement control at a rate of $0.3 \mathrm{~mm} / \mathrm{min}$ up to failure, using an MTS 244.41 actuator with $500 \mathrm{kN}$ capacity. Displacements and load data were gathered automatically at a frequency of $2 \mathrm{~Hz}$ with an HBM QuantumX MX440B acquisition system. Figure 3.19 shows an overview of test setup.

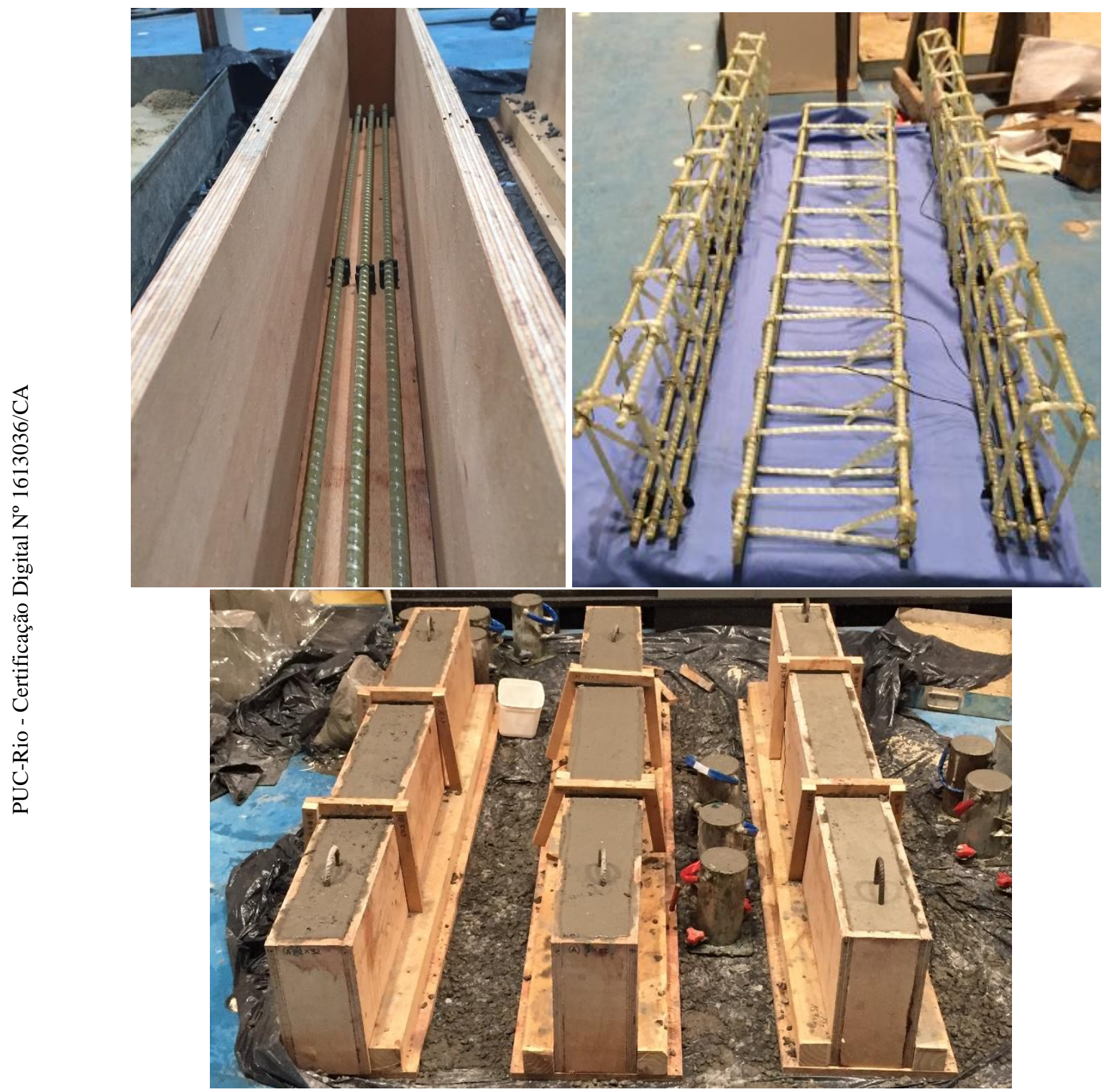

Figure 3.18 - Molding process for beam specimens (BRA). 


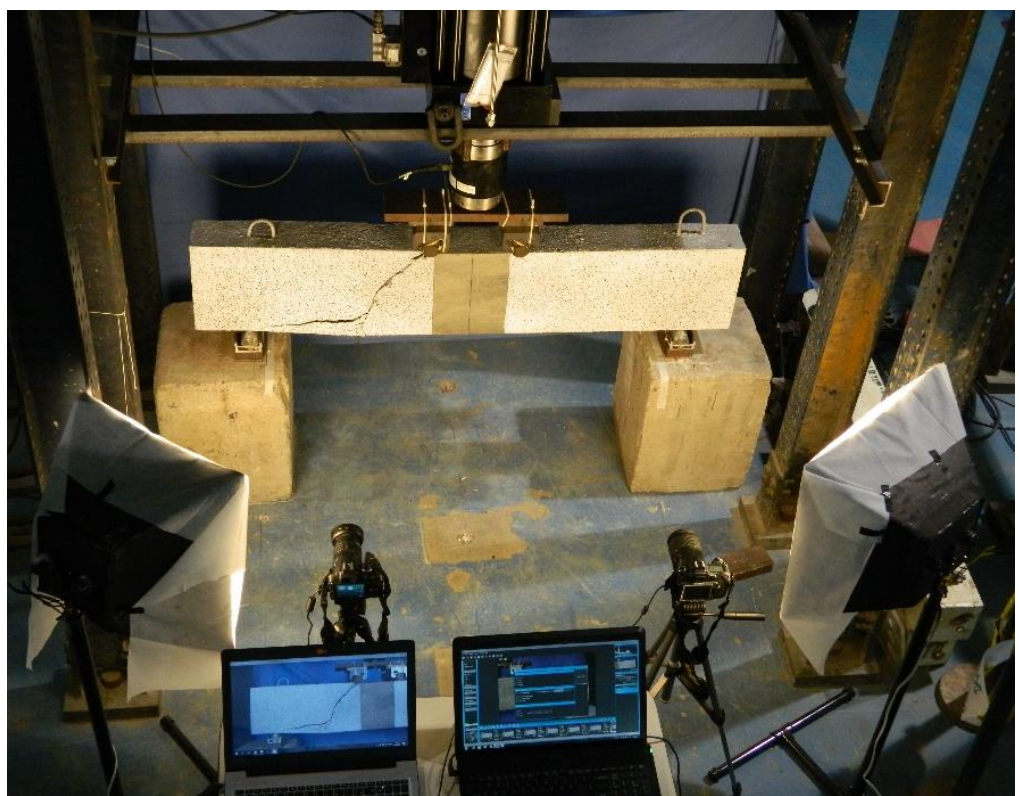

Figure 3.19 - Setup of the beam tests (BRA).

\subsubsection{Canadian campaign}

The tests for the Canadian campaign were supposed to be the same for the Brazilian campaign, but with a different type of surface treatment for the GFRP bars. However, some adjustments were necessary to adapt the tests to the material characteristics and load application system of the Canadian laboratory, which will be discussed at section 5.1.

As well as in the Brazilian campaign, six beams were tested. All beams were longitudinally reinforced with two bars of $12.5 \mathrm{~mm}$ at the bottom side. For three beams, transverse reinforcement using $10 \mathrm{~mm}$ diameter stirrups every $150 \mathrm{~mm}$ was adopted along with two longitudinal bars of $12.5 \mathrm{~mm}$ at the top, for cage assembly purposes. A scheme of the configuration is shown in Figure 3.20.

The procedure of fabrication of the beam specimens was similar to the Brazilian campaign. A needle immersion vibrator was applied to consolidate the concrete. Two hooks were attached to the top edges of the beam for handling. In all specimens, the lateral and bottom covering were $2.5 \mathrm{~cm}$. Figure 3.21 shows the molding process for beam specimens. 

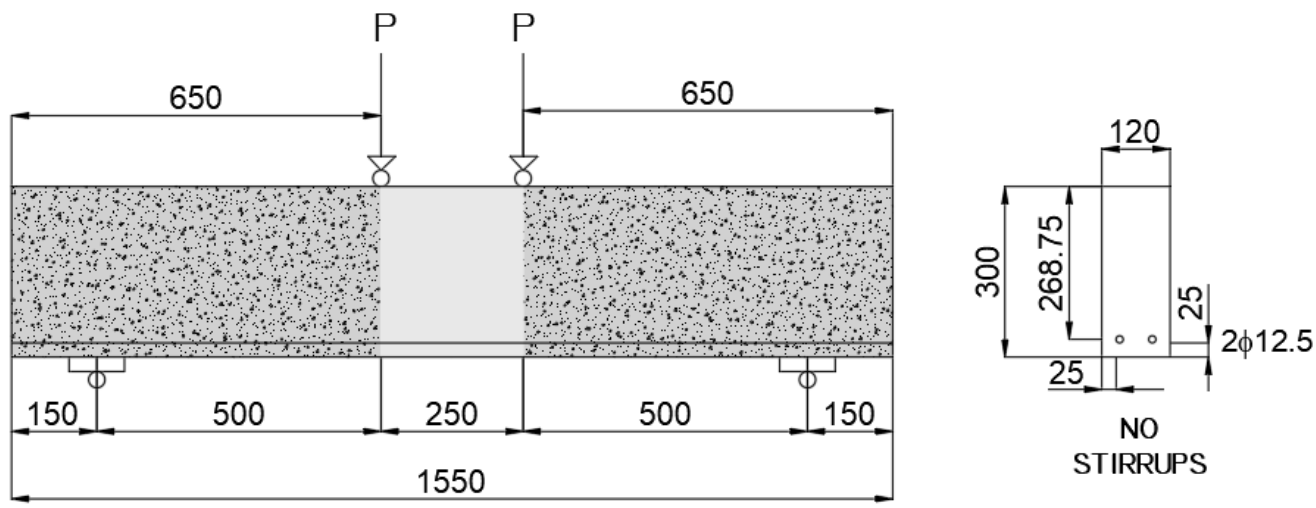

(a)
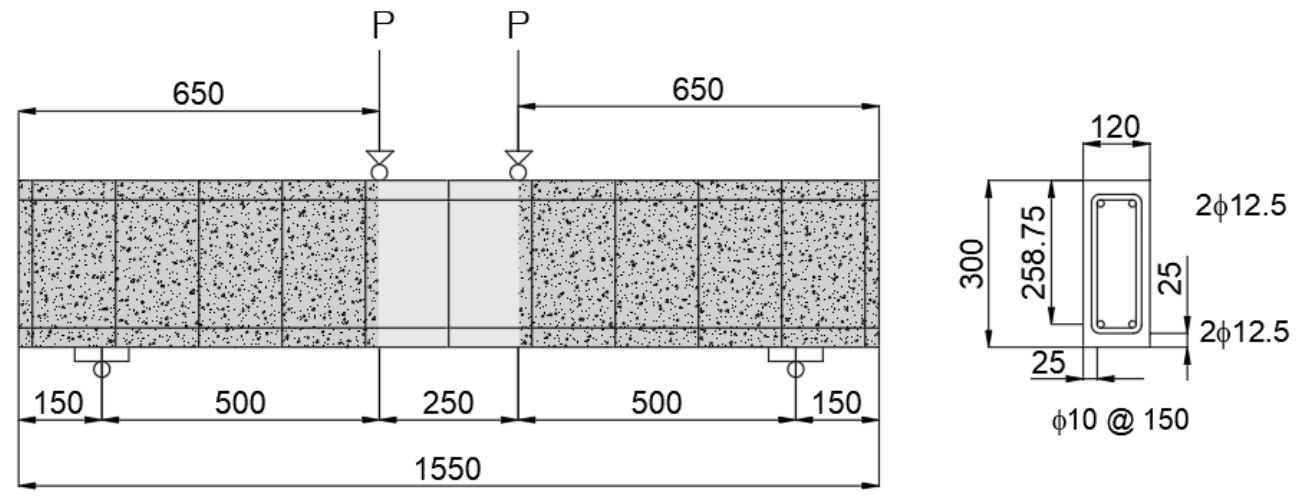

(b)

Figure 3.20 - Scheme of beam specimens (CAN): (a) beams without stirrups; (b) beams with stirrups. Dimensions in millimeters.

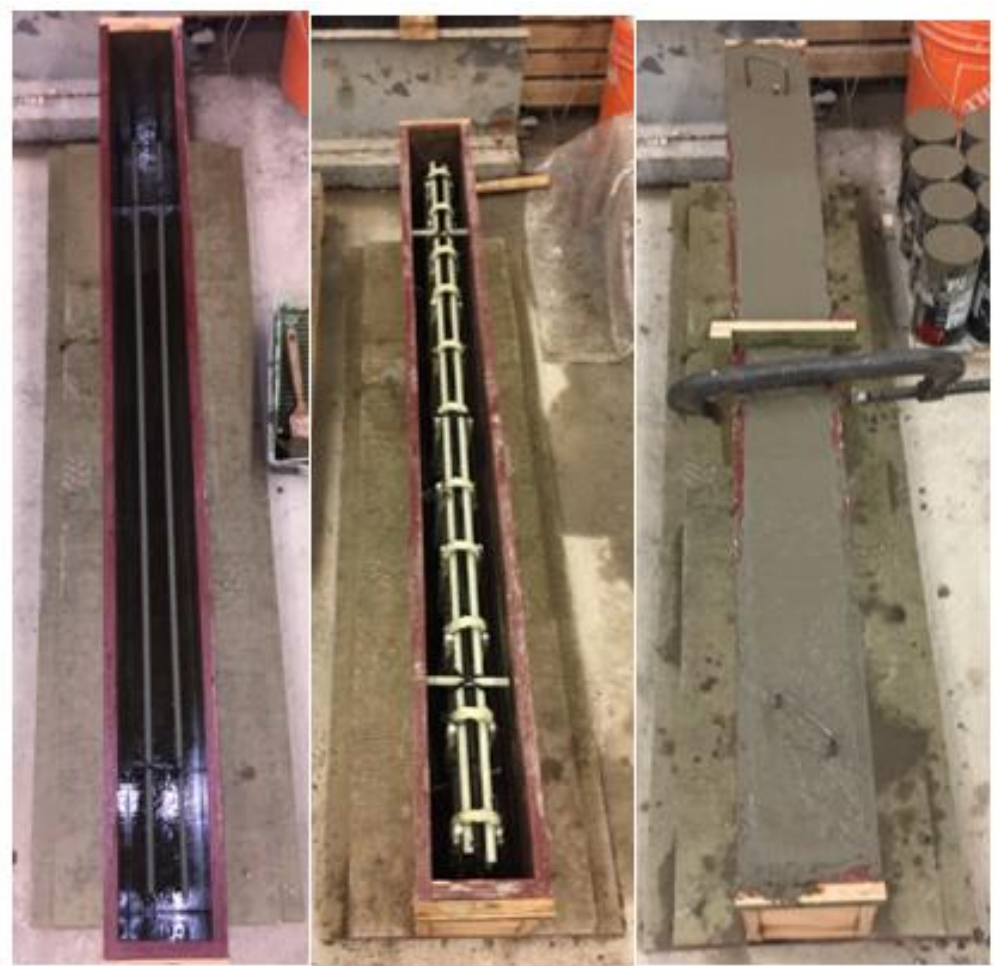

Figure 3.21 - Molding process for beam specimens (CAN). 
To measure the midspan displacements it was used a wire transducer (Compact String Pot Celesco Model SP2-12), as shown in Figure 3.22. It is a compact device that utilizes a flexible cable, a spring-loaded spool and a potentiometer to detect and measure linear position. In the Canadian campaign was also adopted the DIC technique to obtain the crack kinematics and the same procedure to prepare the surface was followed. To apply the load on the beam it was used a hydraulic hand pump (Enerpac Model P462), with 70 MPa maximum operating pressure, as shown in Figure 3.23. An overview of the test setup is shown in Figure 3.24.

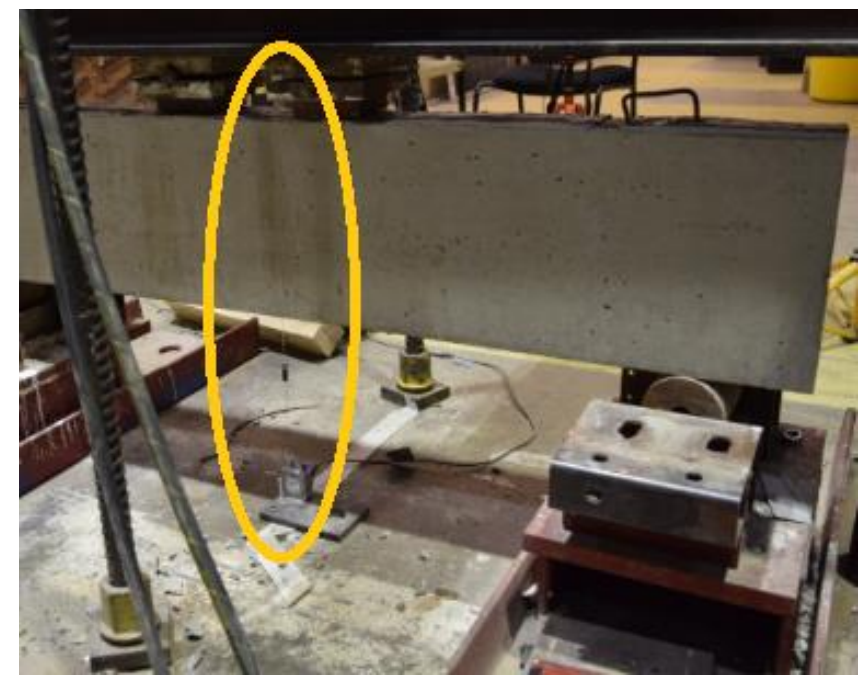

(a)

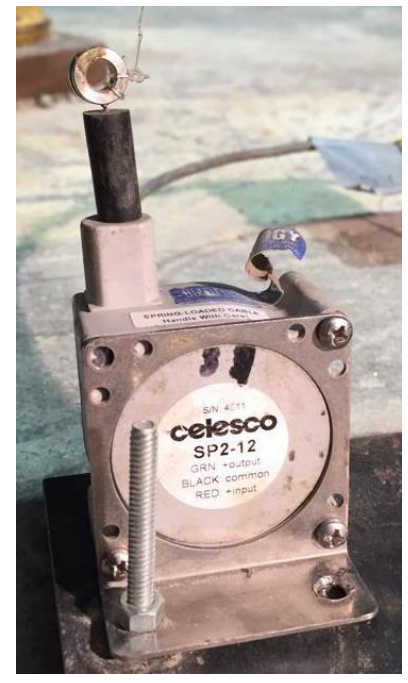

(b)

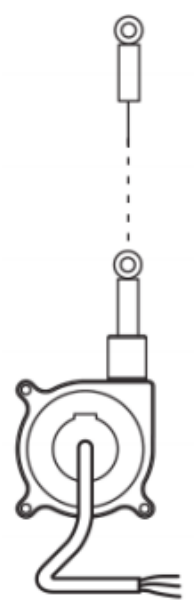

(c)

Figure 3.22 - Wire transducer: (a) position of the transducer; (b) closest view of the transducer; (c) detail of the spring-loaded spool (Source: https://intertechnology.com/Celesco/pdfs/SP2.pdf). 


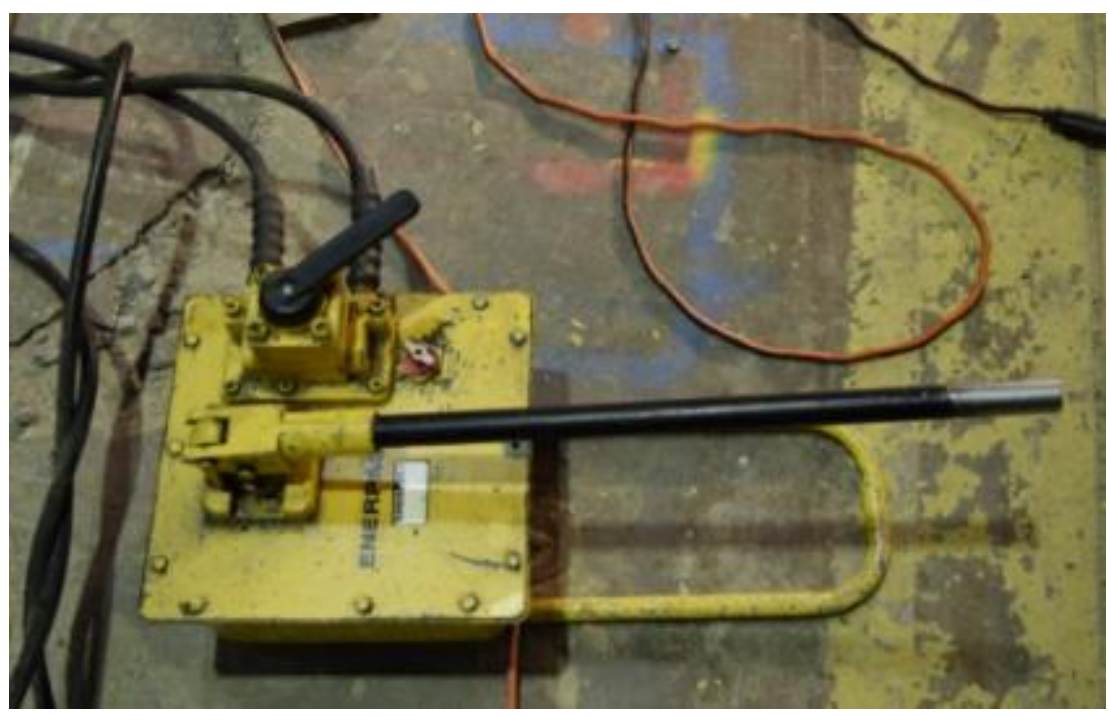

Figure 3.23 - Hydraulic hand pump used to apply load

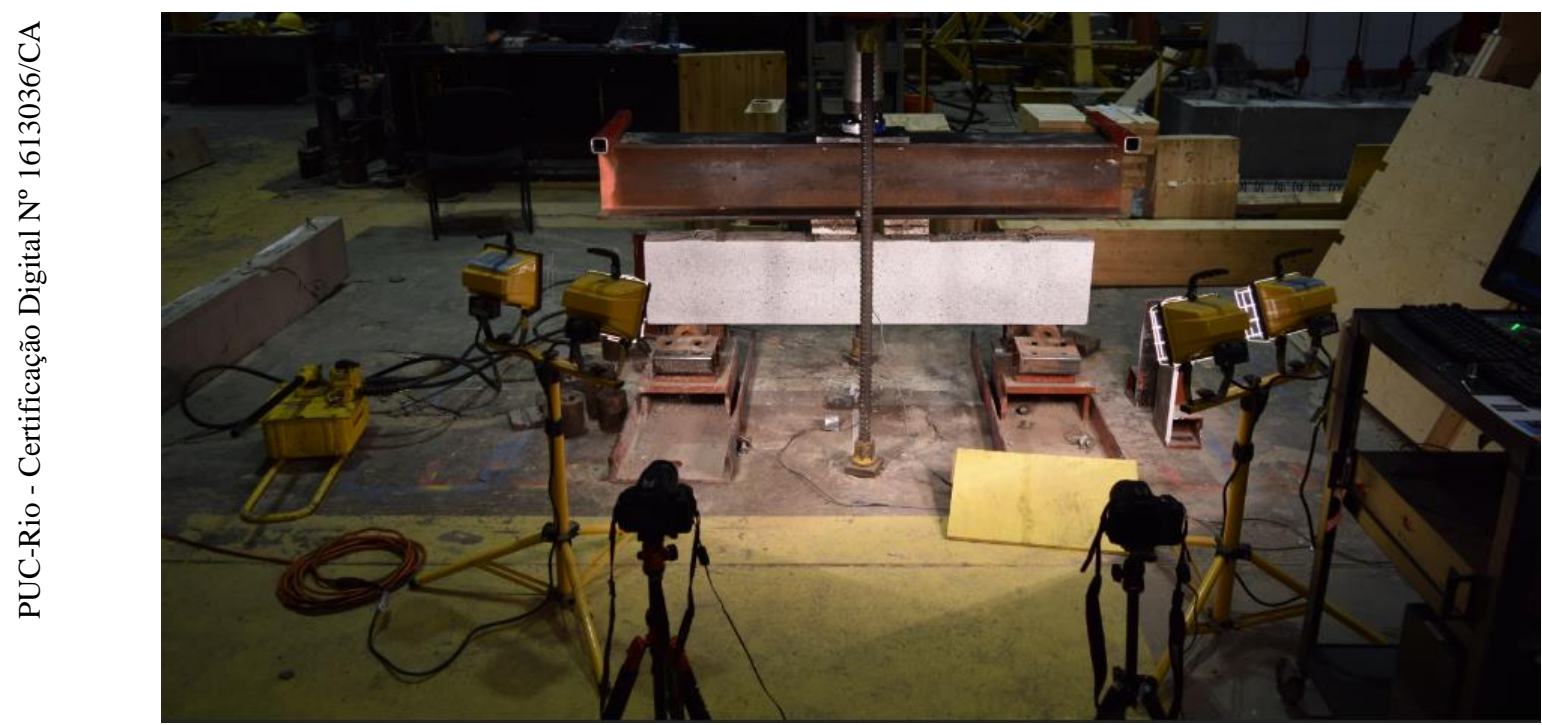

Figure 3.24 - Setup of the beam tests (CAN). 


\section{Results and Discussion}

In this Chapter, the results from all the experimental tests are reported and discussed. From the analysis of the dowel action it is possible to predict the contribution of this shear transfer mechanism to the shear strength of the beams, through the crack patterns and the kinematics of the critical shear crack, recorded by the DIC system. An exploratory analysis of the differences between beam tests performed in Brazil and in Canada is also made.

\subsection{Material Characterization}

\subsubsection{Tensile Tests of GFRP Bars}

The ultimate tensile strength of GFRP bar $f_{t, g f r p}$ was calculated by dividing the maximum load attained during the test by the cross-sectional area of the bar and the tensile modulus of elasticity of GFRP bar $E_{g f r p}$ was obtained from the slope of the stress-strain curve. Stress-strain curves of the GFRP bars for the Brazilian campaign are presented in Figure 4.1-a and the results are given in Table 4.1, along with the ultimate tensile strain of the GFRP bar $\varepsilon_{g f r p}$ These results were obtained by Sá (2018). 


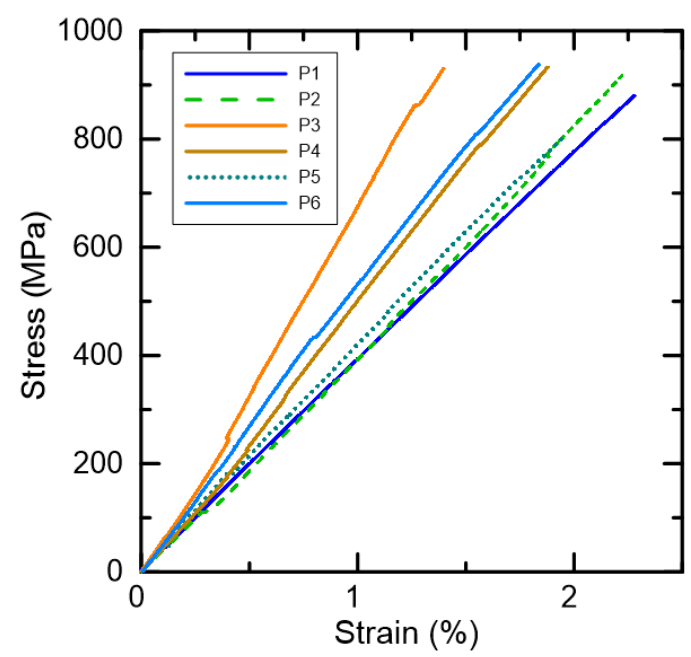

(a)

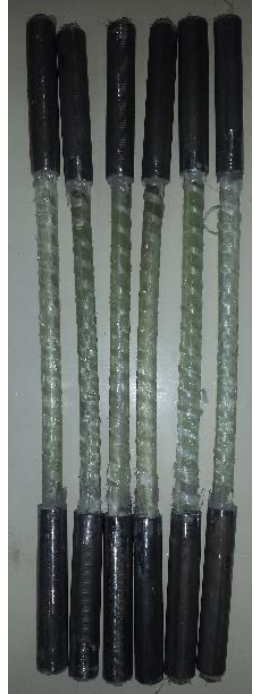

(b)

Figure 4.1 - Tensile test results for GFRP bars (BRA): (a) Experimental stress-strain curves for each specimen; (b) failure modes of tested bars (Adapted from Sá, 2018).

Table 4.1 - Tensile test results in GFRP bars (Adapted from Sá, 2018).

\begin{tabular}{cccc}
\hline & $\boldsymbol{f}_{\boldsymbol{t}, \boldsymbol{g} f \boldsymbol{p}}(\mathbf{M P a})$ & $\boldsymbol{\varepsilon}_{g f r p}(\mathbf{m m} / \mathbf{m m})$ & $\boldsymbol{E}_{\boldsymbol{g f r} \boldsymbol{p}}(\mathbf{G P a})$ \\
\hline P1 & 879.4 & $2.3 \%$ & 40.7 \\
P2 & 916.9 & $2.3 \%$ & 39.0 \\
P3 & 930.5 & $1.4 \%$ & 57.5 \\
P4 & 801.6 & $1.9 \%$ & 47.5 \\
P5 & 932.6 & $1.9 \%$ & 43.6 \\
P6 & 936.1 & $1.8 \%$ & 49.1 \\
\hline Average & 899.5 & $1.9 \%$ & 46.2 \\
Std deviation $^{(1)}$ & 47.8 & $0.3 \%$ & 6.1 \\
(1) $_{\text {Standard deviation }}$ & & &
\end{tabular}

As can be observed, all stress-strain curves collected from the tested bars confirm the linear-elastic behavior of the GFRP bars. An average tensile modulus and strength respectively of $46.2 \pm 6,1 \mathrm{GPa}$ and 899,5 \pm 47,7 MPa were obtained. According to Sá (2018), the unexpected variation in the results observed for specimens P3, P4, and P6 is probably associated with the use of different volumetric fractions in the bars, which explains the higher tensile modulus for these specimens. However, the average tensile modulus and strength obtained from the tested bars are close to those provided by the manufacturer in Table 3.2. The failure mode observed in the tested specimens is shown in Figure 4.1-b. As reported by Sá (2018), the rupture of the GFRP bars occurred in the central region of the free length between the anchors, except for the last bar (from left to right in Figure 4.1-b). It 
was characterized by the appearance of cracks parallel to the axis of the bar, and in some cases, by the rupture of the helical filaments at the surface of the bar. Therefore, it is reasonable to say that the proposed solution (anchors) adopted to prevent grip-induced damage to the ends of the bar for the tensile tests of GFRP bars was successful.

For the Canadian GFRP bars, as previously stated, the tensile tests were performed by Pultrall and the results of those are given in Table 3.2. The tested bars were from the same sample as those which were used in the beam tests carried out at University of Ottawa.

\subsubsection{Compression and Splitting Concrete Tests}

The ultimate compressive strength of concrete $f_{c}^{\prime}$ was determined for each type of test and it ranged from 30 to $40 \mathrm{MPa}$. The splitting tensile strength $f_{t, s p}$ was determined for the cylinders from the beam test specimens and it was between 2.0 and 3.0 MPa. A summary of these results is given in Table 4.2.

Splitted cylinders from both campaigns were selected to examine the aggregate distribution inside the hardened concrete as a qualitative assessment of aggregate segregation. As shown in Figure 4.2, coarse aggregates were uniformly distributed throughout the depth of the cylinder indicating good stability of the concrete mix.

The compressive modulus of elasticity of concrete $E_{c}$ was determined by compression tests according to ABNT NBR 8522. $E_{c}$ was obtained as the slope of the linear portion of the stress-strain curve and it was determined for three cylinders from the beam test specimens of the Brazilian campaign. Stress-strain curves are presented in Figure 4.3 and the results for these curves are given in Table 4.3, along with the strain of concrete at compressive stress peak $\varepsilon_{c 2}$. 
Table 4.2 - Summary of the results for each type of test.

\begin{tabular}{lcc}
\hline Specimen & $\boldsymbol{f}^{\prime} \mathbf{c}(\mathbf{M P a})$ & $\boldsymbol{f}_{\mathbf{t}, \mathbf{s p}}(\mathbf{M P a})$ \\
\hline Dowel 2L & $44.2 \pm 0.9$ & - \\
Dowel 3L & & - \\
\hline $\begin{array}{l}\text { Push-off 12.5-P1 } \\
\text { Push-off 12.5-P2 }\end{array}$ & $36.3 \pm 2.0$ & - \\
Push-off 25-P3 & $33.8 \pm 3.2$ & - \\
Push-off 25-P4 & & - \\
\hline Beam 3L-NS A & & \\
Beam 3L-NS B & $37.8 \pm 0.2$ & $2.66 \pm 0.59$ \\
Beam 3L-NS C & & \\
Beam 3L-S D & & \\
Beam 3L-S E & $32.3 \pm 0.8$ & $2.57 \pm 0.06$ \\
Beam 3L-S F & & \\
\hline Beam 2L-NS A & & \\
Beam 2L-NS B & $33.1 \pm 2.2$ & $3.12 \pm 0.09$ \\
Beam 2L-NS C & & \\
Beam 2L-S D & & \\
Beam 2L-S E & $29.3 \pm 3.3$ & $2.42 \pm 0.28$ \\
Beam 2L-S F & & \\
\hline
\end{tabular}

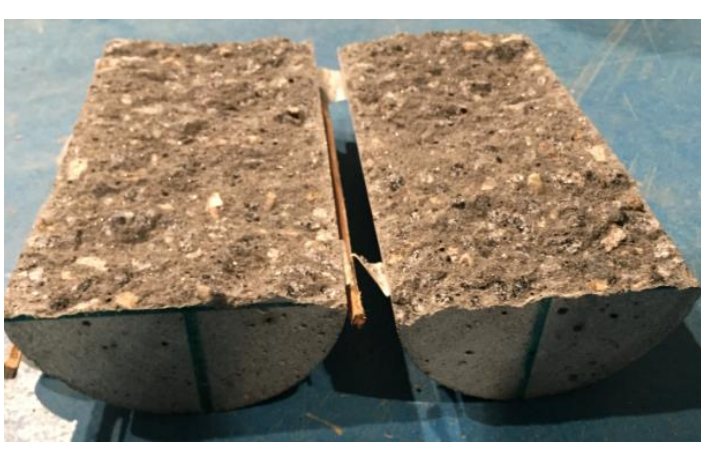

(a)

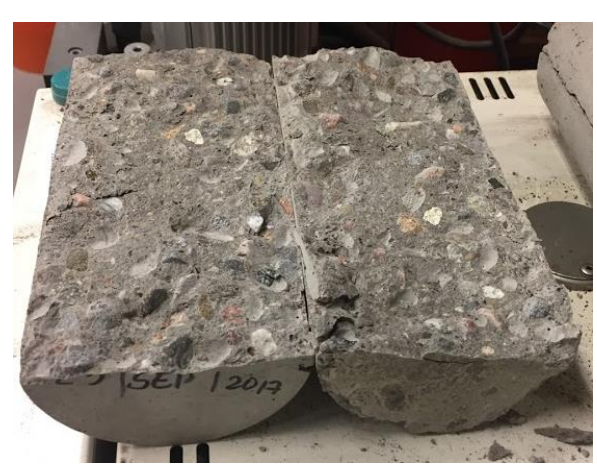

(b)

Figure 4.2 - Segregation analysis of hardened concrete: (a) Brazilian campaign; (b) Canadian campaign. 


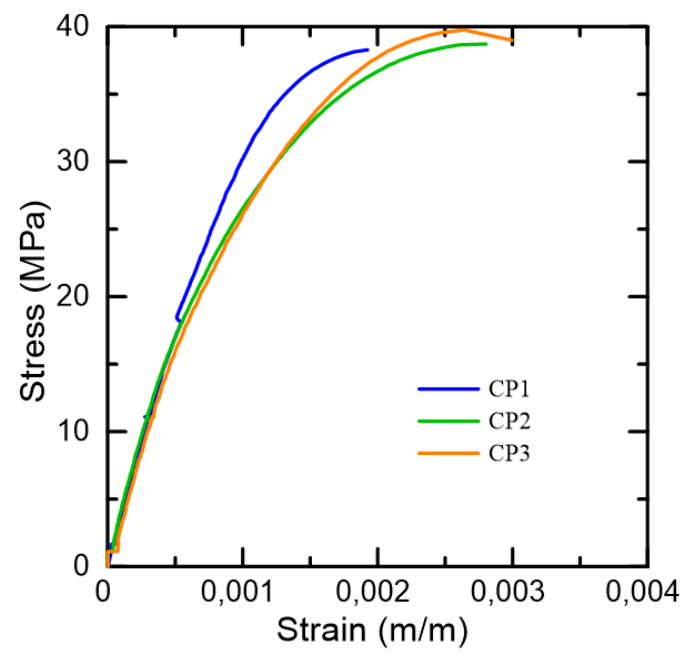

Figure 4.3 - Stress-strain curves.

Table 4.3 - Ultimate compressive strength fc, compressive modulus Ec and strain of concrete at compressive stress peak $\varepsilon c 2$ of the specimens.

\begin{tabular}{cccc}
\hline Specimen & $\mathbf{f}^{\prime} \mathbf{c}(\mathbf{M P a})$ & $\mathbf{E} \mathbf{c}(\mathbf{G P a})$ & $\mathbf{\mathbf { E } _ { \mathbf { c } 2 }} \mathbf{( \% \mathbf { o } )}$ \\
\hline CP1 & 38.2 & 37.3 & 1.93 \\
CP2 & 38.7 & 37.5 & 2.80 \\
CP3 & 39.8 & 36.3 & 2.64 \\
\hline Average & 38.9 & 37.0 & 2.46 \\
Std deviation $^{(1)}$ & 0.80 & 0.59 & 0.47 \\
${ }^{(1)}$ Standard deviation & & &
\end{tabular}

\subsection{Dowel Action Tests}

The relationship between the shear force relative to dowel action $V_{d}$ and relative displacement $\delta_{\mathrm{d}}$ are presented in Figure 4.4, by means of load-displacement curves. The results of dowel action tests are given in Table 4.4, along with the

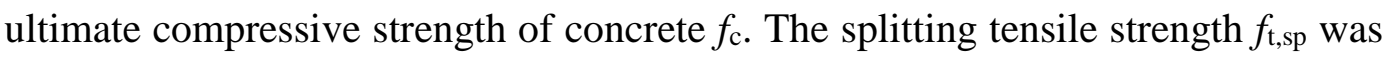
not determined because it was not possible to produce enough cylinder specimens for this test. The maximum shear forces of 10.6 and $10.3 \mathrm{kN}$ were obtained for members reinforced with two and three bars, respectively. While the use of more bars is associated to a reduction in the concrete effective area subject to tension, the bending stiffness increases, mobilizing a longer length subject to tensile stresses. Although only one test of each was performed, it seems reasonable to say that, in the cases studied, these two effects canceled and the peak loads are similar. On the 
other hand, the relative displacement corresponding to peak load is lower for the specimen with three bars, which is related to greater stiffness.

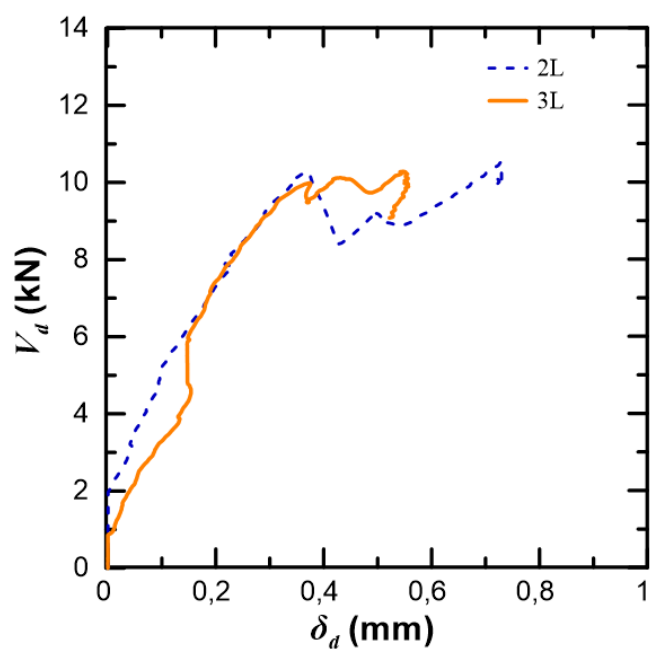

Figure 4.4 - Experimental load-displacement curves for each dowel action specimen.

Table 4.4 - Summary of dowel action test results.

\begin{tabular}{lcccc}
\hline Specimen & $\boldsymbol{f}_{\mathbf{c}}^{\prime}(\mathbf{M P a})$ & $\boldsymbol{f}_{\mathbf{t}, \mathbf{s p}}(\mathbf{M P a})$ & $\boldsymbol{V}_{\mathbf{d}, \max }(\mathbf{k N})$ & $\boldsymbol{\delta}_{\mathbf{d}}(\mathbf{m m})$ \\
\hline Dowel 2L & \multirow{2}{*}{$44.2 \pm 0.9$} & - & 10.6 & 0.38 \\
Dowel 3L & & - & 10.3 & 0.25 \\
\hline
\end{tabular}

The failure modes noticed on the dowel action specimens is shown in Figure 4.5. As can be observed, the failure is governed by splitting of the concrete, with splitting cracks being opened at the bottom portion of the beam. This behavior can be associated with small concrete cover, where the tensile strength of the concrete is decisive for the failure. According to Vintzeleou \& Tassios (1986), when the concrete cover is greater than 6 to 7 times the bar diameter, failure is produced by crushing of concrete and yielding of the bar. It was also observed that after the bottom portion of the beam started detaching, a growth in displacement could be noticed under an approximately constant load.

It should be noted that no research has been found on the contribution of dowel action in shear transfer in concrete members reinforced with GFRP bars in the references consulted. 

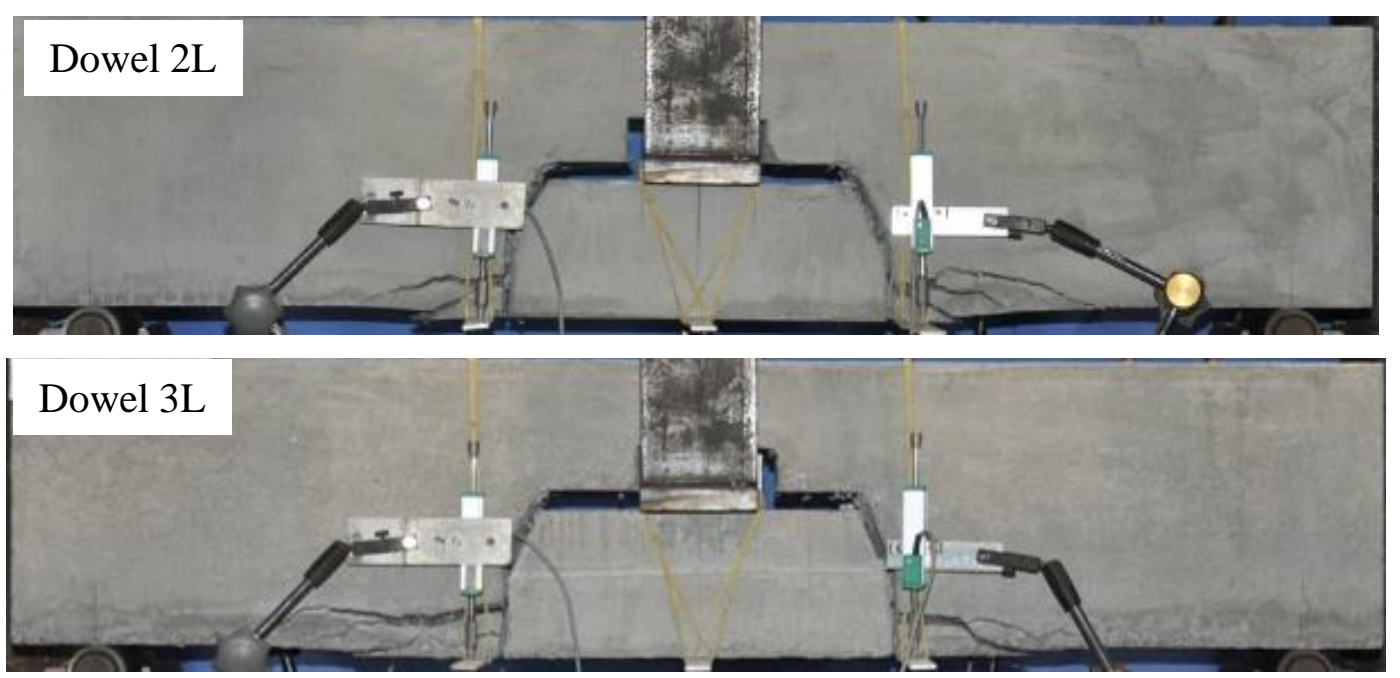

Figure 4.5 - Failure modes of dowel action tested specimens.

\subsection{Push-off Tests}

All specimens had abrupt rupture in the shear plane and no crack formation was observed before the crack. After the peak load is achieved, the load abruptly reduces, formation and crack opening/sliding were observed as well as an increasing in the normal stress, which was immediately adjusted so that normal stress was kept constant throughout the test. A summary of the results of push-off tests are presented in Table 4.5. The splitting tensile strength $f_{\mathrm{t}, \mathrm{sp}}$ was not determined because it was not possible to produce enough cylinder specimens for this test. Curves shear stress $v s$ crack sliding $\left(\tau_{a g} \mathrm{X} s\right)$, shear stress $v s$ crack width $\left(\tau_{a g} \mathrm{X} w\right)$, and crack sliding $v s$ crack width $(s \times w)$ for all tests are presented in Figure 4.6.

The maximum shear force $\left(V_{a g, \max }\right)$ for the specimens with maximum size of the coarse aggregate $12.5 \mathrm{~mm}$ (P1 and P2) were close to each other, unlike specimens with maximum size of the coarse aggregate $25 \mathrm{~mm}$ (P3 e P4), which showed great dispersion for $V_{a g, \max }$. This variation for $\mathrm{P} 3$ and $\mathrm{P} 4$ may be related to the aspect of the shear surface after the rupture, where P4 showed a lower amount of coarse aggregate in the shear plane compared to P3, which can be seen in the pictures of the crack surfaces shown in Appendix 8. Due to the dispersion of the tests and the number of specimens tested, it was not possible to identify the influence of the maximum size of the coarse aggregate to the aggregate interlock. 
Table 4.5 - Summary of push-off tests results.

\begin{tabular}{lccllc}
\hline Specimen & $\boldsymbol{f}_{\mathbf{c}}{ }^{\prime}(\mathbf{M P a})$ & $\begin{array}{c}\boldsymbol{f}_{\mathbf{t , s}} \\
(\mathbf{M P a})\end{array}$ & $\begin{array}{l}\boldsymbol{V}_{a g, \max } \\
(\mathbf{k N})\end{array}$ & $\begin{array}{l}\boldsymbol{\tau}_{a g, \max } \\
(\mathbf{M P a})\end{array}$ & $\begin{array}{c}\boldsymbol{\sigma}_{\mathbf{a g}} \\
(\mathbf{M P a})\end{array}$ \\
\hline Push-off 12.5-P1 & \multirow{2}{*}{$36.3 \pm 2.0$} & - & 142.4 & 5.48 & 0.31 \\
Push-off 12.5-P2 & & - & 139.4 & 5.36 & 0.31 \\
Push-off 25-P3 & \multirow{2}{*}{$33.8 \pm 3.2$} & - & 150.0 & 5.77 & 0.32 \\
Push-off 25-P4 & & - & 121.4 & 4.67 & 0.31 \\
\hline
\end{tabular}

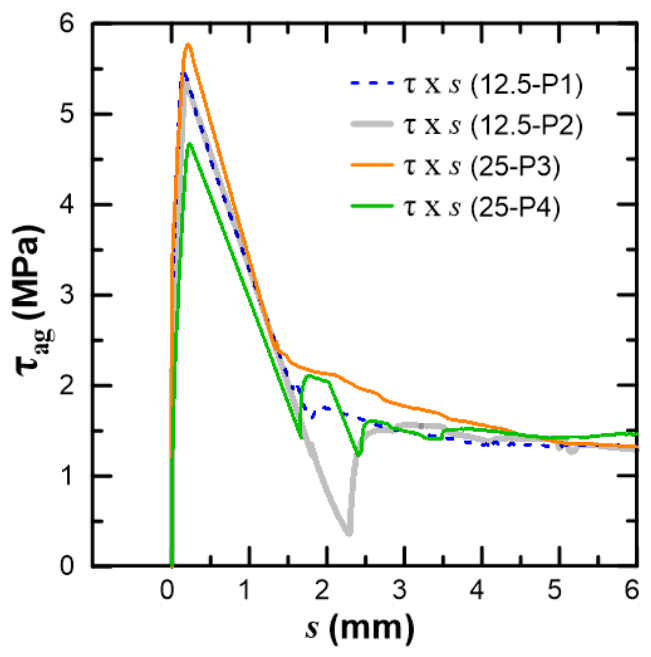

(a)

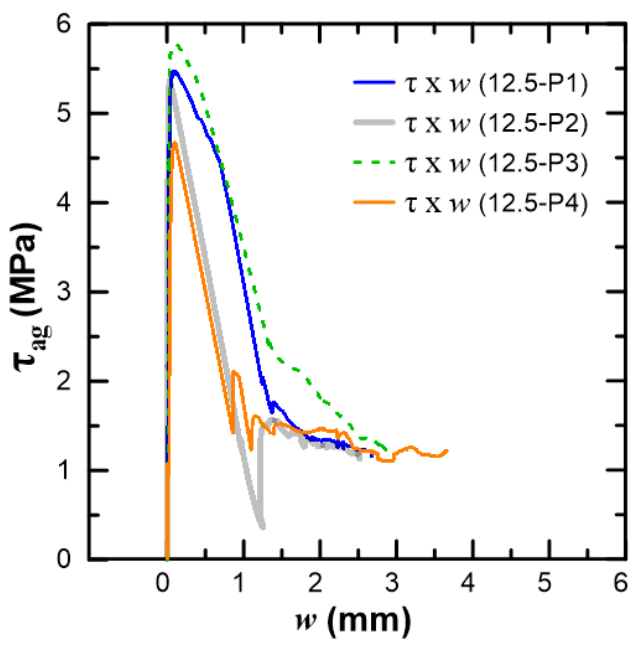

(b)

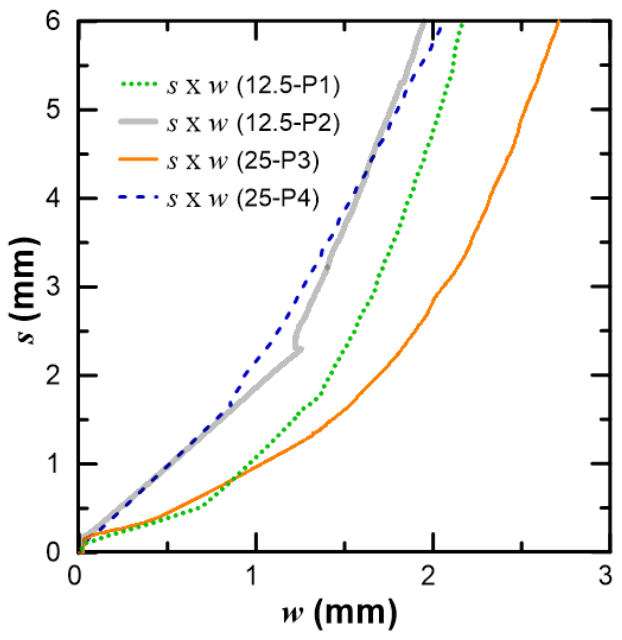

(c)

Figure 4.6 - Shear stress curves: (a) shear stress vs crack sliding; (b) shear stress $v s$ crack width; (c) crack sliding $v s$ crack width. 
According to the graphs $\tau_{a g} \times s$ and $\tau_{a g} \mathrm{X} w$, it is possible to identify that all specimens showed similar behavior, with greater convergence for the curves $\tau_{a g} \mathrm{X}$ s. For small crack widths ( $\mathrm{w}<0.5 \mathrm{~mm}$ ), it was observed that $64 \%$ of $\tau_{a g, \max }$ is still resisted by the aggregate interlock. According to the graph $s \times \mathrm{x}$, it is observed an initial adjustment region and then the ratio s/w shows a linear behavior. Failure modes of each push-off specimen is show in Figure 4.7.

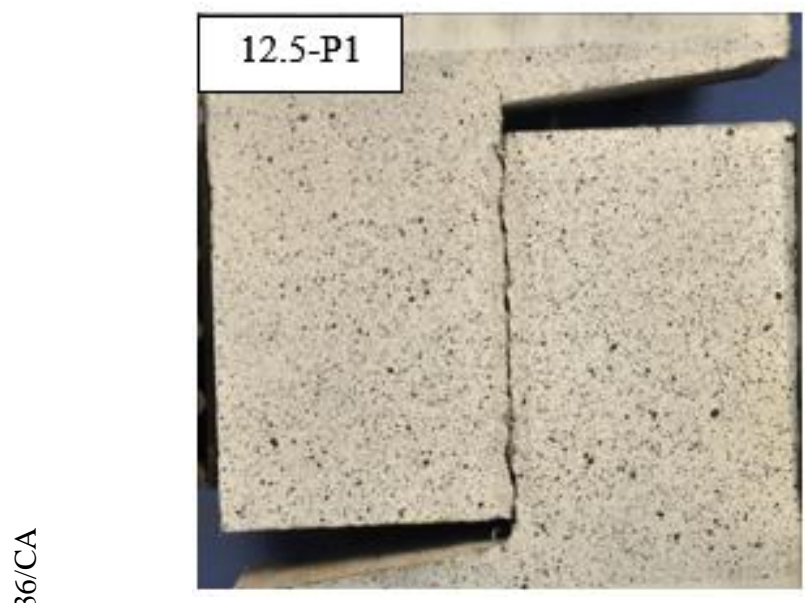

(a)

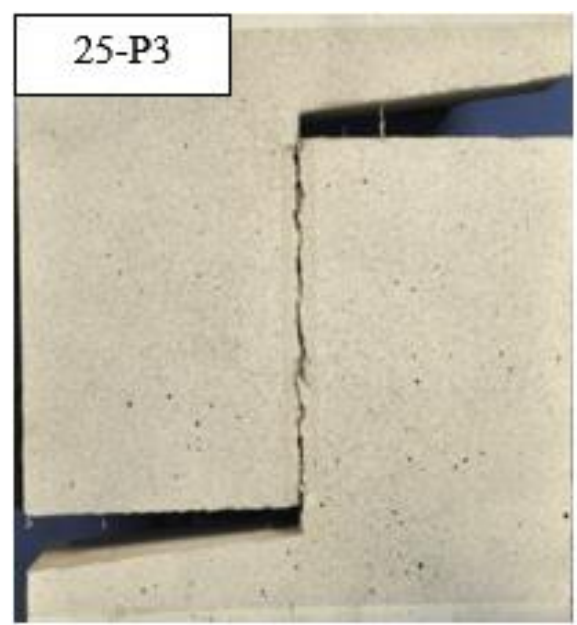

(c)

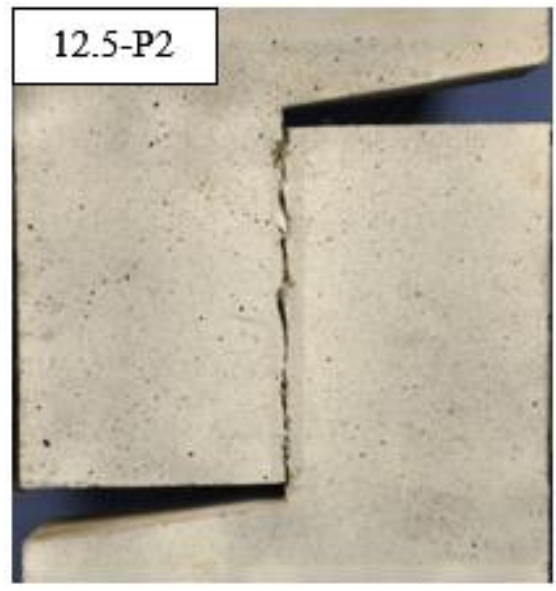

(b)

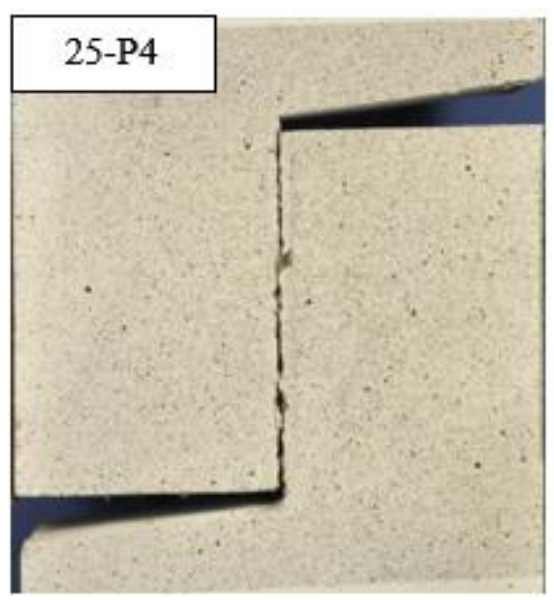

(d)

Figure 4.7 - Failure modes of push-off tested specimens. 
To study the contribution of shear transfer mechanisms, DIC software GOM Correlate (GOM, 2009) was used to capture crack kinematics. From the first photo recorded after the rupture, it was verified that crack opening (LX in Figure 4.8) and sliding (LY in Figure 4.8) along the length of the shear plane were approximately constant, as shown in Figure 4.8 for P3.

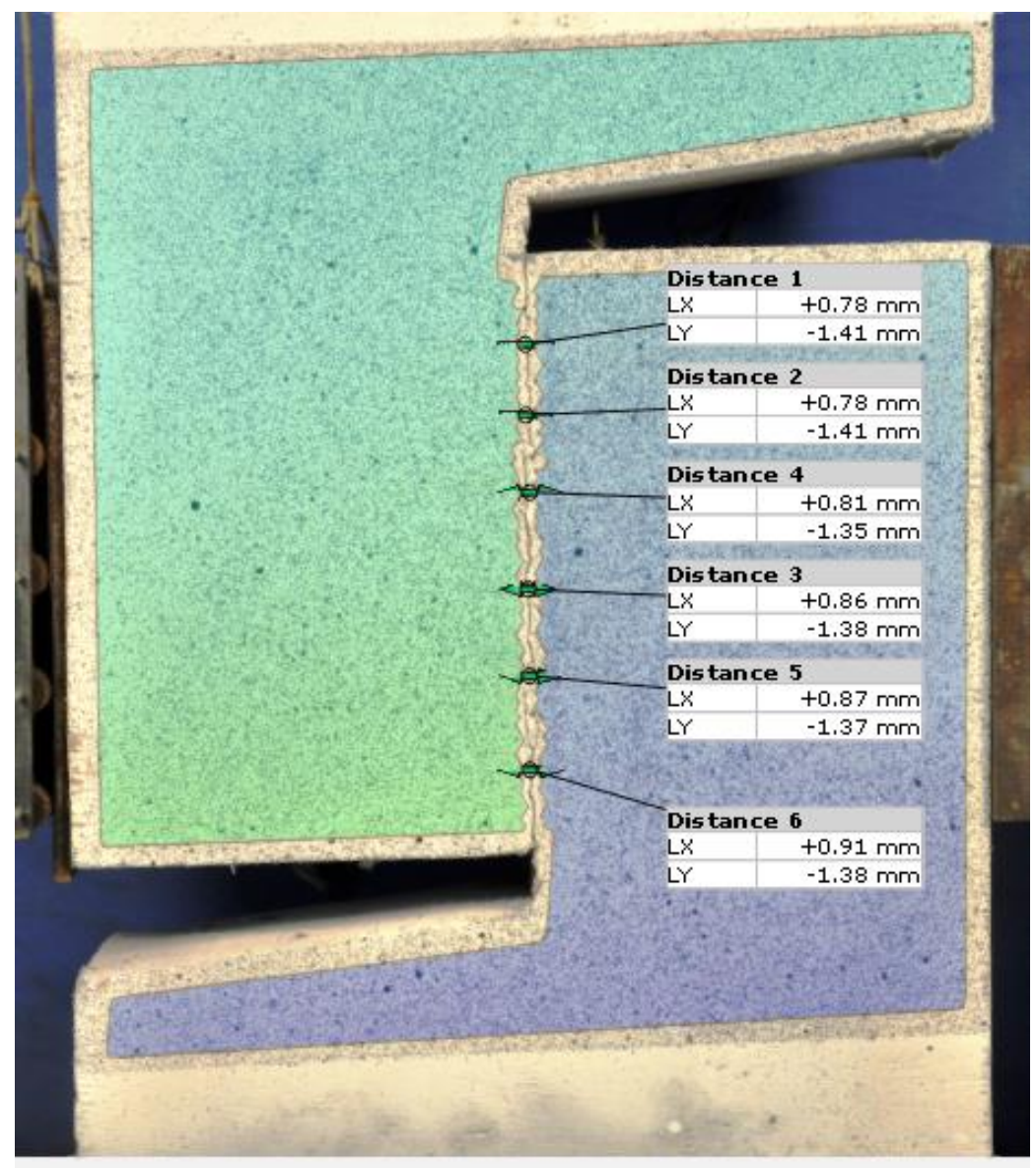

Figure 4.8 - Crack opening and sliding immediately after the rupture obtained from DIC analysis. 


\subsection{Beam Tests}

\subsubsection{Brazilian campaign}

All beam specimens failed in shear and exhibited flexural cracks in the constant moment region prior to cracking in the shear span. Maximum shear forces $V_{\max }$ and corresponding displacements $\delta$ are summarized in Table 4.6 and loaddisplacement curves for all specimens are presented in Figure 4.9.

Table 4.6 - Summary of the beam tests results.

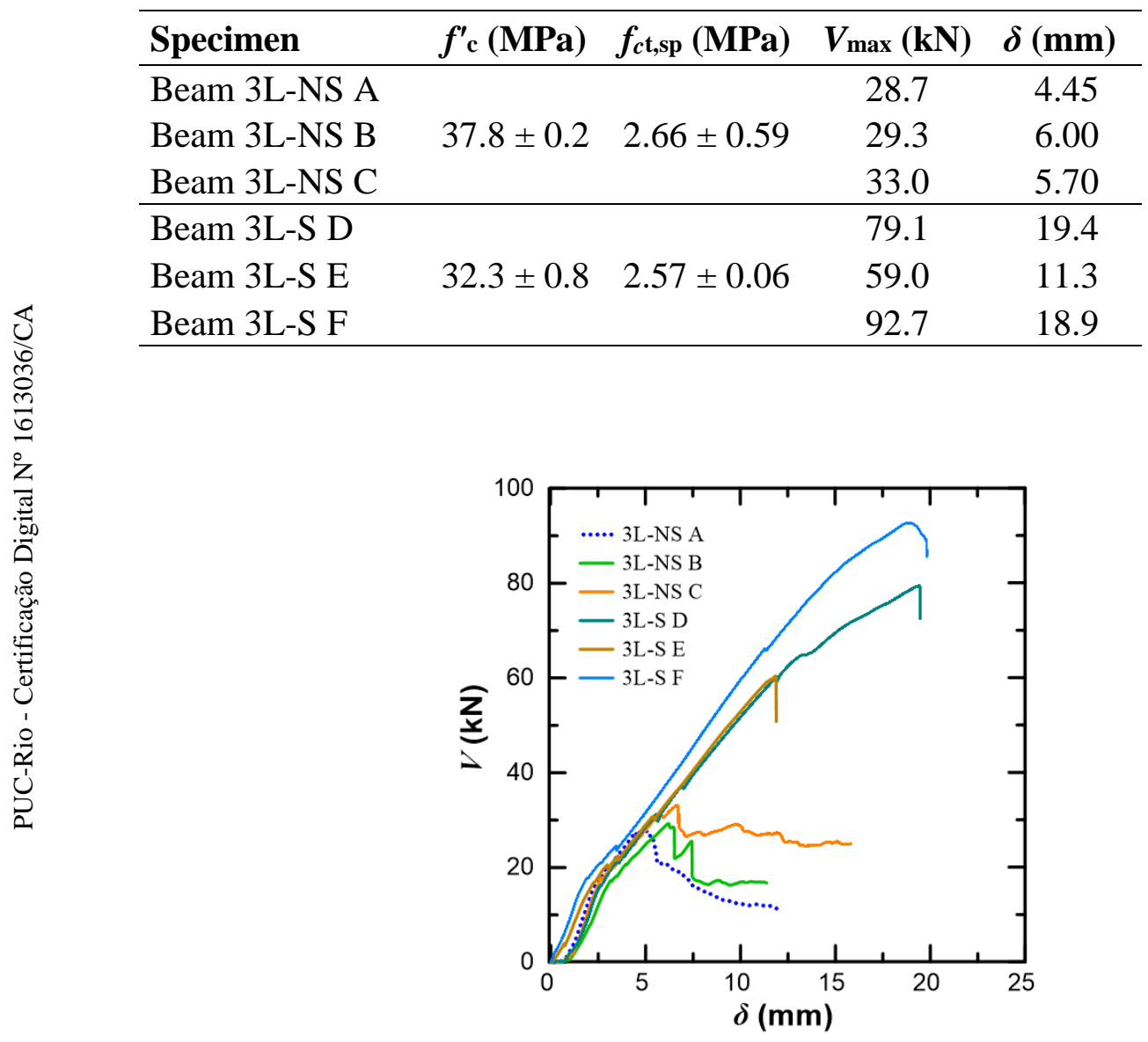

Figure 4.9 - Load-displacement curves of beam tested.

For the beams without stirrups, the peak load coincided with the formation of the critical shear crack. After cracking, the load gradually reduces as deflection increases, resulting from the loss of aggregate interlock as the crack opens. At this stage, dowel action apparently provides a significant contribution to the strength and pronounced longitudinal splitting can be observed. The crack shape exhibited 
a slope with respect to the longitudinal direction ranging from approximately 25 $30^{\circ}$ near the loading point to $50-60^{\circ}$ at the bottom. Figure 4.10 -a shows the crack formation process for beam 3L-NS A, obtained from DIC analysis with the software GOM Correlate.

For beams with stirrups, steeper cracks developed within the spacing between stirrups and shorter or indistinguishable longitudinal splitting at the level of reinforcement was observed. For all specimens, critical shear crack formed at loads around $25-30 \mathrm{kN}$ but, after this, a combination of aggregate interlock and dowel action seemed to contribute to the strength. Figure 4.10-b shows the crack formation process for beam $3 \mathrm{~L}-\mathrm{S}$ E, as an example. It is important to note that stirrups were only intercepted at the top and bottom of the crack. Although a greater dispersion of results could be observed, the shear strength for beams with stirrups was up to three times greater than that for beams without stirrups. This variation is probably because the stirrups presented defects and imperfections in the bent region and the innermost fibers seem to be kinking under different patterns because of the manufacturing process for this specific batch of stirrups.

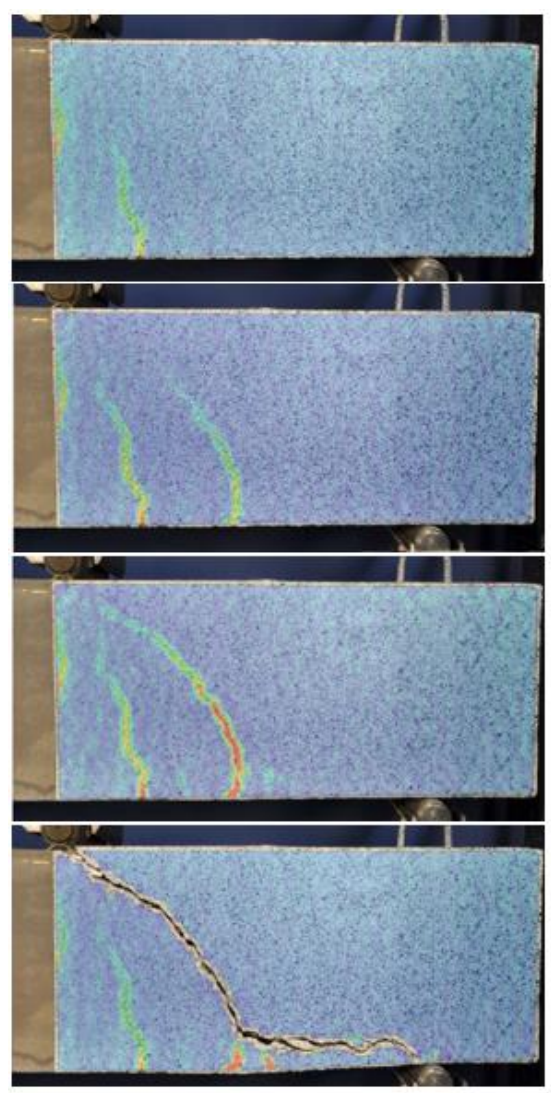

(a)

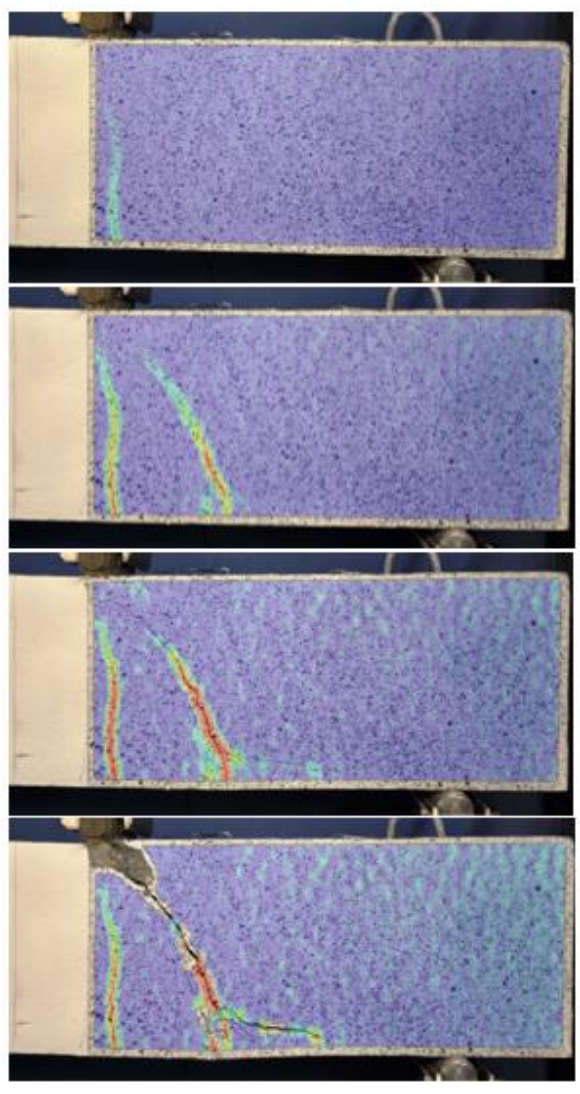

(b)

Figure 4.10 - Crack formation process: (a) Beam 3L-NS A; (b) Beam 3L-S E. 
The shape of the critical shear crack for beams with and without stirrups is shown in Figure 4.11 and photographs taken during the test showing the failure mode for each tested beam is presented in Appendix C. Typical failure modes for beams with and without stirrups is presented in Figure 4.12. All the specimens exhibited a concrete diagonal tension failure, which started with the formation of an inclined crack oriented to the direction of the maximum principal tensile stress. For beams with stirrups, abrupt failure was observed due to rupture of the stirrup at the bent corner, as shown in Figure 4.13.

* For easy viewing, the shape of all the critical shear cracks was represented at the left side. Thus, for 3LNS-A, 3L-S D, and 3L-S E the critical shear crack is a mirrored representation.

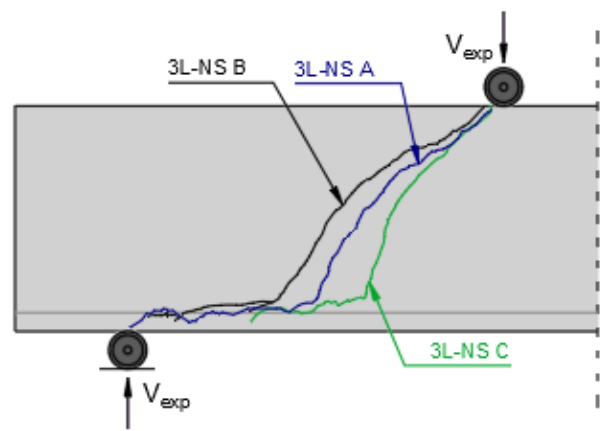

(a)

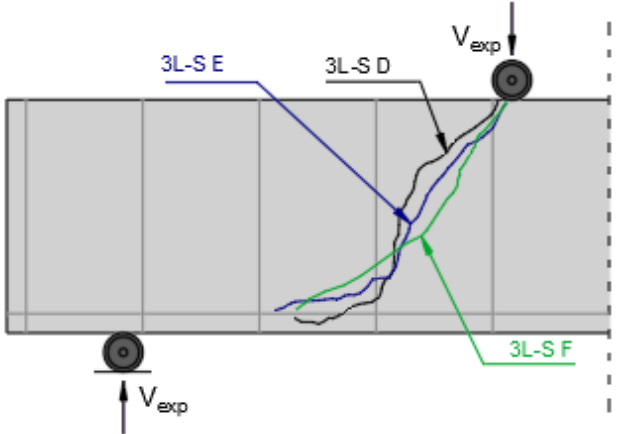

(b)

Figure 4.11 - Crack pattern of the critical shear crack: (a) specimens without stirrups; (b) specimens with stirrups.

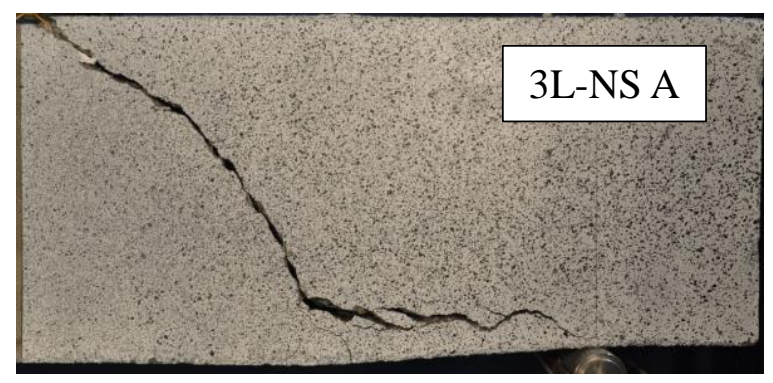

(a)

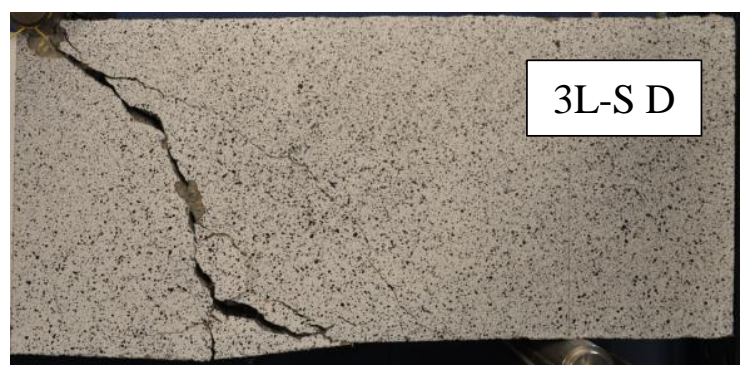

(b)

Figure 4.12- Typical failure modes: (a) beams without stirrups; (b) beams with stirrups. 


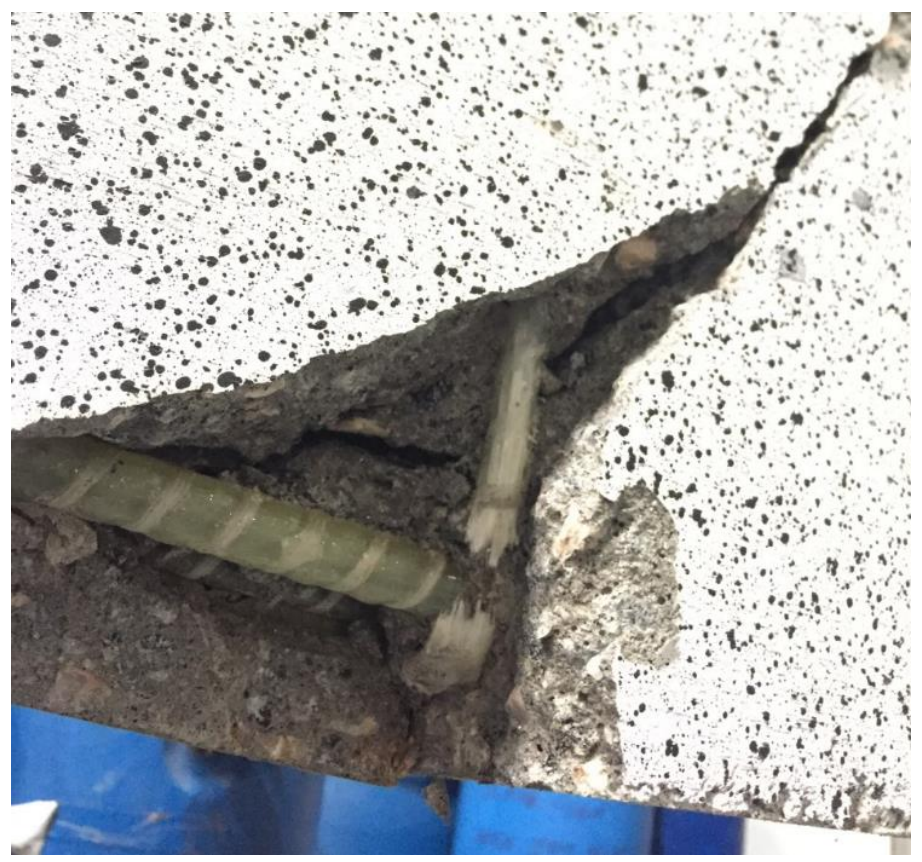

Figure 4.13 - Rupture of stirrup.

To study the contribution of shear transfer mechanisms, DIC software GOM Correlate (GOM, 2009) was used to capture crack kinematics. Figure 4.14 presents crack pattern of beam 3L-NS A obtained from DIC analysis.

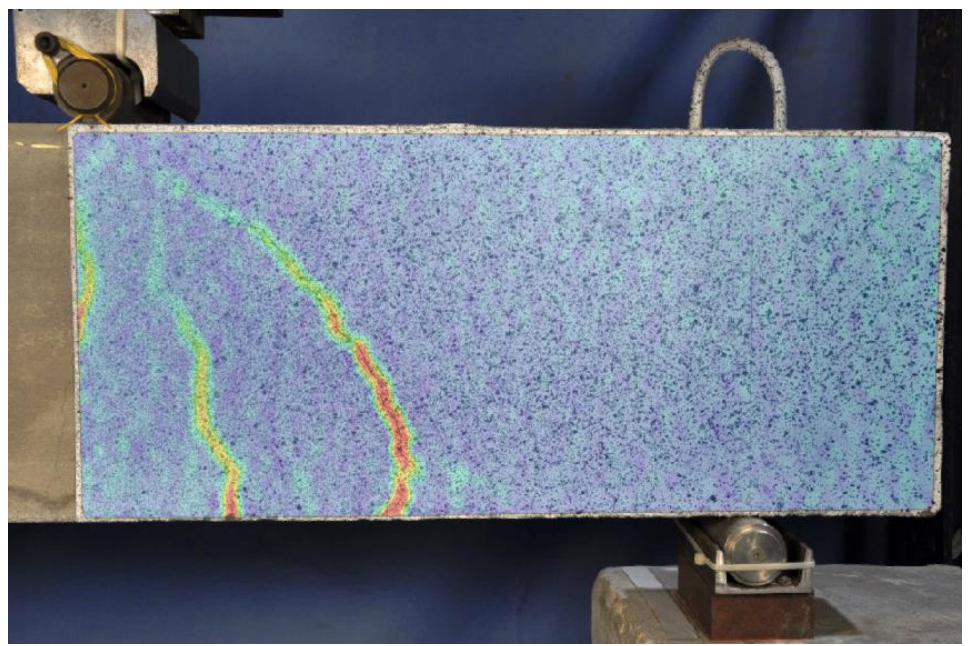

Figure 4.14 - Crack pattern for beam 3L-NS A obtained from DIC analysis.

To illustrate how the contribution of each shear transfer mechanism could be quantitatively estimated from the measured crack kinematics, the critical diagonal crack could be divided into two straight segments and the following steps could be adopted: 
1) the length and slope angles of each segment must be measured;

2) at the middle of each segment, a pair of points perpendicular to the crack must be selected, as shown in Figure 4.15. For each pair, average crack opening and sliding can be measured using DIC, for a given instant of time;

3) For beams with stirrups, a pair of points parallel to each stirrup must also be selected and the displacements parallel to the orientation of the stirrup must be measured

4) Based on the crack geometry and kinematics and adopting theoretical load-displacement relationships associated to each mechanism, their contribution can be estimated and total theoretical shear resistance can be compared to the applied shear.

To carry out this analysis, theoretical models for each mechanism are necessary, which was out of scope of this work. However, in an attempt to illustrate the methodology, an example is presented in Figure 4.16, for beam A. Neglecting the contribution of concrete at uncracked zone (very reduced area) and assuming an elastic-plastic relationship for dowel action based on the results obtained from dowel tests, it can be seen that, for beams without stirrups, strength is provided by a combination of aggregate interlock and dowel action after shear crack formation. It can also be noted that the aggregate interlock contribution reduces gradually as the crack opens (loss of interlock). 


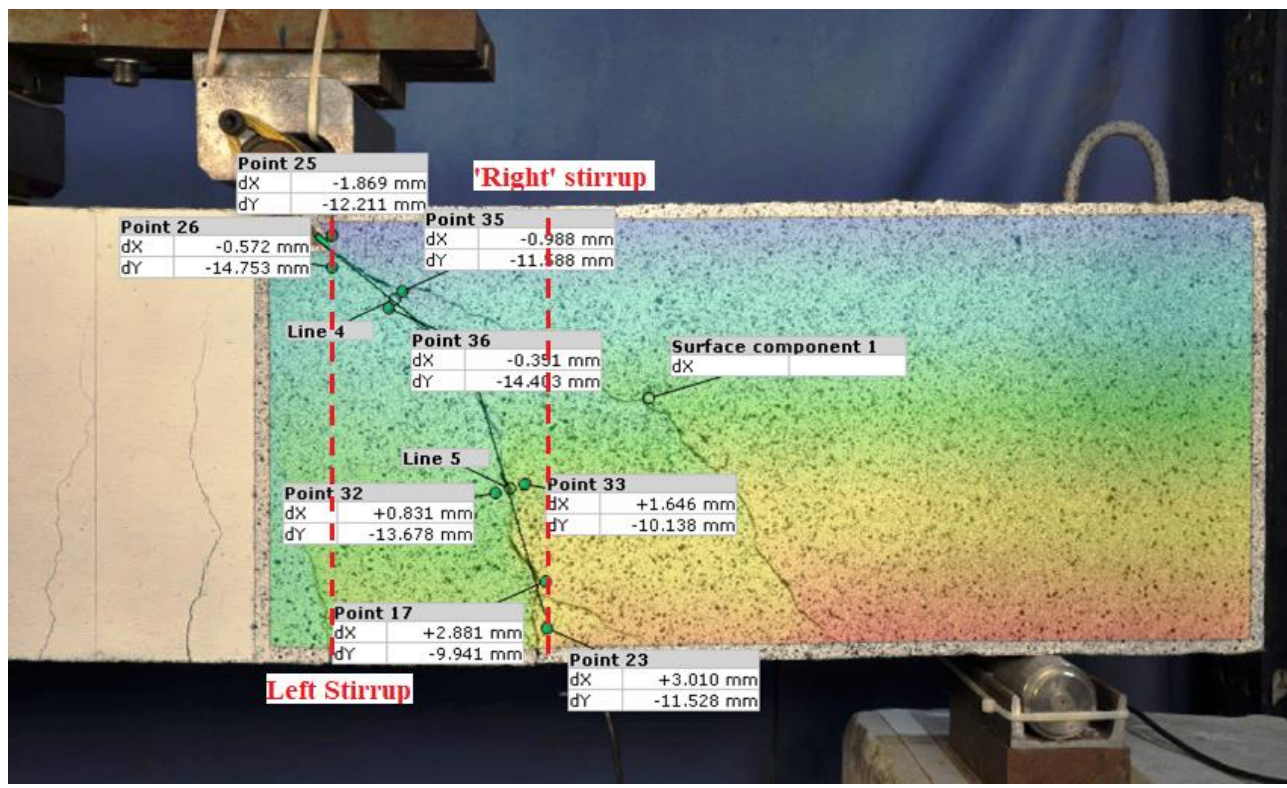

Figure 4.15 - Selection of crack segments and points for analysis using DIC for the Brazilian campaign.

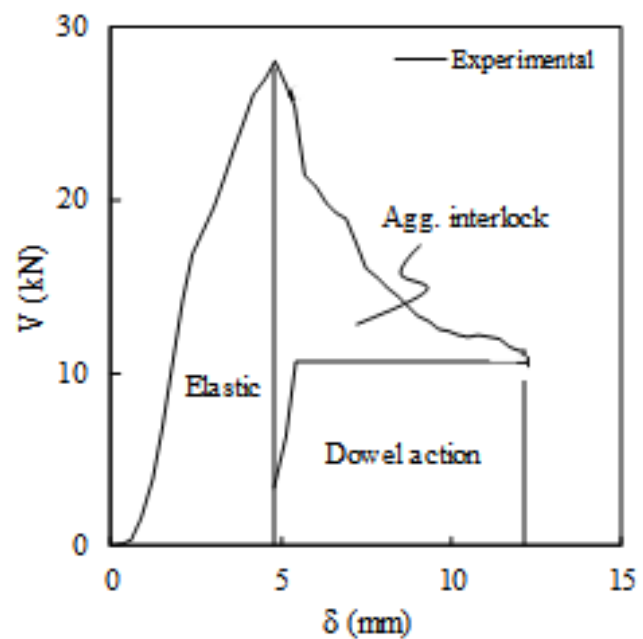

Figure 4.16 - Prediction of the contribution of shear transfer mechanisms for Beam 3L-NS A; 


\subsubsection{Canadian campaign}

All beam specimens failed in shear and it was observed that the first cracks (flexural cracks) appeared in the constant moment region at the midspan section. These flexural cracks propagated vertically with increasing loading, reflective of the absence of shear stress. As load increased, some flexural cracks appeared within the shear span and the existing cracks were widening. Because of the presence of shear stresses, these flexural-shear cracks became progressively more inclined and propagated towards the load application point. Maximum shear forces $V_{\max }$ and corresponding displacements $\delta$ are summarized in Table 4.7 and load-displacement curves for all specimens are presented in Figure 4.17.

Table 4.7 - Summary of the beam tests results.

\begin{tabular}{lllll}
\hline Specimen & $\mathbf{f}_{\mathbf{c}}{ }^{\prime}(\mathbf{M P a})$ & $\mathbf{f}_{\mathbf{t}, \mathbf{s p}}(\mathbf{M P a})$ & $\mathbf{V}_{\max }(\mathbf{k N})$ & $\boldsymbol{\delta}(\mathbf{m m})$ \\
\hline Beam 2L-NS A & & & 45.4 & 15.1 \\
Beam 2L-NS B & $33.1 \pm 2.2$ & $3.12 \pm 0.09$ & 45.1 & 10.8 \\
Beam 2L-NS C & & & 55.3 & 12.9 \\
\hline Beam 2L-S D & & & 84.1 & 17.3 \\
Beam 2L-S E & $29.3 \pm 3.3$ & $2.42 \pm 0.28$ & 75.4 & 14.8 \\
Beam 2L-S F & & & 81.6 & 15.8 \\
\hline
\end{tabular}

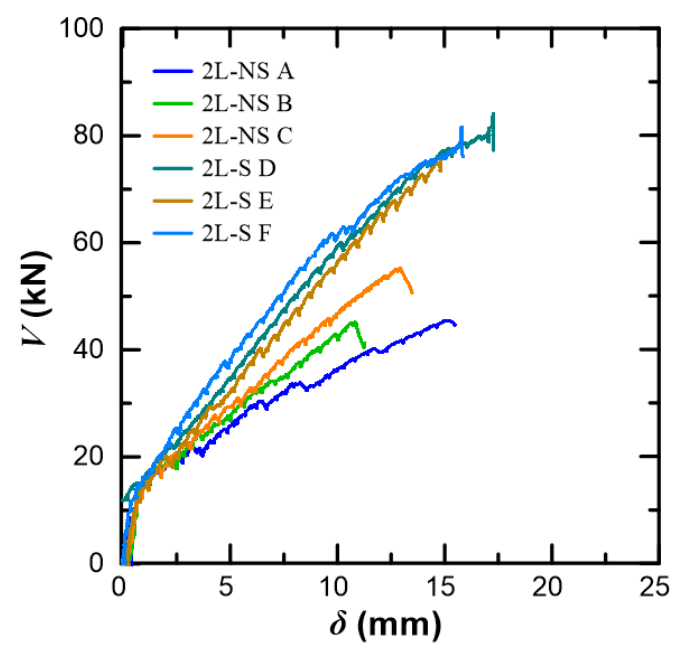

Figure 4.17 - Experimental load-displacement curves of beam tested.

For beams without stirrups, it was observed that the flexural-shear crack located farthest from midspan eventually led to the diagonal-tension shear failure. The crack shape exhibited a slope with respect to the longitudinal direction ranging 
from approximately $55-60^{\circ}$ near the loading point to $25-35^{\circ}$ at the bottom. Figure 4.18-a shows the crack formation process for beam 2L-NS C, as an example. Pushoff and dowel action tests were not carried out for this campaign, therefore there are no experimental data available to evaluate the contribution of these shear transfer mechanisms to the shear strength of the tested beams.

For beams with stirrups, it was only possible to analyze the formation of cracks using DIC for the beams 2L-S D and 2L-S F, since a technical problem occurred during the test with Beam 2L-S E and the camera was not able to record the pictures for this specimen. Diagonal cracks in the shear span started to appear at loads around 35-40 kN. Figure 4.18-b shows the crack formation process for beam 2L-S F, as an example. The shear strength for beams with stirrups was up to $86 \%$ greater than that for beams without stirrups. For $2 \mathrm{~L}-\mathrm{S}$ D, it was observed that stirrup was only intercepted at top of the crack. For 2L-S F, stirrups were intercepted at three different regions: at the top, approximately in the middle, and at the bottom of the critical shear crack.

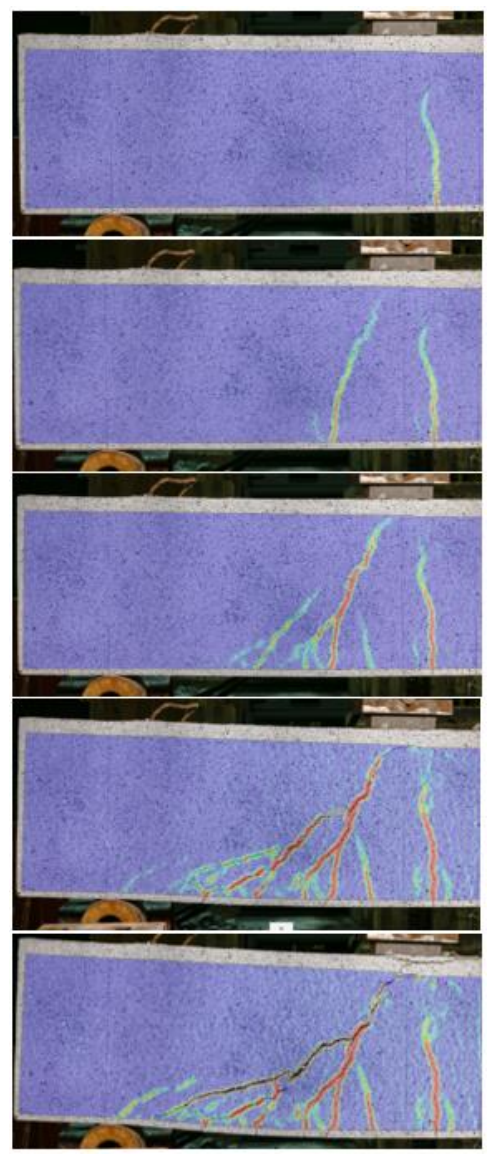

(a)

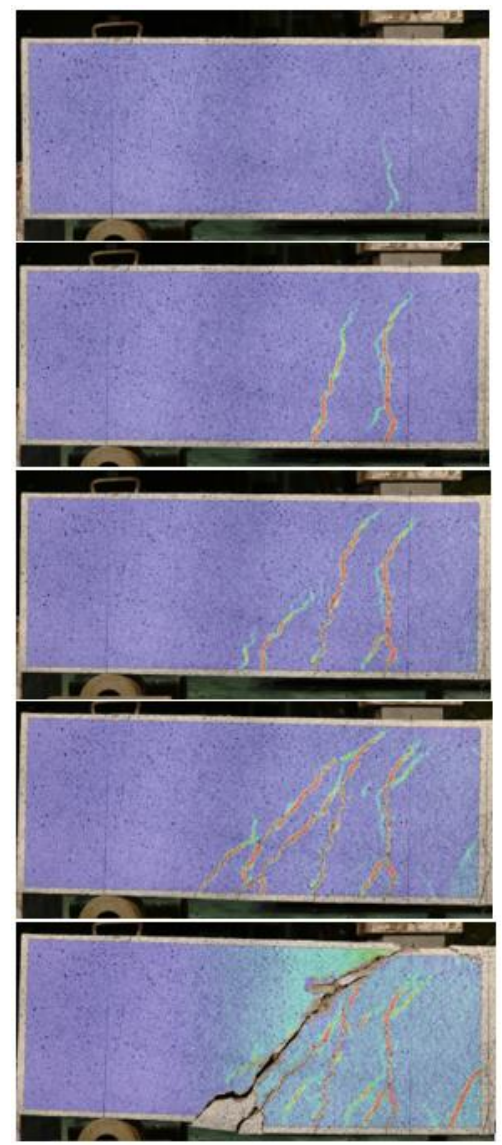

(b)

Figure 4.18 - Crack formation process: (a) Beam 2L-NS C; (b) Beam 2L-S F. 
The shape of the critical shear crack for beams with and without stirrups is shown in Figure 4.19 and photographs taken during the test showing the failure mode for each tested beam is presented in Appendix C (except for 2L-S E). Typical failure modes for beams with and without stirrups is presented in Figure 4.20. All the specimens exhibited a concrete diagonal tension failure. For 2L-S D, it was observed rupture of the stirrup, where the "U" shaped came apart, as shown in Figure 4.21. However, for 2L-S F, it was not observed rupture of the stirrup, as illustrated in Figure 4.22. This observation may be associated to the fact that these beams presented different crack shape. Figure 4.23 presents crack pattern of beam 2L-NS C obtained from DIC analysis. It can be observed that displacements obtained immediately before the beam failure by means of the DIC and the wire transducer shows a good agreement.

* For easy viewing, the shape of all the critical shear cracks was represented at the left side. Thus, for $2 \mathrm{~L}$ NS B and 2L-S D beams the critical shear crack is a mirrored representation.

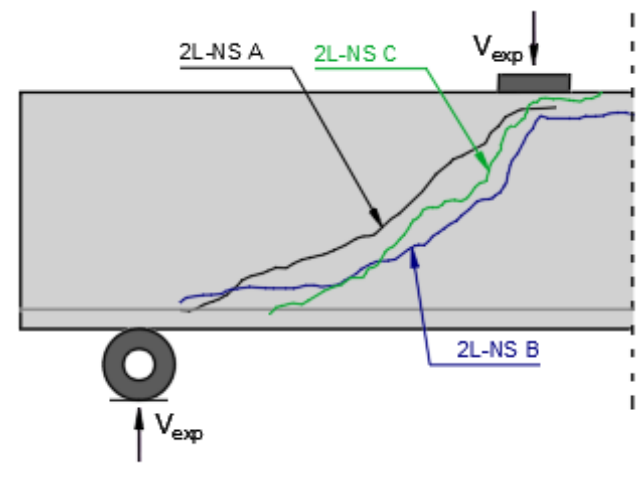

(a)

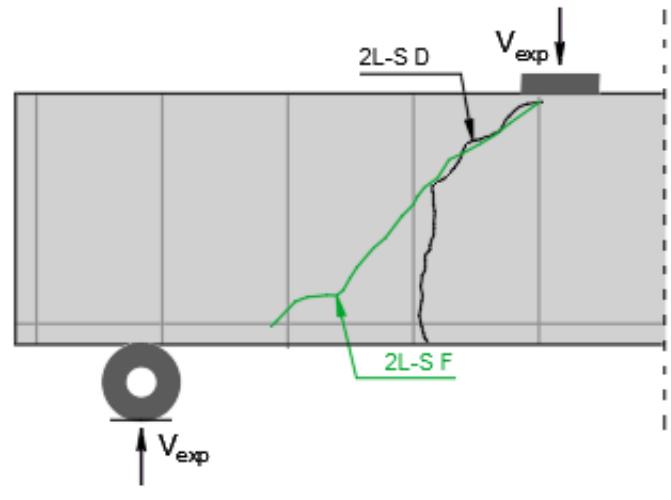

(b)

Figure 4.19 - Crack pattern of the critical shear crack: (a) specimens without stirrups; (b) specimens with stirrups. 


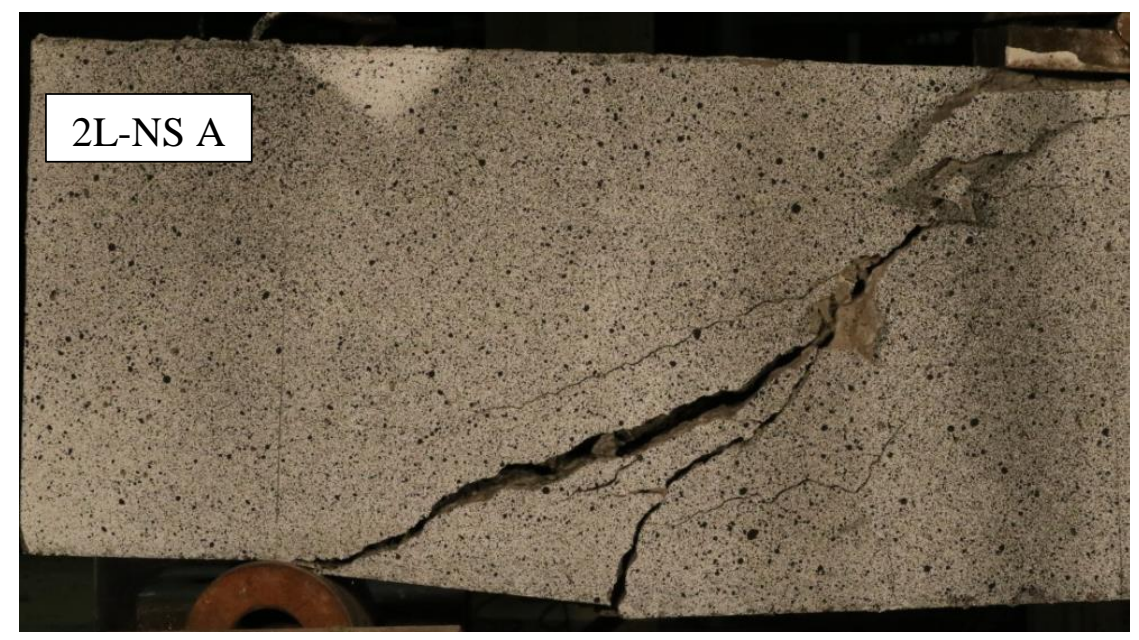

(a)

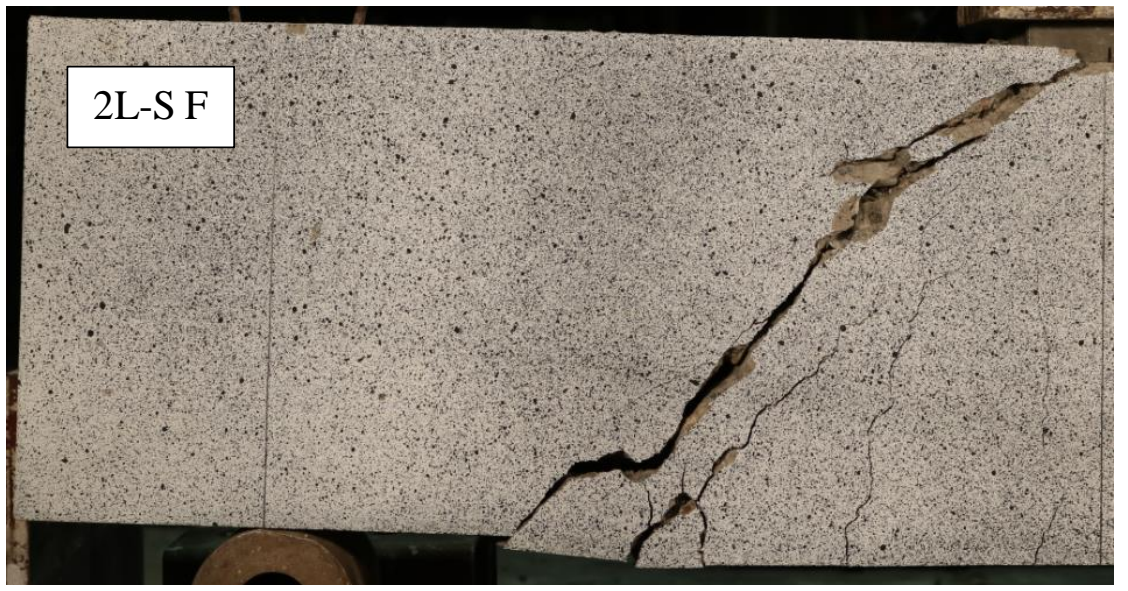

(b)

Figure 4.20 - Typical failure modes: (a) beams without stirrups; (b) beams with stirrups.

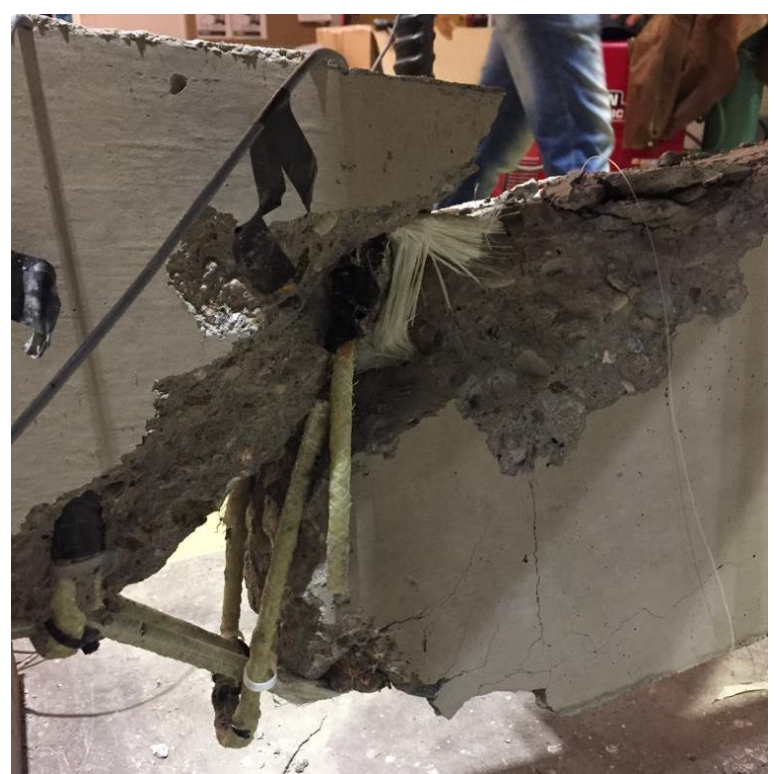

Figure 4.21 - Rupture of stirrup for 2L-S D specimen. 


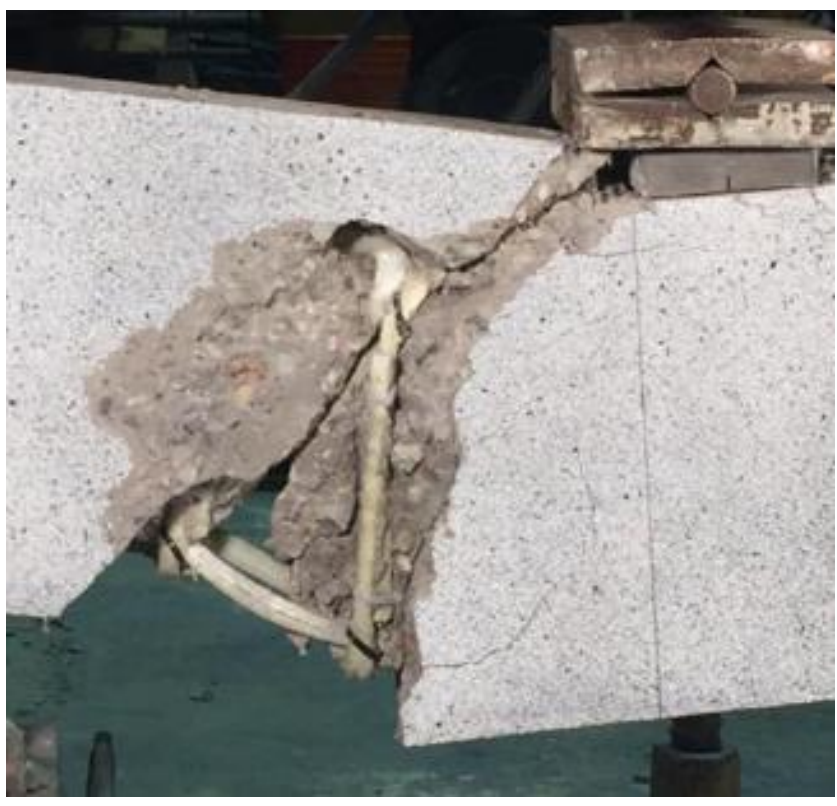

Figure 4.22 - Rupture of stirrup for 2L-S F specimen.

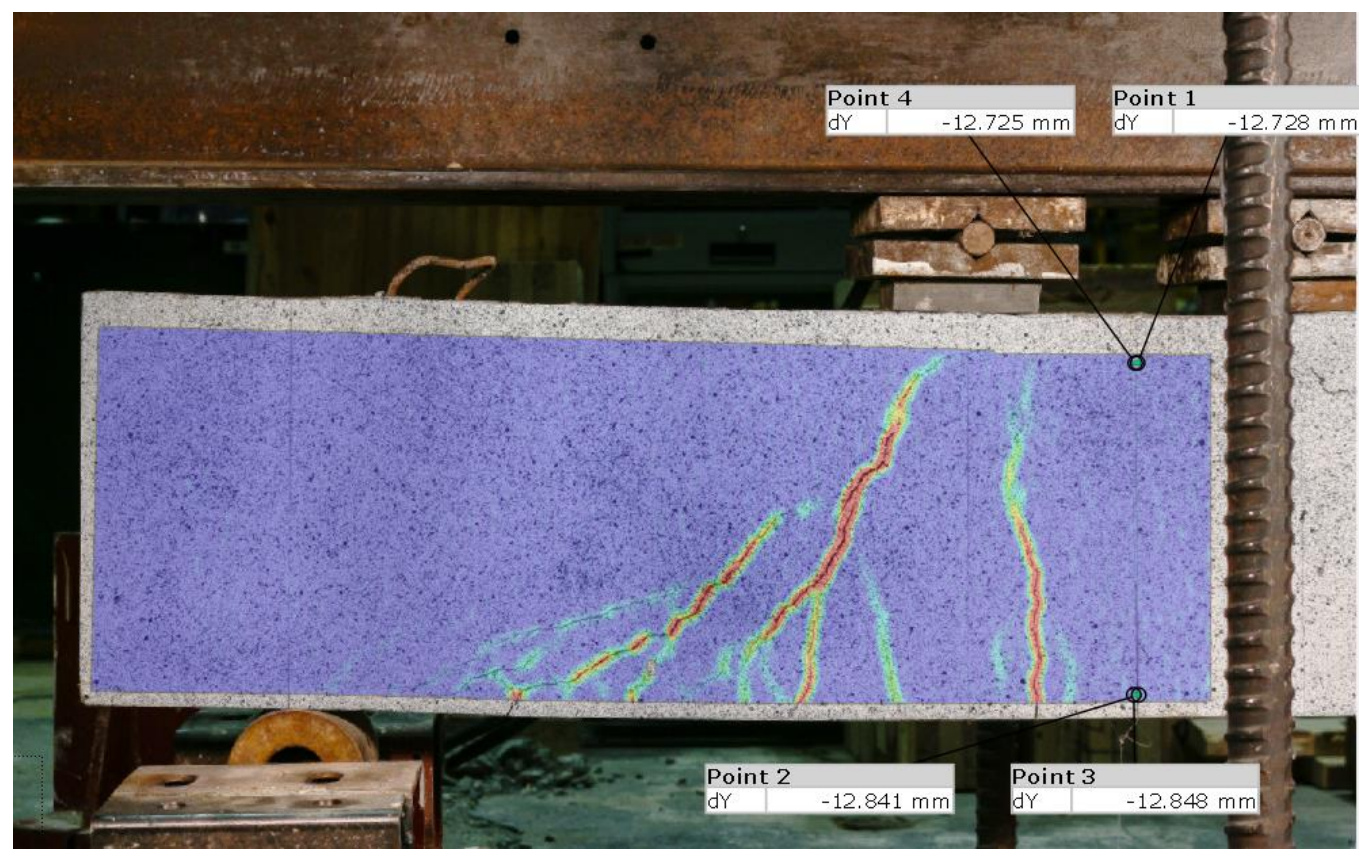

Figure 4.23 - Crack pattern for beam 2L-NS C obtained from DIC analysis. 


\section{Conclusions}

\subsection{Final Considerations}

In this study, a brief review on the shear transfer mechanisms for RC beams, and on the mechanical properties and shear behavior of concrete beams reinforced with GFRP bars was presented. Twelve tests were conducted on GFRP RC beams to investigate the shear behavior of beams with and without stirrups. In addition, two dowel action tests were carried out in order to evaluate the contribution of longitudinal GFRP bars to the shear transfer through cracked zones, and four pushoff tests were performed in order to investigate the assess the influence of aggregate type/density. Based on the results provided throughout the dissertation, the following conclusions can be drawn:

- For dowel action tests, the use of more bars is associated to a reduction in the concrete effective area subject to tension and an increasing of the bending stiffness. Although only one test of each was performed, it seems reasonable to say that, in the cases studied, these two effects canceled and the peak loads were similar. The failure of the dowel action specimens was governed by splitting of the concrete, with splitting cracks being opened at the bottom portion of the beam;

- It was not possible to identify the influence of the maximum size of the coarse aggregate to the aggregate interlock, since the results for the specimens with $25 \mathrm{~mm}$ diameter coarse aggregate showed great dispersion;

- DIC seemed to be an adequate technique to gather information about opening and sliding of cracks with loading for tests under displacement control, since it allows the observation of the post peak behavior;

- For beam tests, all the specimens exhibited a concrete diagonal tension failure. For Brazilian beams without stirrups, dowel action seemed to provide significant contribution to the shear strength after the crack, when the load reduces and the 
deflections increases, resulting from the loss of aggregate interlock as the crack opens;

- Brazilian beams with stirrups showed steeper cracks and shear strength up to three times greater than that for beams without stirrups, although a greater dispersion of results was observed. This variation may be caused by the bad surface treatment in the bent portion of the stirrup. Failure was governed by rupture of stirrup at the bent corner;

- Canadian campaign showed consistent results. All the specimens exhibited a concrete diagonal tension failure. Since push-off and dowel action tests were not carried out for this campaign, no experimental data was available to evaluate the contribution of these shear transfer mechanisms to the shear strength of the tested beams;

- For Canadian beams with stirrups, the shear strength was up to $86 \%$ greater than that for beams without stirrups. Not all the beams showed rupture of the stirrup in the bent zone.

The tests carried out in the Brazilian and Canadian campaigns had some differences and, although it is not possible to directly correlate the tests, some considerations about both campaigns can be done. The main observed differences were:

- Artificial sand (BRA) x Natural sand (CAN);

- Maximum size of coarse aggregate: $12.5 \mathrm{~mm}$ (BRA) x $19 \mathrm{~mm}$ (CAN);

- Surface treatment: helically wrapped (BRA) x sand-coated (CAN)

- Diameter of stirrups: $8 \mathrm{~mm}$ (BRA) x $10 \mathrm{~mm}$ (CAN);

- Loading application system: displacement control (BRA) x load control hand pump (CAN);

Follow considerations could be given:

a) The results observed in the Canadian campaign were more consistent when comparing beams with stirrups tested in the Brazilian campaign. This 
probably occurred because of the stirrups used in the Brazilian campaign, which do not present good surface treatment;

b) The maximum shear force for beams without stirrups obtained in the Canadian campaign was $60 \%$ greater than in the Brazilian campaign, possibly because of the greater maximum size of the coarse aggregate used in Canada. This hypothesis should be verified carrying out push-off tests using the same Canadian materials used in beam tests.

c) Due the internal size of the Canadian stirrup, only two longitudinal bars could be used, leading to a lower reinforcing ratio $(0,79 \%)$ compared with Brazilian campaign $(1,18 \%)$. Besides that, the splitting tensile strength of the Canadian campaign was greater. These facts may contribute to a greater dowel action effect and, consequently, a greater a shear strength. This hypothesis should be verified carrying out dowel tests using the same Canadian materials used in beam tests.

d) In the Brazilian campaign, the loads were applied using concentrated points, whereas in the Canadian campaign the loads were applied over a plate measuring $22 \times 100 \mathrm{~mm}$. These points of load application can be seen in Figure 4.12 and 4.19 , respectively. This fact can be associated to the different crack patterns between the campaigns.

\subsection{Future Works}

In order to improve the study of the shear transfer mechanisms in GFRP RC beams, several suggestions for further investigations are proposed:

- Develop theoretical models to correlate the crack kinematics measured using DIC technique with the forces transferred by each ; 
- Conduct an experimental program on more specimens for dowel action and push-off tests to validate the dowel action and aggregate interlock contribution for the Brazilian campaign;

- Conduct an experimental program on dowel action and push-off tests adopting the same material used in Canadian beams to determinate the contribution of the shear mechanisms for the Canadian campaign;

- Conduct an experimental program on beam tests using different types of aggregate particle sizes and types of bars; 


\section{References}

AHMED, E. A.; EL-SALAKAWY, E. F.; BENMOKRANE, B. Performance evaluation of GFRP shear reinforcement in concrete beams. ACI Structural Journal 107 (1): 53-62 (2010).

AHMED, E. A.; EL-SAYED, A. K.; EL-SALAKAWY, E. F.; BENMOKRANE, B.; Bend Strength of FRP Stirrups: Comparison and Evaluation of Testing Methods", Journal of Composites for Construction, 14(1), pp 3-10, (February) 2010 .

ALKHRDAJI, T., WIDEMAN, M., BELARBI, A., NANNI, A. Shear strength of GFRP RC beams and slabs, In: Proceedings of the International Conference of Composites in Construction, 409-414, 2001.

AMERICAN ASSOCIATION OF STATE HIGHWAY AND TRANSPORTATION (AASHTO LRFD): Bridge Design Guide Specifications for GFRP Reinforce Concrete Bridge Decks and Traffic Railings , 2009.

AMERICAN CONCRETE INSTITUTE. ACI 318-14: Building Code Requirements for Structural Concrete - and Commentary. Farmington Hills, USA, 2014.

AMERICAN CONCRETE INSTITUTE. ACI440.3R-04: Guide Test Methods for Fiber-Reinforced Polymers (FRPs) for Reinforcing or Strengthening Concrete Structures. Farmington Hills, Mich.; USA, 2006.

AMERICAN CONCRETE INSTITUTE. ACI440.1R-06: Guide for the design and construction of concrete reinforced with FRP bars. Farmington Hills, Mich.; USA, 2006.

AMERICAN CONCRETE INSTITUTE. ACI445R-99: Recent approaches to shear design of structural concrete. ACI-ASCE Committee 445, 55 p. 1999. 
AMERICAN SOCIETY for TESTING and MATERIALS. ASTM D7205M 06R16: Standard Test Method for Tensile Properties of Fiber Reinforced Polymer Matrix Composite Bars. USA, 2016.

ASSOCIAÇÃO BRASILEIRA DE NORMAS TÉCNICAS (ABNT) - NBR-8522: Concreto - Determinação dos Módulos Estáticos de Elasticidade e de Deformação e da Curva Tensão-Deformação, Brasil, 2003.

BANK, L. C. Composites for Construction: Structural Design with FRP Materials. New Jersey: John Wiley \& Sons, Inc, 2006.

BAZANT, Z. P.; GAMBAROVA, P. G. Rough crack models in reinforced concrete. ASCE - Journal of Structural Engineering, v. 106, n. 4, p. 819-842, 1980.

BAUMANN, T.; RUSCH, H. Versuche zum stadium der verdubelungswirkung der biegezugbewehrung eines stahlbetonbalkens. Deutscher Ausschuss fur Stahlbeton, Heft 210, Berlim, Germany, p. 45-83, 1970.

BENTZ, E. C.; MASSAM, L.; COLLINS, M. P. Shear Strength of Large Concrete Members with FRP Reinforcement, Journal of Composites for Construction, 14(6), pp 637-646, November/December 2010.

CANADIAN STANDARDS ASSOCIATION. CSA-S806-12: Design and Construction of Building Structures with Fiber-Reinforced Polymers. Ontario, Canada, 2002 and 2012.

CANADIAN STANDARDS ASSOCIATION. CSA-S807-10: Specification for Fiber-Reinforced Polymers. Ontario, Canada, 2010.

CAMPANA, S; RUIZ, M. F.; ANASTASI, A.; MUTTONI. Analysis of sheartransfer actions on one-way RC members based on measured cracking pattern and failure kinematics. Magazine of Concrete Research, v. 65, n. 6, p. 386-404, 2013.

CAVAGNIS, F.; RUIZ, M. F.; MUTTONI, A. Shear failures in reinforced concrete members without transverse reinforcement: an analysis of the critical shear crack development on basis of test results. Engineering Structures, v. 103, p. 157-173, 2015. 
CAVAGNIS, F. Shear in reinforced concrete without transverse reinforcement: from refined experimental measurements to mechanical models. École Polytechnique Fédérale De Lausanne: PhD Thesis, 223p. 2017.

CORRELATED SOLUTIONS Product Catalog, 2018.

CURRIER, J.; FOGSTAD, C.; WALRATH, D.; DOLAN, C. Bond Development of Thermoplastic FRP Shear Reinforcement Stirrups, Proceedings of the ASCE Third Material Engineering Conference Infrastructure: New Materials and Methods of Repair", San Diego, California, United States, Ed. Basham, K. D.; American Society of Civil Engineers, New York, New York, United States, pp 592-597, (November) 1994.

DUTTON, M. Digital Image Correlation for Evaluating Structural Engineering Materials. Queen's University: Master Thesis, Ontario, Canada, 2012.

EL-SAYED, A. K.; EL-SALAKAWY, E. F.; BENMOKRANE, B. Shear strength of concrete beams reinforced with FRP bars: Design method. Proceedings, 7th International Symposium on Fiber Reinforced Polymer Reinforcement for Concrete Structures, FRPRCS-7, Kansas City, MO, SP 230-54, 955-974 (2003).

EL-SAYED, A.; EL-SALAKAWY, E.; BENMOKRANE, B. Shear strength of one-way concrete slabs reinforced with fiber-reinforced polymer composite bars. Journal of Composites for Construction, Vol. 9, No. 2, pp. 147-157, 2005.

GAMBAROVA, P. On Aggregate Interlock Mechanism in Reinforced Concrete Plates with Extensive Cracking. IABSE Colloquium on Advanced Mechanics of Reinforced Concrete, Final Report. Delft, 1981.

GANGARAO, H. V. S.; TALY, N.; VIJAY, P. V. Reinforced Concrete Deign with FRP Composites. Boca Raton: CRC press, 2007.

GOORANORIMI, O.; NANNI, A. "GFRP Reinforcement in Concrete after 15 Years of Service". Journal of Composites for Construction 21.5 (2017): 04017024 
GOORANORIMI, O.; BRADBERRY, T.; DAUER, E.; MYERS，J.; NANNI, A. FRP Reinforcement for Concrete: Performance Assessment and New Construction Volume I: Sierrita De La Cruz Creek Bridge. Technical report. 2016. HAJIMIRAGHA, B. Glass Fiber Reinforced Polymer (GFRP) Rebar for Sustainable Infrastructure, 2016.

HUANG, Z.; TU, Y.; MENG, S.; SABAU, C.; POPESCU, C.; SAS, G. Experimental study on shear deformation of reinforced concrete beams using digital image correlation. Engineering Structures, v.181, p. 670-698, 2019.

HUBER, P.; HUBER, T.; KOLLEGGER, J. Investigation of the shear behavior of $\mathrm{RC}$ beams on the basis of measured crack kinematics. Engineering Structures, v. 113, p. 41-58, 2016.

HUBER, T.; HUBER, P.; KOLLEGGER, J. Influence of aggregate interlock on the shear resistance of reinforced concrete beams without stirrups. Engineering Structures, v. 186, p. 26-42, 2019.

IMJAI, T.; GUADAGNINI, M.; PILAKOUTAS, K. Mechanical Performance of Curved FRP Rebars - Part I: Experimental Study, Proceedings of the First AsiaPacific Conference on FRP in Structures, APFIS 2007, by the International Institute for FRP in Construction (IIFC), Hong Kong, China, Ed. Smith S. T.; University of Hong Kong, Hong Kong, China, pp 333-338, December 2007.

IMJAI, T.; GUADAGNINI, M.; PILAKOUTAS, K. Mechanical Performance of Curved FRP Rebars - Part II: Analytical Study, Proceedings of the First AsiaPacific Conference on FRP in Structures, APFIS 2007, by the International Institute for FRP in Construction (IIFC), Hong Kong, China, Ed. Smith S. T.; University of Hong Kong, Hong Kong, China, pp 339-344, December 2007. 
INTELLIGENT SENSING FOR INNOVATIVE STRUCTURES (ISIS) - ISIS Design Manual No. 3: Reinforcing Concrete Structures with Fiber Reinforced Polymers. Canada, 2001.

JAPAN SOCIETY OF CIVIL ENGINEERS. JSCE.23: Recommendation for Design and Construction of Concrete Structures Using Continuous Fiber Reinforcing Materials. Japan, 1997.

JELIC, I.; PAVLOVIC, M. N.; KOTSOVO, M. D. A study of dowel action in reinforced concrete beams. Magazine of Concrete Research, v. 51, n. 2, p. 131-141, April 1999.

KIM, J-K.; PARK, Y-D. Prediction of shear strength of reinforced concrete beams without web reinforcement. ACI Materials Journal, v. 93, n. 3, p. 213- 223, mayjun. 1996.

KREFELD, W.; THURSTON, C. W. Contribution of longitudinal steel to shear resistance of reinforced concrete beams, ACI Journal Proceedings, v. 63, n. 3, p. 325-344, 1966.

MALLICK, P. K. Fiber-reinforced composites: materials, manufacturing, and design. CRC press, 2007.

MARUYAMA, T.; HONMA, M.; OKAMURA, H. Experimental Study on Tensile Strength of Bent Portion of FRP Rods. Special Publication of the ACI, 138, pp 163176, September 1993.

MATTOCK, J. A.; JOHAL, L.; CHOW, H. C. Shear transfer in reinforced concrete with moment or tension acting across the shear plane. PCI Journal, p. 76-93, JulyAugust, 1975.

MATTOCK, A.H.; LI, W.K.; WANG, T.C. Shear transfer in lightweight reinforced concrete. PCI Journal 21 (1):20-39, 1976.

MICHALUK, C. R.; RIZKALLA, S.; TADROS, G.; and BENMOKRANE, B. Flexural behavior of one-way concrete slabs reinforced by fiber reinforced plastic reinforcement. ACI Structural Journal, Vol. 95, No. 3, pp. 353-364, 1998. 
MÖRSCH, E. Der Einsenbetonbau (in english: Concrete-Steel Construction). The Engineering News Publishing Company, 368 p. 1909.

NAGASAKA, T.; FUKUYAMA, H.; TANIGAKI, M.; hear Performance of Concrete Beams Reinforced with FRP Stirrups. Special Publication of the ACI, 138, pp 789-812, September 1993.

NANNI, A.; DE LUCA, A.; ZADEH, H. J. Reinforced Concrete with FRP Bars: Mechanics and Design. Boca Raton: CRC press, 2014.

OVIEDO, J. et al. Upgrading the push-off test to study the mechanisms of shear transfer in frc elements. In: VIII International Conference on Fracture Mechanics of Concrete and Concrete Structures, 2013, Spain, 10p.

PANDA, S. S.; GANGOLU, A. R. Study of dowel action in reinforced concrete beam by factorial design of experiment. ACI Structural Journal, v. 114, n. 6, p. 1495-1505, nov-dec. 2017.

PERERA, SVTJ.; MUTSUYOSHI, H. Shear behaviour of reinforced high-strength concrete beams. ACI Struct J 2013;110(1):43-52.

SÁ, F. R. G. Influência da adição de fibras de polipropileno no comportamento de elementos estruturais de concreto armado com barras de GFRP. Master Thesis. Rio de Janeiro: Pontifícia Universidade Católica do Rio de Janeiro, 2018.

SAGASETA, J.; VOLLUM, R. L. Influence of aggregate fracture on shear transfer through cracks in reinforced concrete. Magazine of Concrete Research, v. 63, n. 2, p. 119-137, 2011.

SARKAR, S.; ADWAN, O.; BOSE, B. Shear stress contributions and failure mechanisms of high strength reinforced concrete beams. Material and Structures, v. 32, p. 112-116, March 1999.

SHEHATA, E.; MORPHY, R.; RIZKALLA, S.; Fibre Reinforced Polymer Shear Reinforcement for Concrete Members: Behaviour and Design Guidelines, Canadian Journal of Civil Engineering, 27(5), pp 859-872, October 2000. 
SHERWOOD, E. G.; BENTZ, E. C.; COLINS, M. P. Evaluation of shear design methods for large, lightly-reinforced concrete beams. Advances in Engineering Structures, Mechanics \& Construction, p. 153-164, Springer: Netherlands, 2006.

SHERWOOD, E. G. One-way shear behaviour of large, ligthly-reinforced concrete beams and slabs. Toronto, Canadá: PhD Thesis - University of Toronto, 2008.

SINGH, B.; CHINTAKINDI, S. An appraisal of dowel action in reinforced concrete beams. Proceedings of Institution of Civil Engineers, Structures and Buildings, $n$. SB5, p. 257-267, May 2013.

TAYLOR, H. P. J. The fundamental behavior of reinforced concrete beams in bending and shear. ACI Special Publication, v. 42, p. 43-77, 1974.

TUREYEN, A. K.; FROSCH, R. J. Shear tests of FRP-reinforced concrete beams without stirrups. ACI Structural Journal, Vol. 99, No. 4, pp. 427-434, 2002.

UEDA, T.; SATO, Y.; KAKUTA, Y.; IMAMURA, A.; KANEMATSU, H. Failure Criteria for FRP Rods Subjected to a Combination of Tensile and Shear Forces, Proceedings of the Second International RILEM Symposium on Non-Metallic (FRP) Reinforcement for Concrete Structures, Ghent, Belgium, Ed. Taerwe, L.; E \& FN Spon, London, United Kingdom, pp 26-33, (August) 1995.

VINTZELEOU, E. N.; TASSIOS, T. P. Mathematical models for dowel action under monotonic and cyclic conditions. Magazine of Concrete Research, v. 38, n. 134, p. 13-22, 1986.

WALRAVEN, J. C. Aggregate interlock: A theoretical and experimental analysis. Delft (Netherlands), 197p. PhD Thesis - Delft University of Technology, 1980.

WALRAVEN, J. C.; REINHARDT, H. W. Theory and experiments on the mechanical behavior of cracks in plain and reinforced concrete subjected to shear loading. Heron, Dept. of Civil Engineering, Delft University of Technology, v. 26, n. 1A, 68p, 1981. 
WIGHT, J, K.; MACGREGOR, J. G. Reinforced Concrete - Mechanics and Desing. $6^{\text {th }}$ ed. Upper Saddle River: Pearson, 2012.

YANG, K. H.; SIM, J. I.; CHOI, B. J.; LEE, E. T. Effect of Aggregate Size on Shear Behavior of Lightweight Concrete Continuous Slender Beams. ACI Materials Journal, V. 108, N 5, p. 501-509, Sep.-Oct. 2011.

YANG, Y. Shear behaviour of reinforced concrete members without shear reinforcement - a new look at an old problem. Delft: PhD Thesis - Deft University of Technology, 344 p. 2014.

YOST, J. R.; GROSS, S. P.; DINEHART, D. W. Shear strength of normal strength concrete beams reinforced with deformed GFRP bars. Journal of Composites for Construction, Vol. 5, No. 4, pp. 268-275, 2001. 
7. Appendix A - Dowel Action Tests Report

7.1. Post-crack aspect of dowel specimens

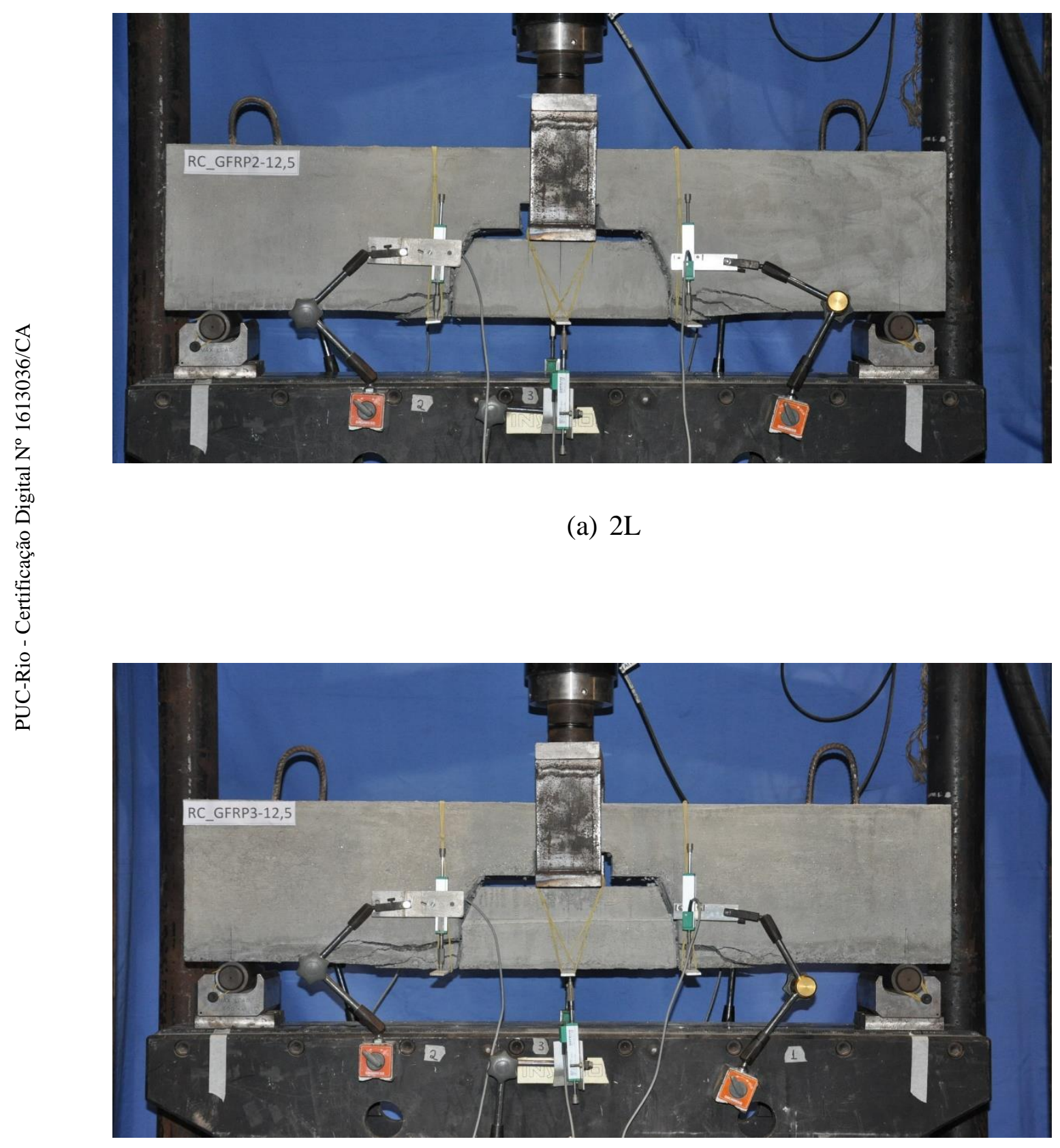

(b) $3 \mathrm{~L}$ 
7.2. Load-displacement curves

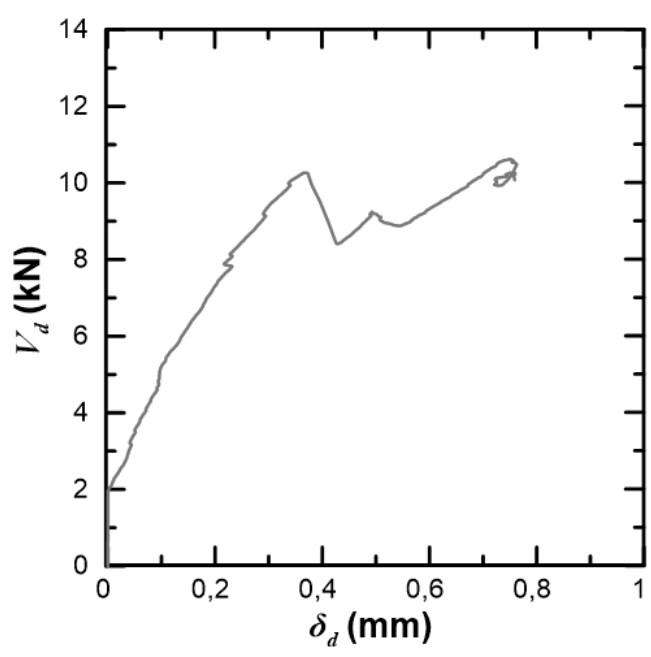

(a) $2 \mathrm{~L}$

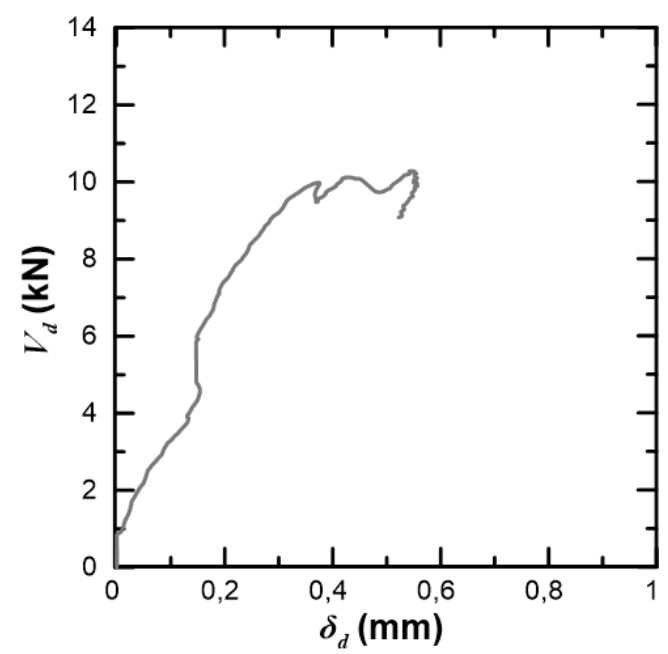

(b) $3 \mathrm{~L}$ 


\section{Appendix B - Push-off Tests Report}

8.1. Shear plane surface aspect after test

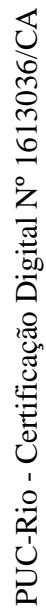

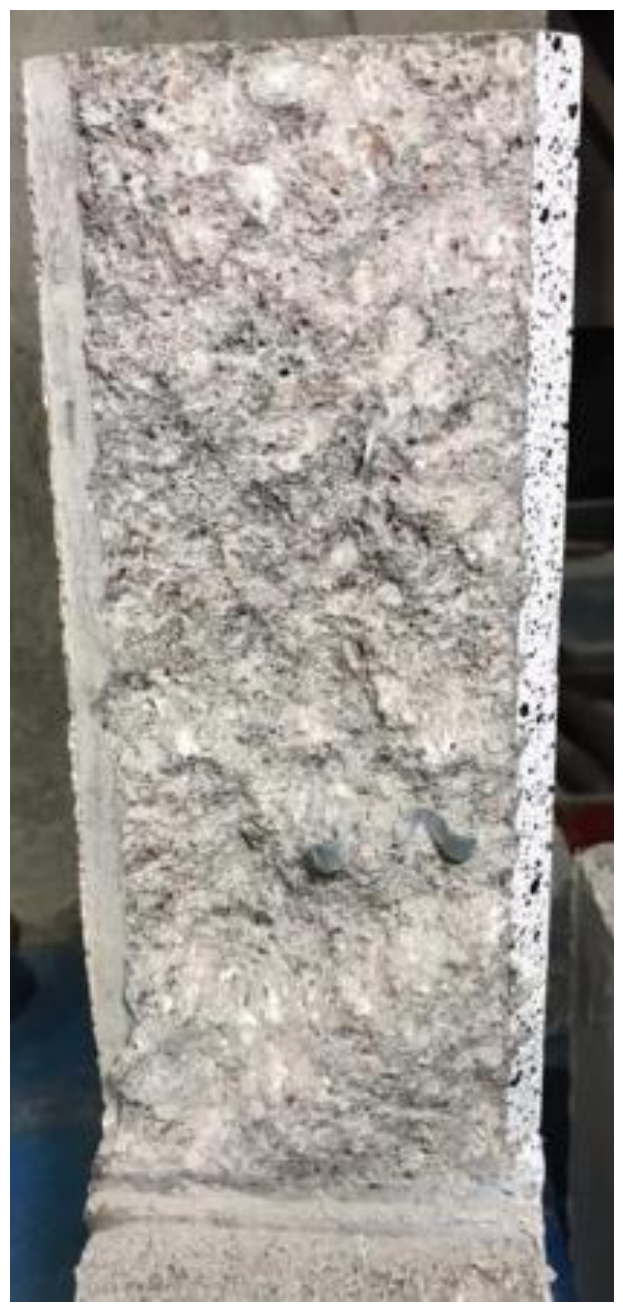

12.5-P1

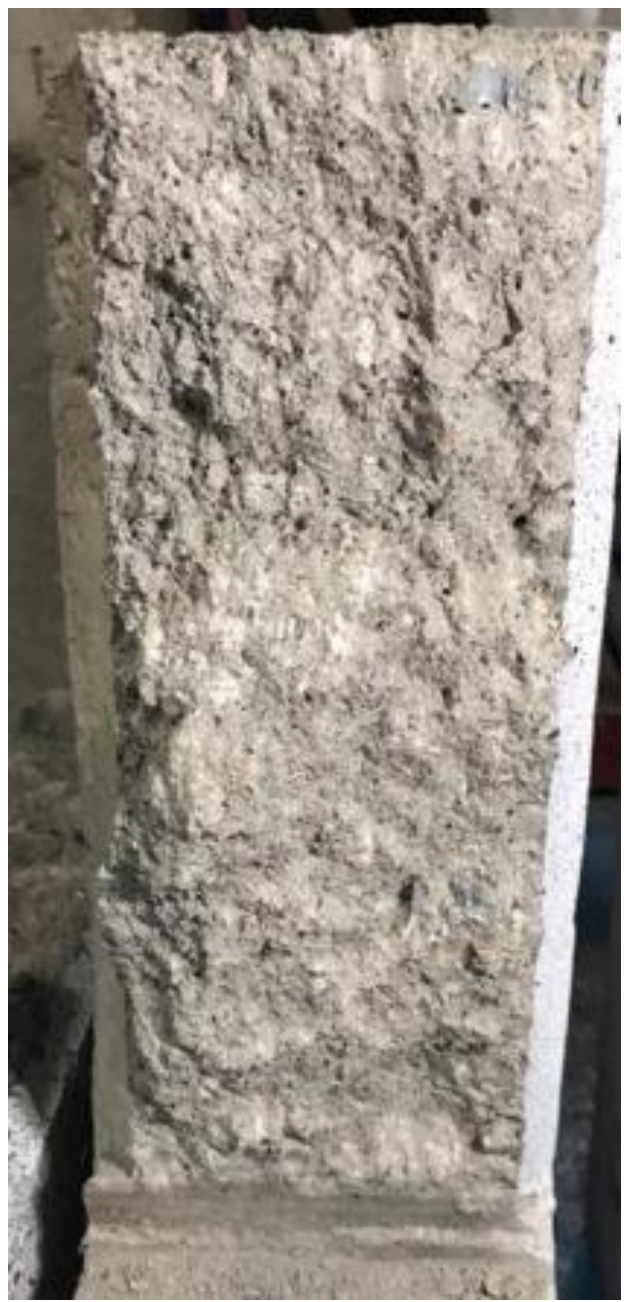

12.5-P2 


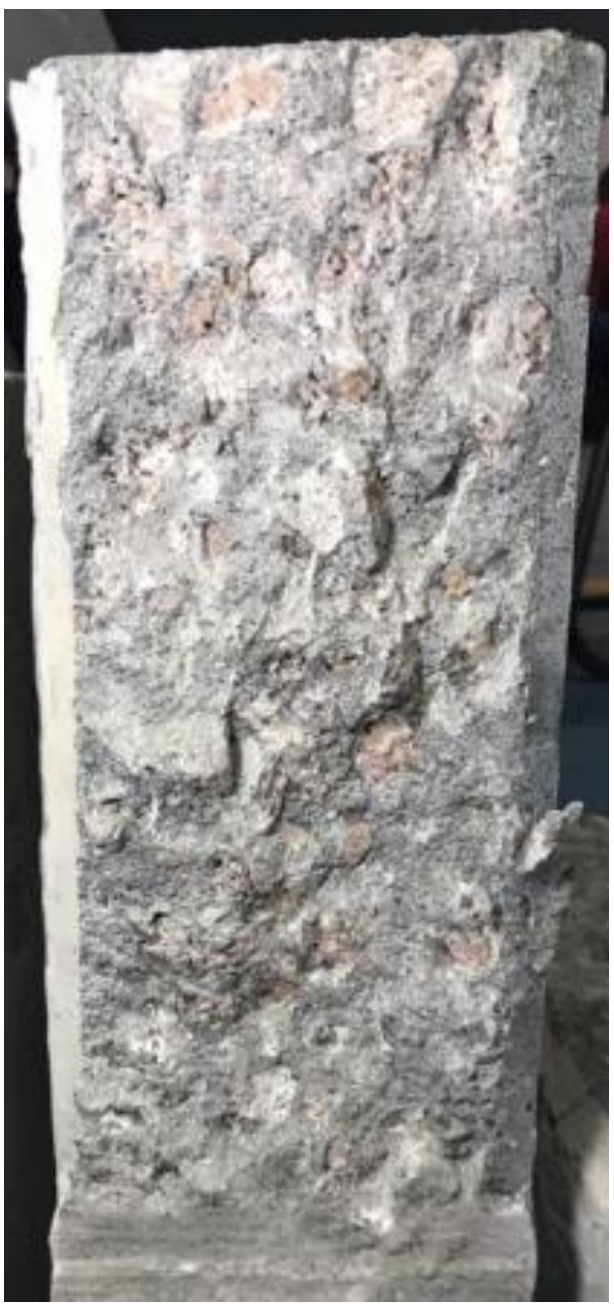

25-P3

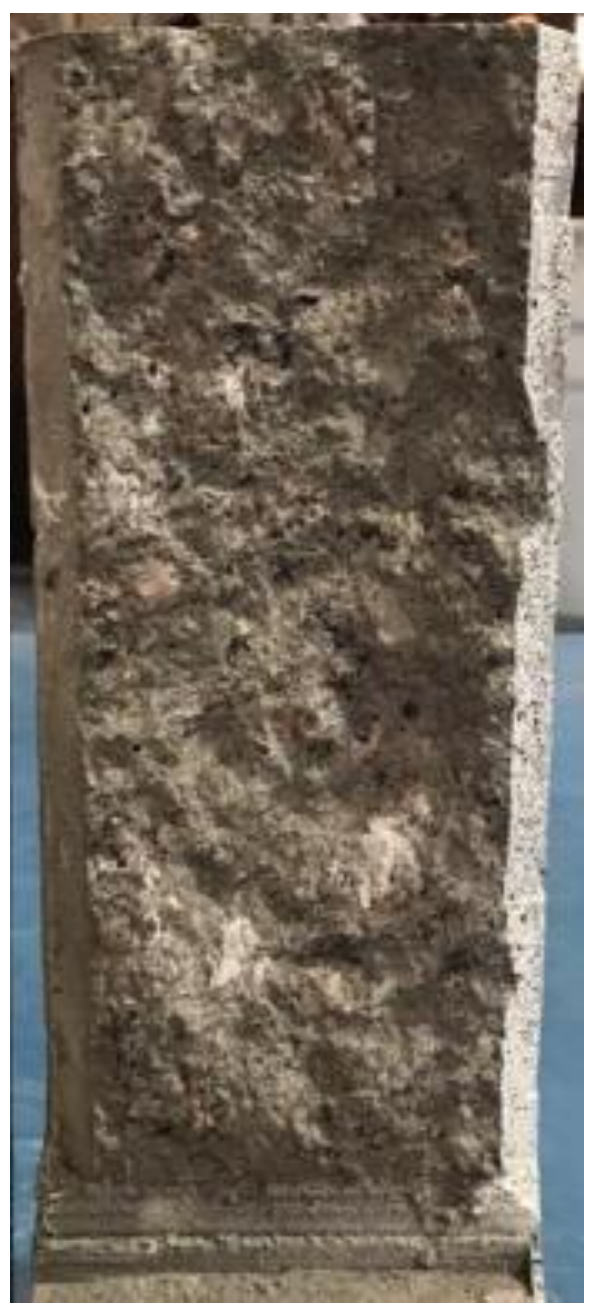

25-P4 


\subsection{Shear stress curves}

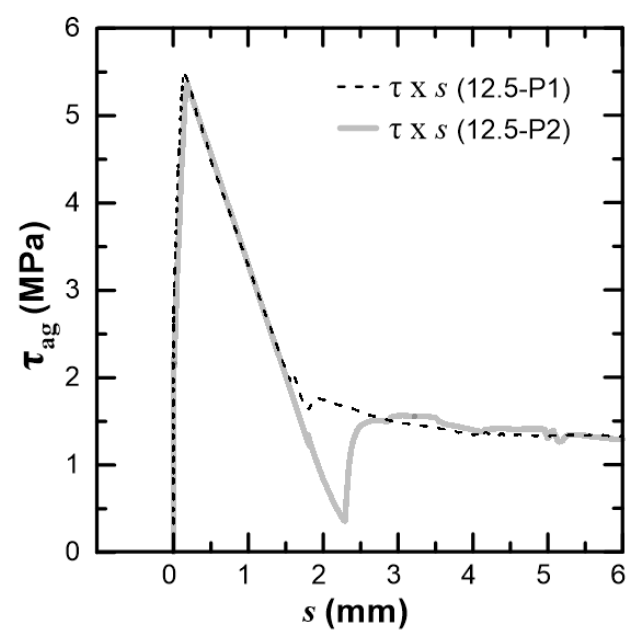

(a)

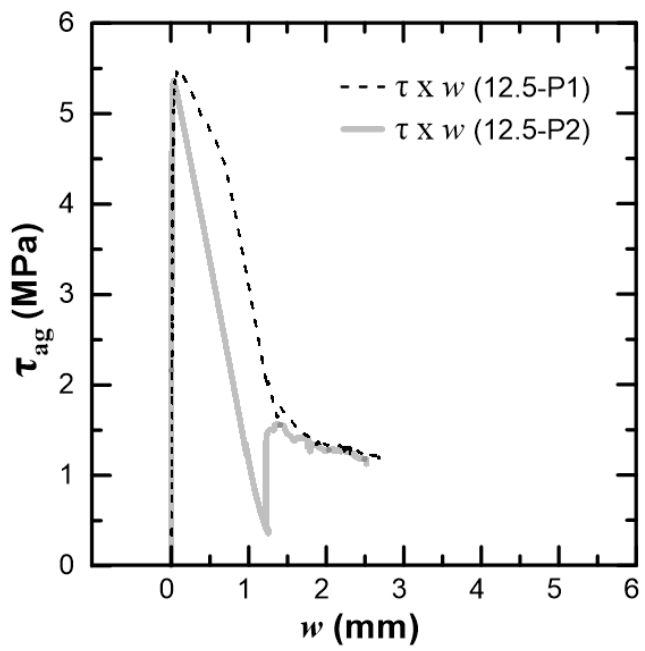

(c)

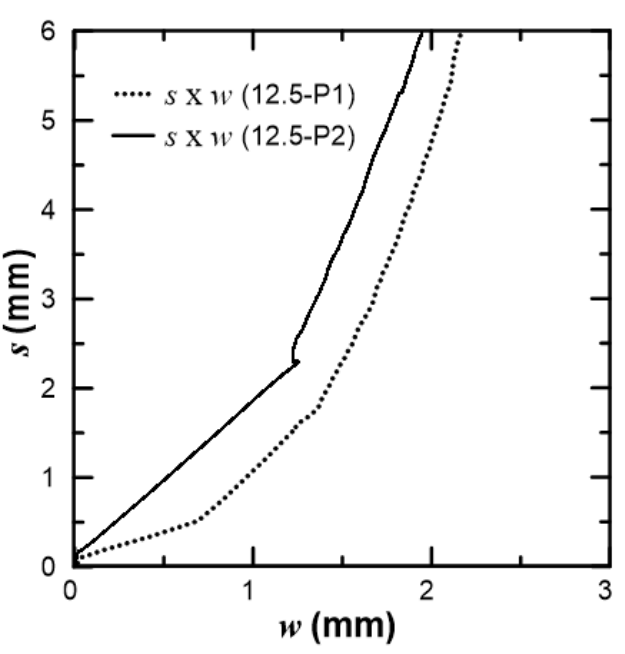

(e)

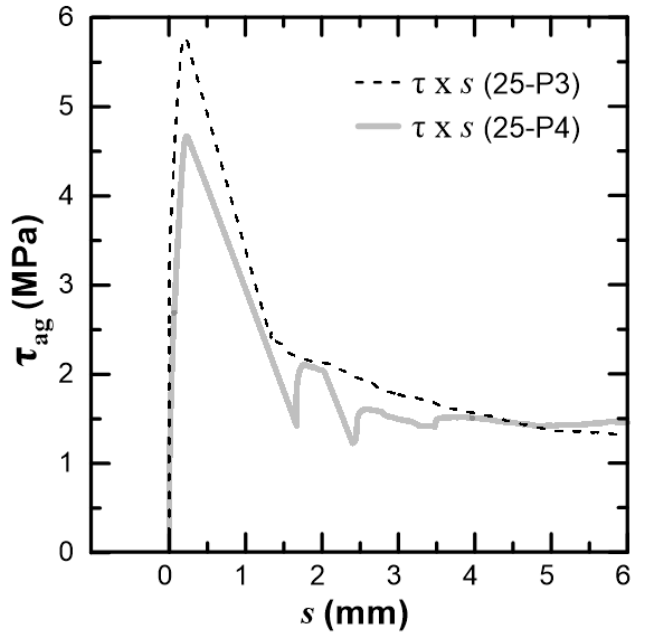

(b)

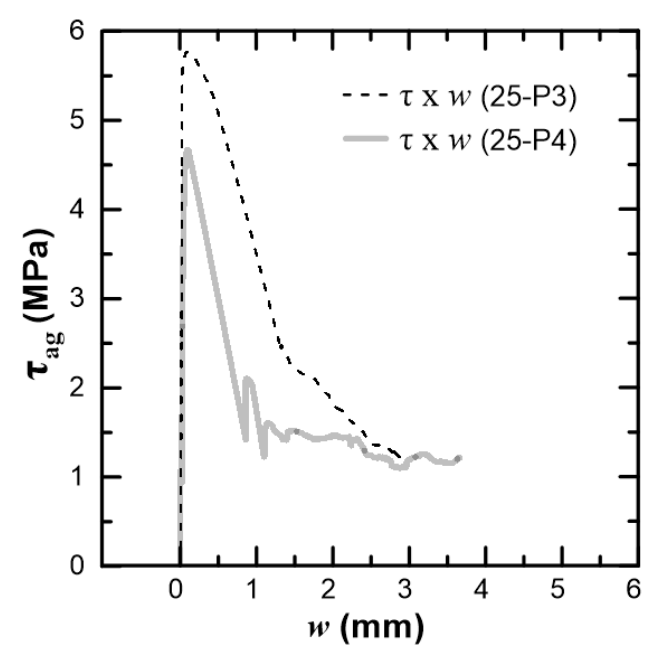

(d)

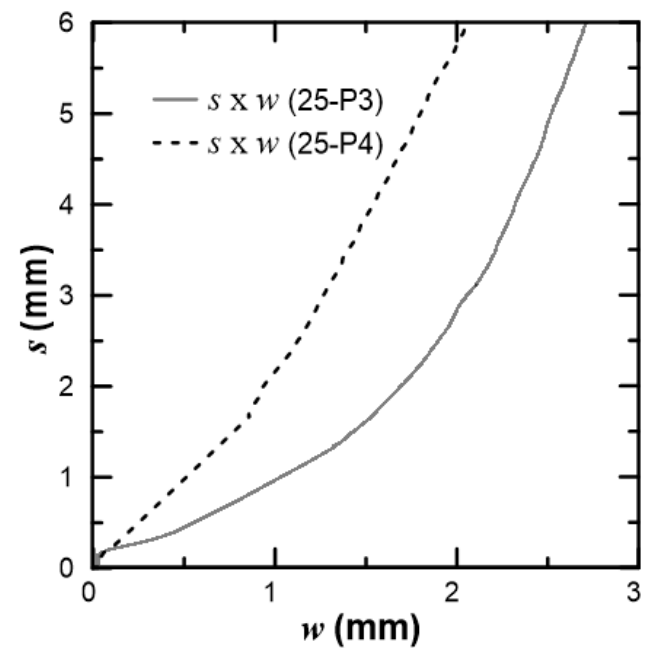

(f) 


\section{Appendix C - Beam Tests Report}

\subsection{Failure mode of Brazilian campaign tested beams}

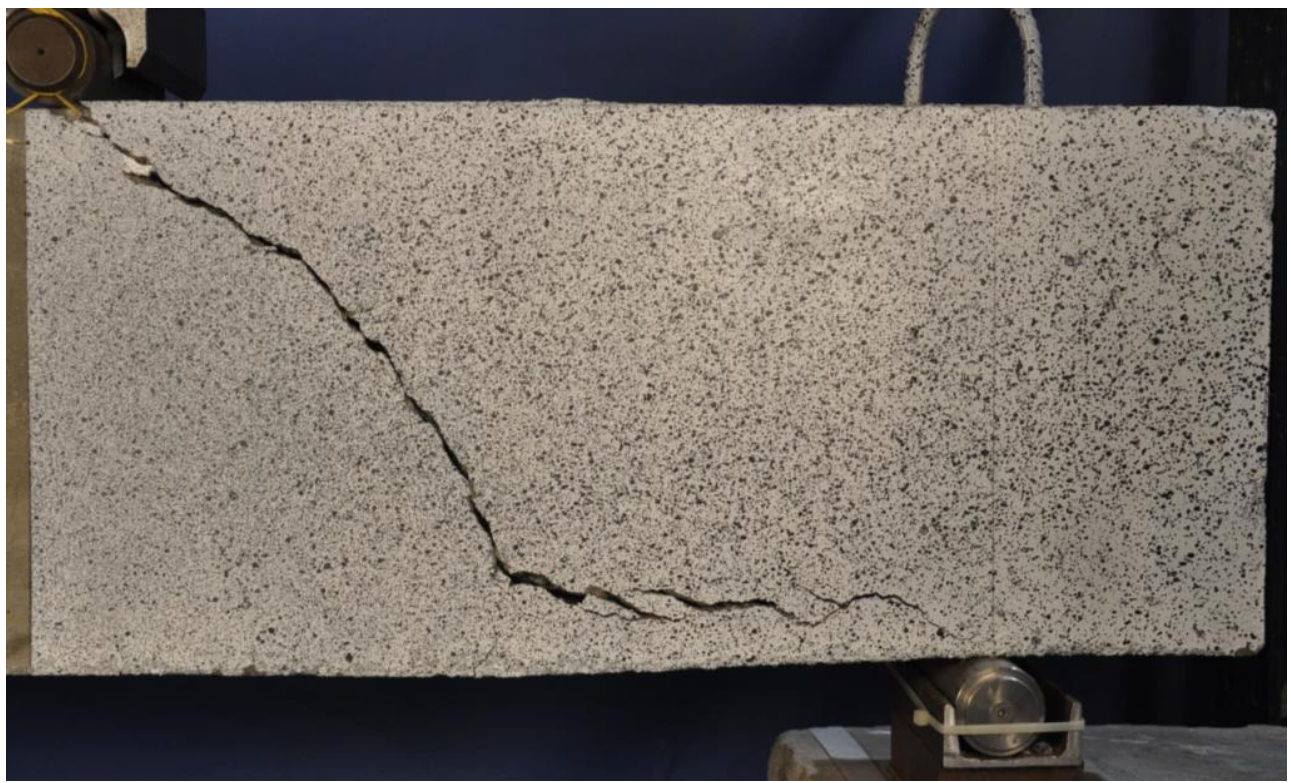

(a) Beam 3L-NS A

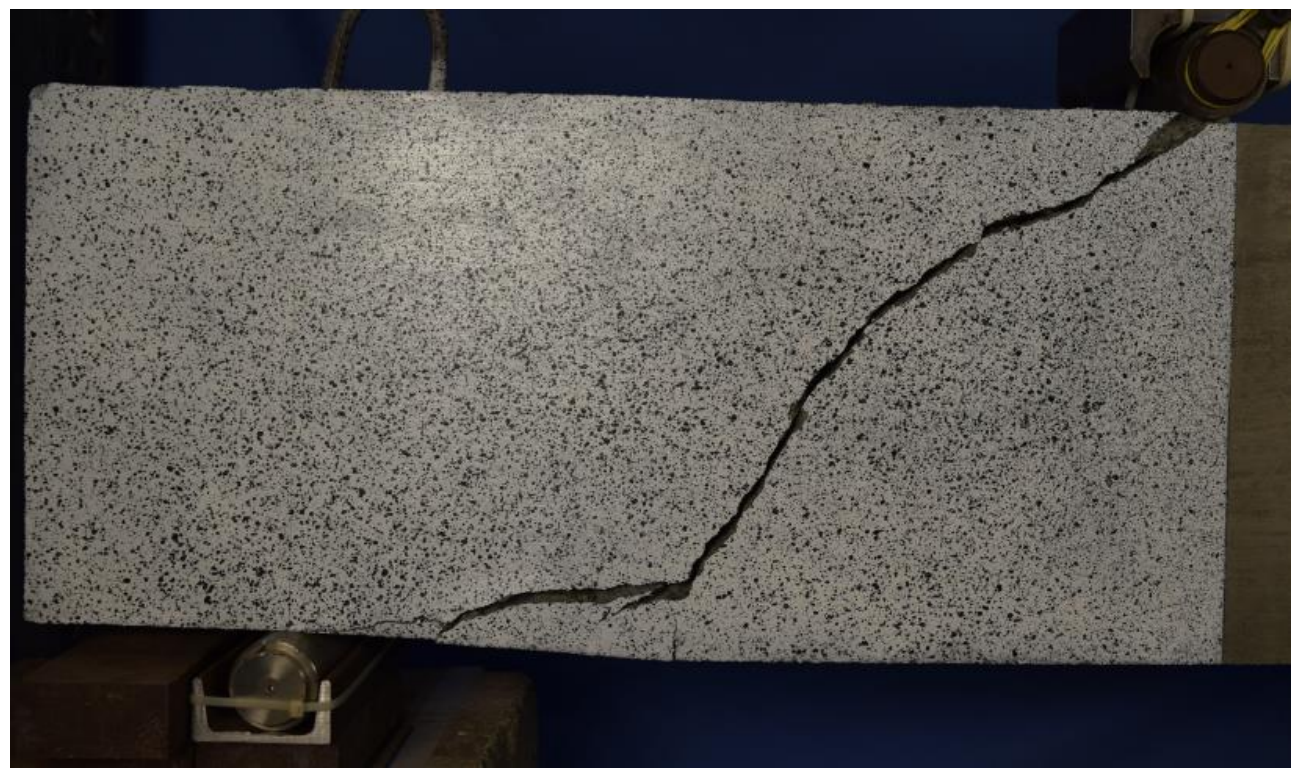

(b) Beam 3L-NS B 


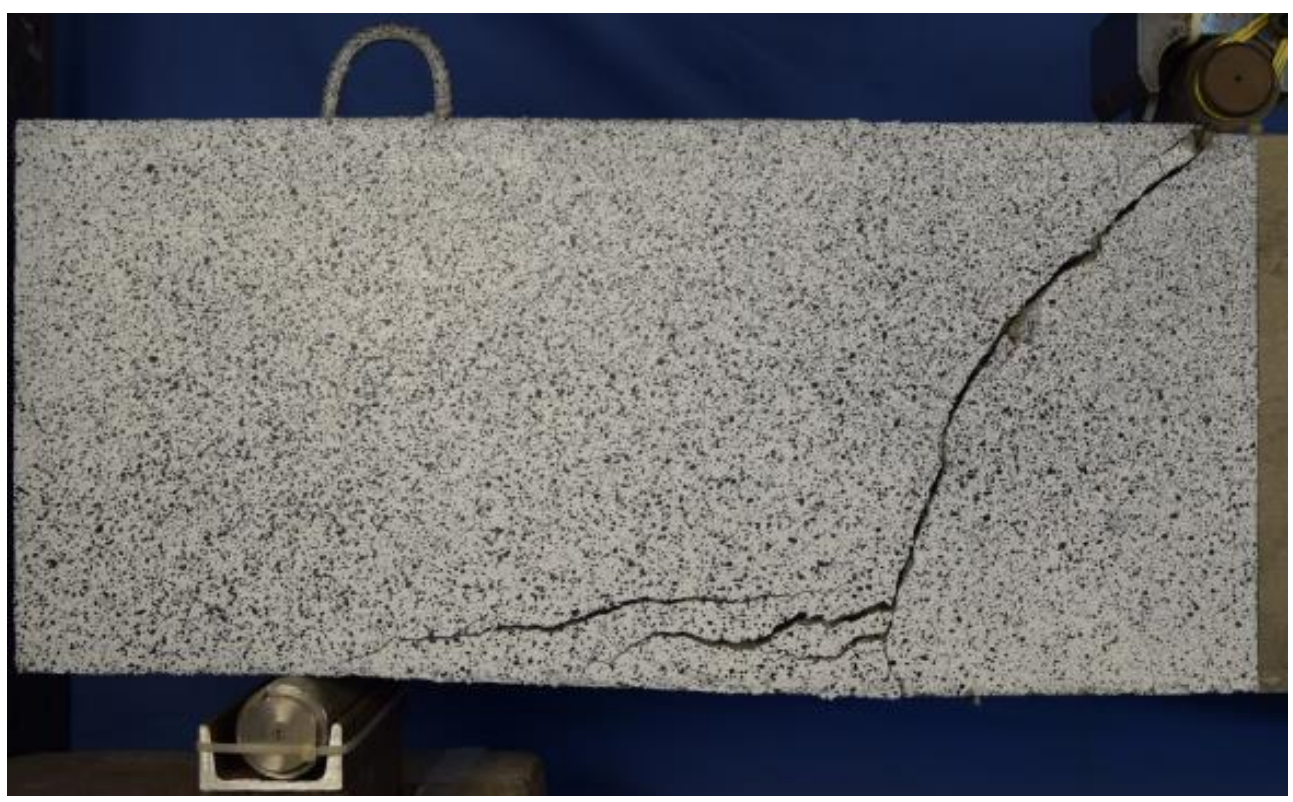

(c) Beam 3L-NS C

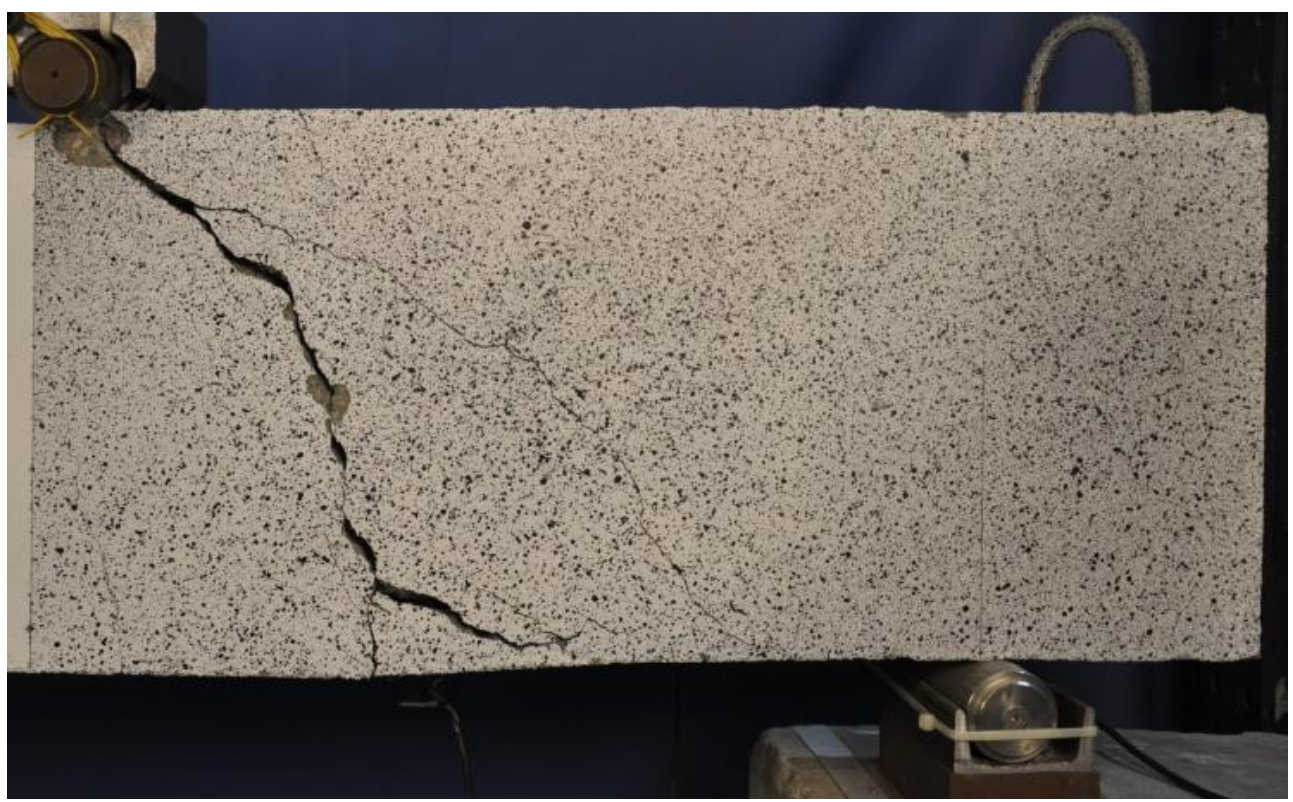

(d) Beam 3L-S D 


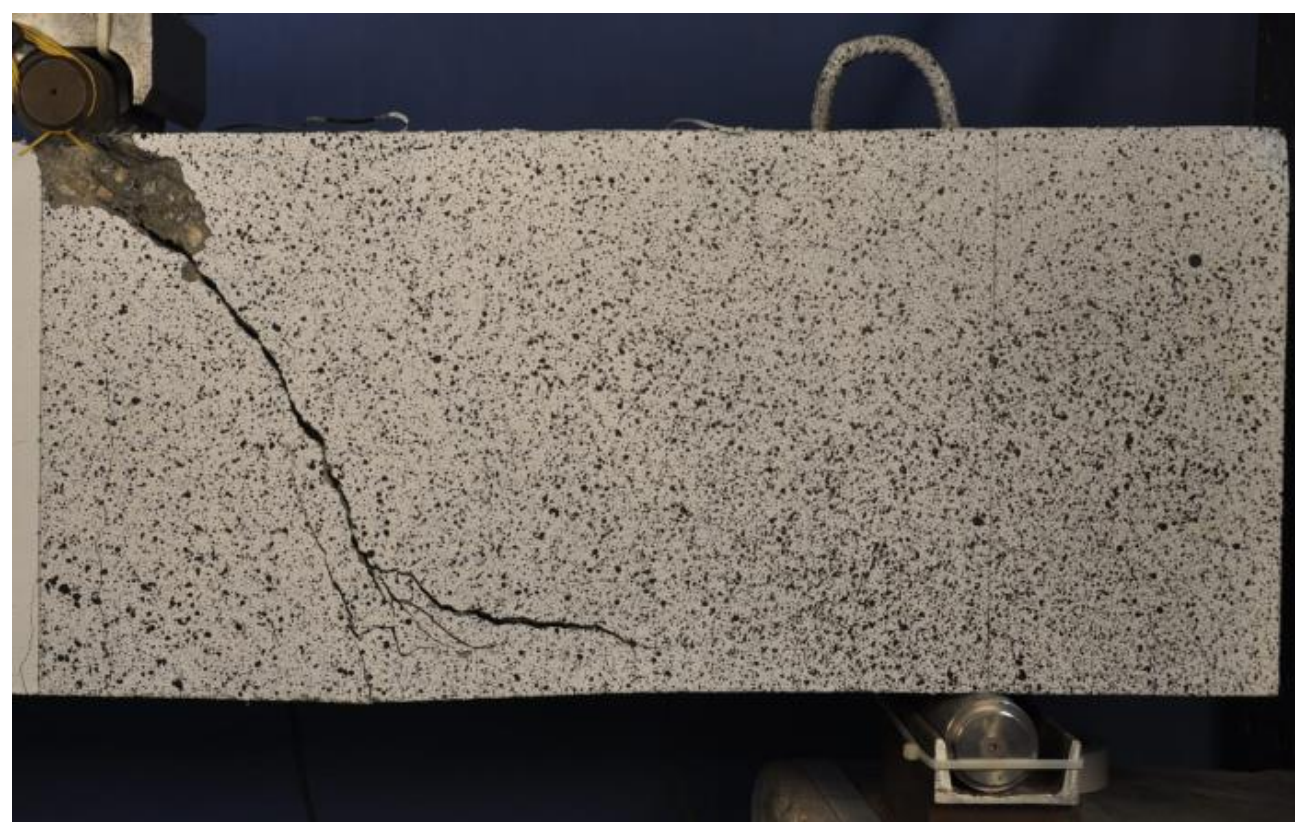

(e) Beam 3L-S E

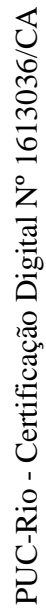

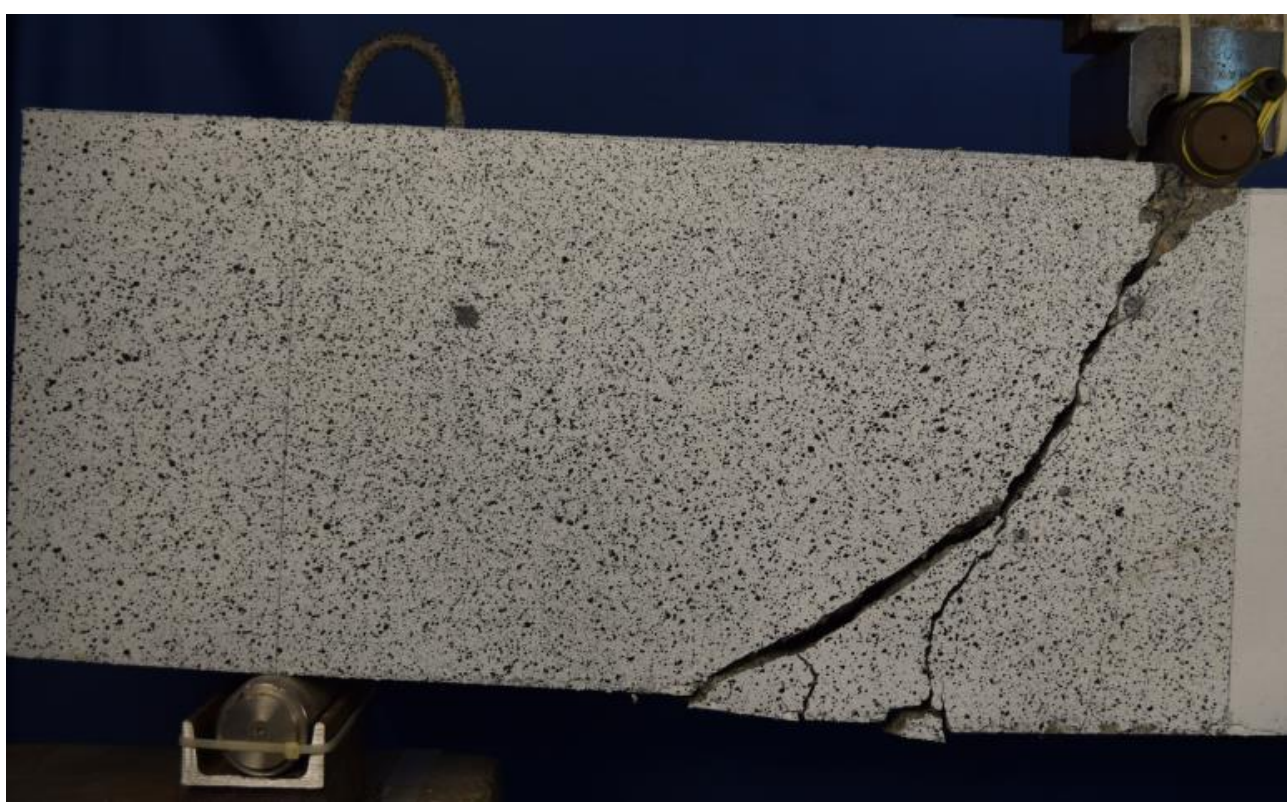

(f) Beam 3L-S F 


\subsection{Failure mode of Canadian campaign tested beams}

*A technical problem occurred during the test with Beam 2L-S E and the camera was not able to record the pictures for this specimen.

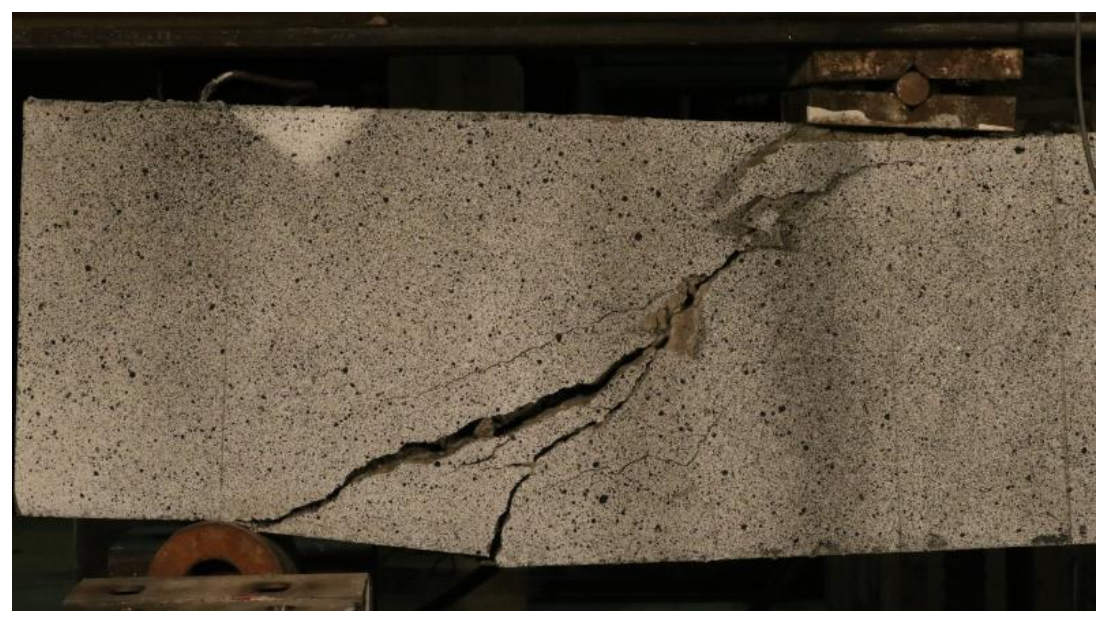

(a) Beam 2L-NS A

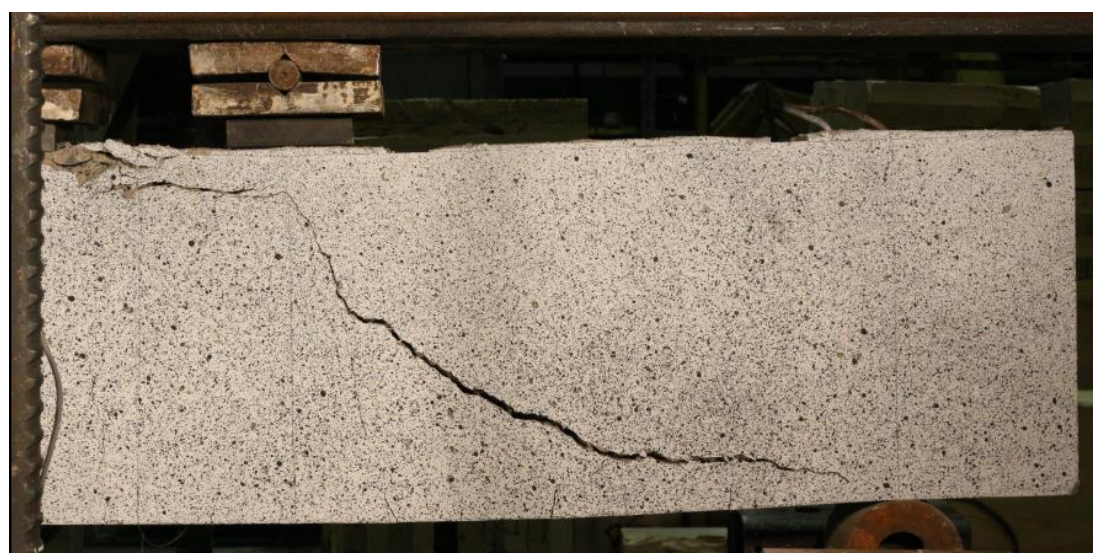

(b) Beam 2L-NS B 


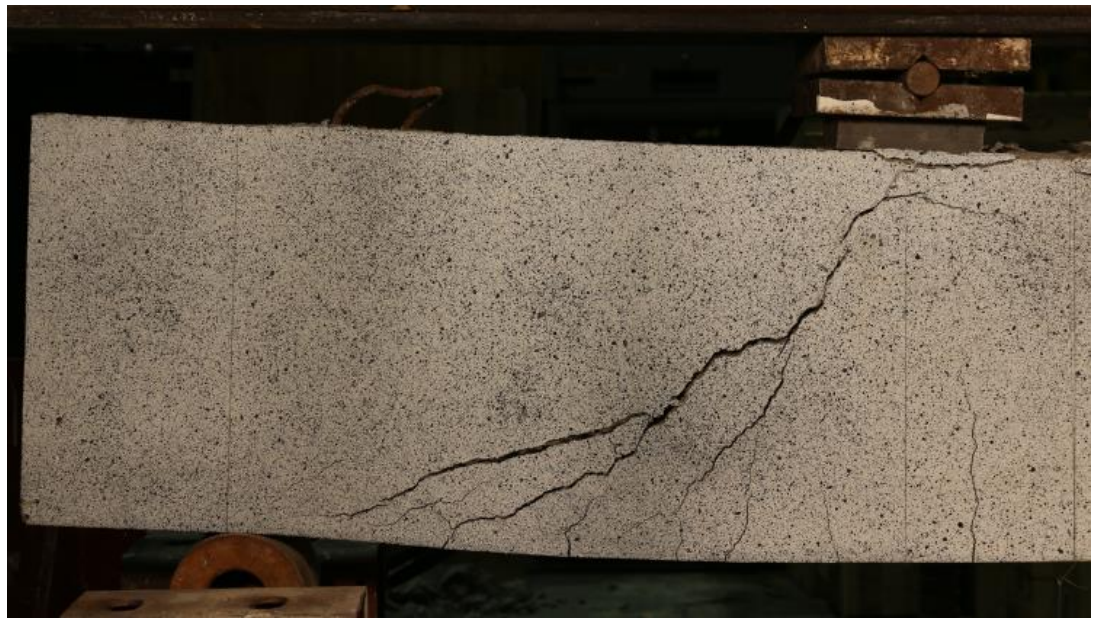

(c) Beam 2L-NS C

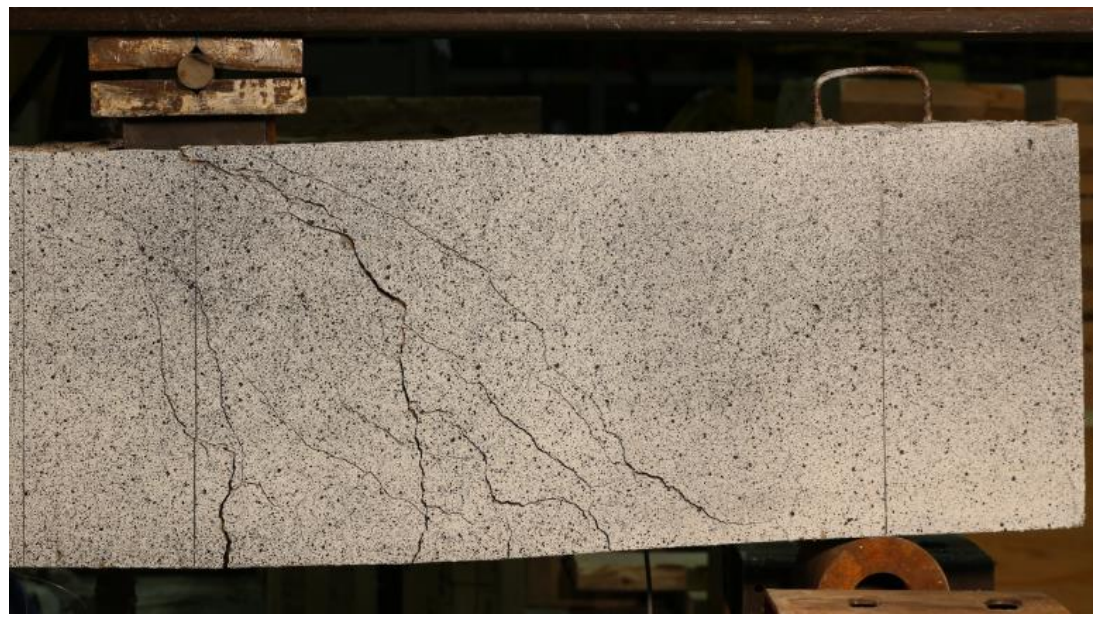

(d) Beam 2L-S D

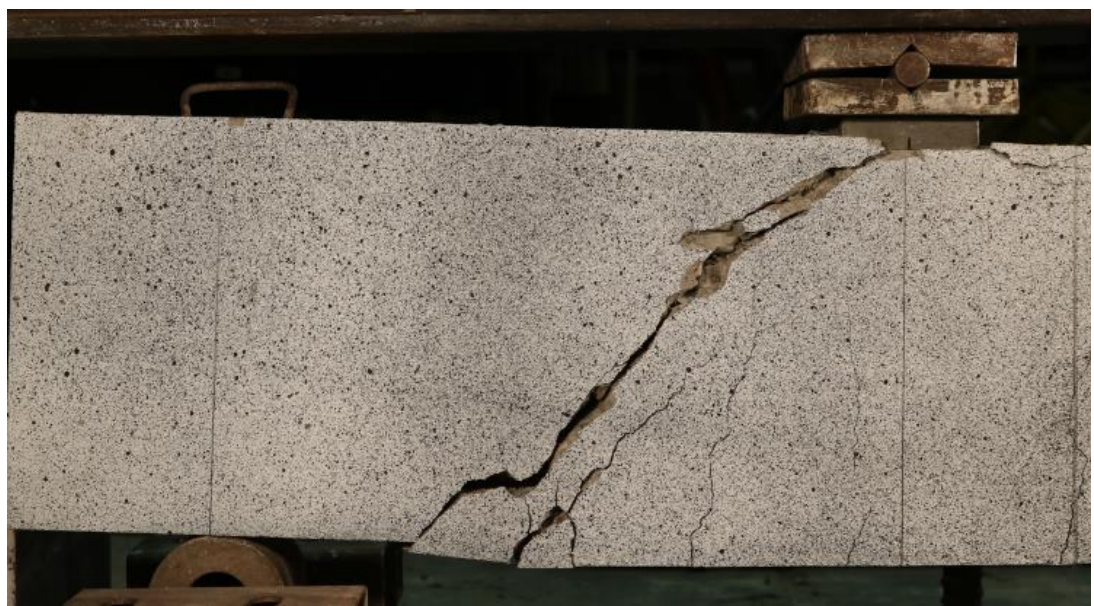

(e) Beam 2L-S F 